\title{
An Anthropological Journey of Belonging: Somali Women Re-Imagine Home in Wellington, New Zealand.
}

Content not available. Please consult the print version for access.

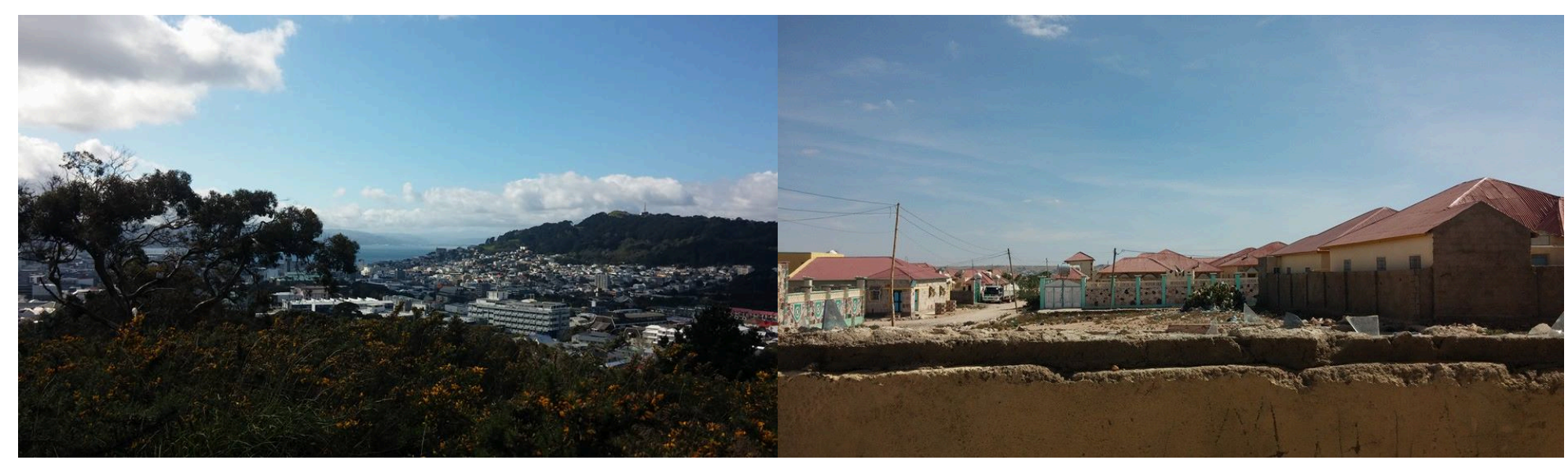

Shani Luxford

A thesis submitted to Victoria University of Wellington in fulfilment of the requirements for the degree of Masters of Arts in Cultural Anthropology.

Victoria University of Wellington 
This thesis provides insights into refugee-background Somali women's active productions of belonging in New Zealand, after resettlement in Wellington communities. It explores how Somali women actively negotiate belonging between three key processes: place, identity and acceptance. It does this by situating their resettlement in the context of the Somali civil conflict. I argue that home in New Zealand is based on emotional and physical attachments to multiple locales across space and time, as enacted and embodied through performances of 'Somali woman' identities across social fields. I show how intersectional differences produce diverse experiences of re-imagining home, and the ways that a 'Somali woman' identity is changing through the actions of 'edgewalking' participants. It also explores how belonging is a two-sided process that is affected by discourses of tolerance in New Zealand. This thesis is structured through both anthropological and feminist frameworks and thus emphasises the voices and positions of the participants at all times. The understandings presented here unfolded from interviews with eight participants, four Somali women and four non-Somalis who had extensive connections with the Somali community. Using the stories from these eight participants, this thesis demonstrates the importance of the homeland, Somaliness and tolerance in creating a sense of belonging in Wellington communities after resettlement processes.

\section{Cover Image and Title Quote}

The left image is of Wellington and the right image is of Hargeisa - photographer, Shani Luxford. The quote is by Warsan Shire, an up and coming female Somali poet. 
First and foremost I would like to express my sincere gratitude towards the wonderful Somali women that allowed me into their lives and spoke so candidly and openly with me. Without you, this thesis would not exist.

To my other participants, words cannot express my gratefulness for the way you took time out of your busy lives to speak with me. Before I met all of you, I truly feared this thesis would never get off the ground.

I wish to acknowledge my supervisors, Brigitte Bönisch-Brednich and Lorena Gibson. Thank you for your continued guidance throughout all stages of this thesis. I especially want to express gratefulness for the way you nurtured and allowed my creative voice to flow into my work, guiding me back on track when I would lose the way and keeping my head up when moments seemed dark.

Veronica - My anth buddy and office mate, I apologise for always being a distraction and cherish the many moments we have shared laughing over YouTube clips as we procrastinated. I especially want to say thank you for your support in the last few days of my thesis, your help editing and comforting me about my writing in those final moments was deeply appreciated.

Jess, the bonds of honours still hold strong! Thank you for putting yourself forward to help edit and provide feedback in the last parts of this process, your thoughts were invaluable.

To the man who has cooked for me, put up with my 'Gordon Ramsey' moments and has been my own personal support system, words cannot express how much I appreciate all you have done. Tom, your stability in those final hectic moments means the world to me. I would not have wanted to experience this with anyone else by my side.

To my family, as always you have remained a constant source of love and support. Nana and Grandad in particular, thank you for always being two of my biggest supporters and always believing that I can achieve whatever I put my mind to.

Finally, I would not have been able to survive this process without the constant love, support and guidance of my mum. Thank you for always having the door open for those moments when I needed to save my sanity and escape the city. Thank you for always being by your phone for those moments when I needed to simply hear your voice. Thank you for the words of wisdom. Thank you for always knowing exactly what I needed to hear. Lastly, thank you for being the light that has sustained me and allowed me to grow into the woman I am today, without you none of this would have been possible. 


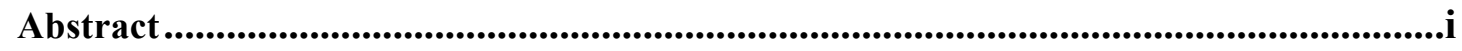

Acknowledgements .................................................................................................. ii

Chapter One: Introduction - There is a country alive in the east. Her name is Somalia..1

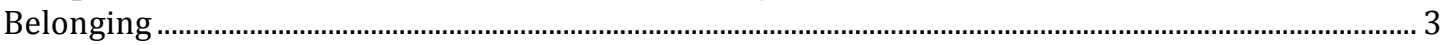

Place

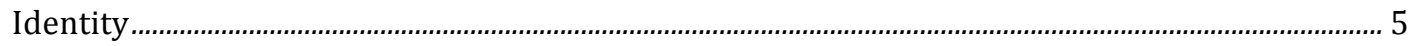

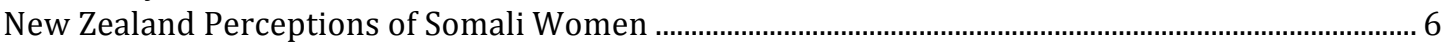

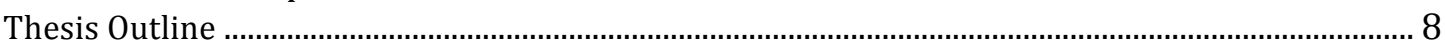

Chapter Two: Methods .........................................................................................................10

Breaking Down Walls, Meeting New Faces: Participants and Problems................................................11

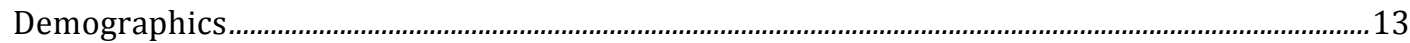

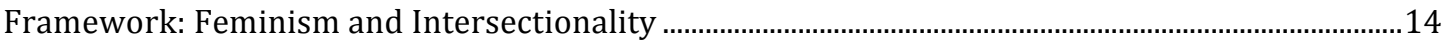

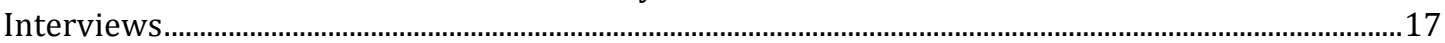

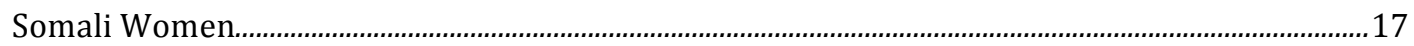

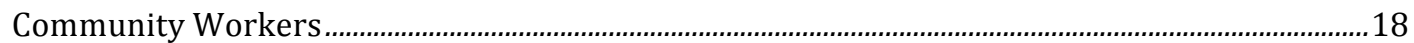

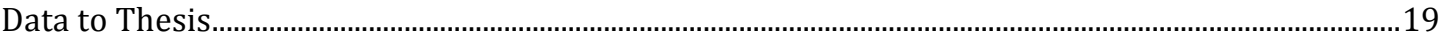

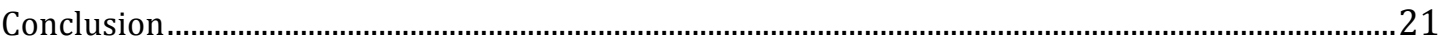

Chapter Three: The Somali Civil War and Refugee Resettlement in New Zealand.......23

The Somali war and its consequences: Flight, Refugee Camps and Trying to Survive ......................23

The Importance of Clan for the Understanding of the Somali Civil Conflict...........................................27

Biri-Ma-Geydo and Xayn Iyo Xiniin: Gender, Displacement and War Consequences......................30

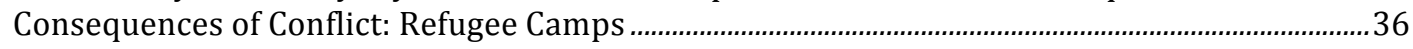

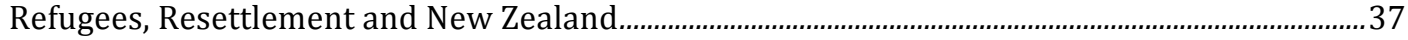

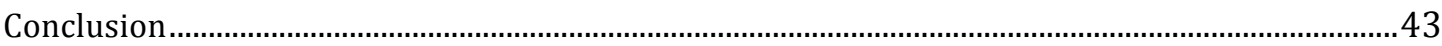

Chapter Four: Belonging: Place-Making and 'Home'..............................................44

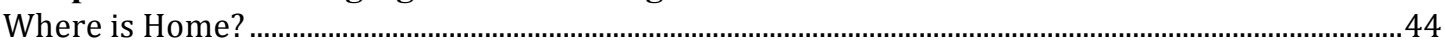

Where is Home? Betwixt and Between a Sense of Possibility ................................................................48

Home within Community: Living in Newtown ................................................................................ 52

Home Through Family: Support, Isolation and Reunification ............................................................56

Laying Down Roots: Citizenship and Jumping Across the Ditch.........................................................59

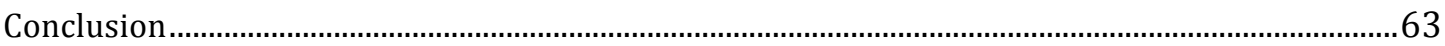

Chapter Five: Belonging: Identity and Somaliness ...................................................65

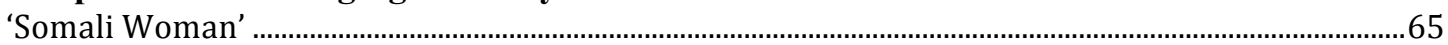

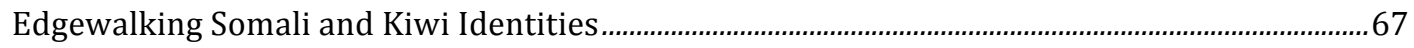

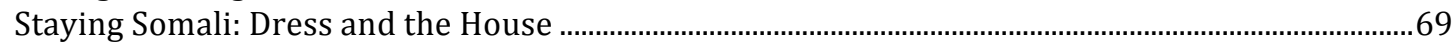

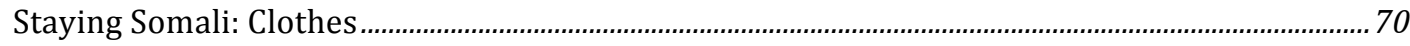

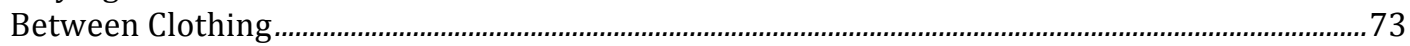

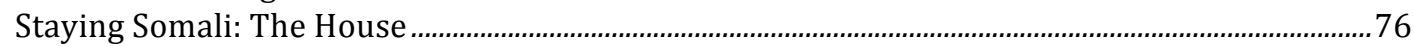

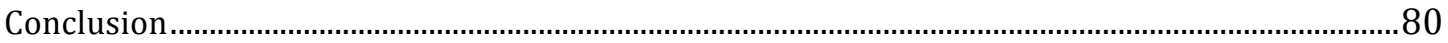

Chapter Six: Hindering a Sense of Place: Perceptions and 'Tolerance' .......................82

Part One - Hibo's Story: Perceptions and Stereotypes in a Wellington School ....................................82

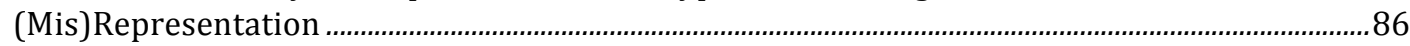

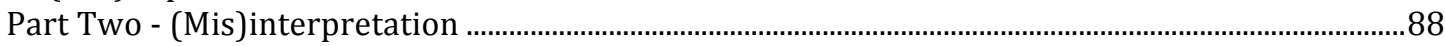

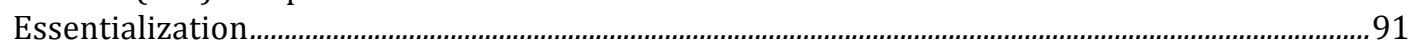

(Mis) interpretation: Consequences for Community Support..........................................................93

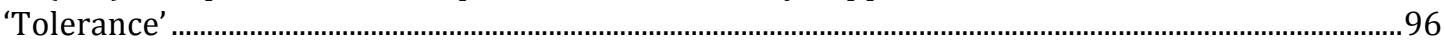

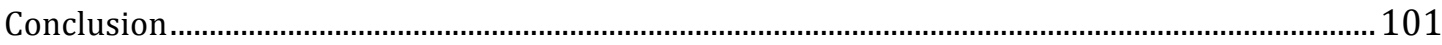

Conclusion: It is ok, maybe we are not the majority, we are the minority - but look into the needs of Somalis 


\section{Introduction: There is a country alive in the east. Her name is Somalia}

I am the sister of the martyr. I am the aunt of the potato seller at the local market. I am the daughter of the local sheikh. I am the injured of the revolution, the protester, the jailed, the detained. I am the tortured, the exiled, the kidnapped, the raped. I am the veiled, the non-veiled, I am a beautiful soul. I am a Somali woman'1.

This thesis is about resilient Somali women creating a sense of place and belonging in Wellington, New Zealand. It describes their efforts to maintain a sense of Somaliness after traumatic, forced migration in the context of resettlement in New Zealand, specifically in communities in the Wellington region. My goal is to explore the relationship between place, identity and tolerance in order to gain a deeper understanding of how their complex interplays both aid in creating and hindering a sense of belonging in these women's lives. This in turn might lead to a better understanding of the experiences of Somali women who resettle in New Zealand, aiding in clarifying what support is not only necessary but also what the women themselves see as being helpful to create a sense of belonging in this country.

I became interested in the experiences of Somali women in Wellington, after visiting Somaliland in 20142. This experience mirrored the dislocation felt by anthropologists during fieldwork experiences, where 'culture shock' and outsiderhood abound (Trundle 2014). In the clash between my cultural world and the one I had thrust myself into, I began to think about the disorientation and difficulties Somali women must face when resettled in New Zealand.

\footnotetext{
${ }^{1}$ This is a selected part of a longer poem written by Somali-Dutch poet and anthropologist Sahro Ahmed Koshin labelled I am a 'Somali woman'.

2 I lived for three months in Hargeisa, the capital of the currently unrecognized state of Somaliland, Somalia.
} 
Thinking reflexively about my experiences of 'otherness' made me question how Somali women, who do not have a return ticket and do not exist in the categories of privilege ${ }^{3}$ that I do, came to create or feel a sense of belonging in New Zealand. Being 'other' although only briefly, had opened my eyes to Somali women in communities around me, driving me to create a research project that focused on the experiences of these women in Wellington communities.

Substantial work has been carried out in countries like England, Canada, America and Australia looking at how the Somali community has experienced migration and resettlement processes. The main themes found in this work focus on the process of integration. They explore this through multiple areas such as acceptance by the new country, the institutions in place to help with resettlement and how these differ country to country, religious resurgence and stronger adherence to Islamic beliefs after migration, and how women traverse the shift from patriarchal, communal societies, to an individualistic culture where women have more 'freedom' (see Hopkins 2010, Langellier 2010, Mcgown 1999, Pucherova 2013, Spitzer 2007). However while a substantial amount of literature can be found overseas, there appears to be a lack of research on the Somali community, particularly the female Somali community in New Zealand. Instead, Somali women are viewed in tandem with other migrant/refugee background groups or are subsumed under a Muslim identity ${ }^{4}$ (see Dobson 2011; 2012; 2013, James 2013, savage et al. 2004, Jelle, Guerin \& Dyer 200655).

\footnotetext{
${ }^{3}$ Privilege in this context is the economic and social benefits that I have, because I am white (refer to Peggy McIntosh 1989)

${ }^{4}$ While being Muslim was clearly, an important part of the lives of the women I spoke with, I chose to focus on their cultural identity and how being Somali played a part in their integration. What can be seen in Somali women is that cultural and religious identities are intimately linked; it becomes hard to separate out religion and culture. Instead, following the intersectional lens that I develop through this thesis, we need to look at how cultural and religious aspects intersect to play a role in integration and resettlement processes.

${ }^{5}$ An interesting point to note is that there does appear to be a small amount of research that focuses predominantly on Somali women coming out of Waikato University (see Guerin, Elmi \& Corrigan 2007, Guerin et al. 2004, Jelle, Guerin \& Dyer 2006) which could reflect the larger and more settled Somali community in the Waikato region.
} 
Following in the steps of anthropologists like Jacqueline Leckie, who has studied Indians in New Zealand communities to understand, share and highlight their place in New Zealand's past and present (Leckie 2007), the stories and experiences in this thesis provide snapshots into the way that the Somali women I spoke with create places for themselves in New Zealand. I started out this thesis focusing on the ways that the resettlement process created a re-imagining of Somaliness, leading to the formation of a Somali-New Zealand identity. However, through the research process my questions have become:

1. What does a sense of belonging entail for Somali women in Wellington communities?

2. How does this sense of belonging reflect New Zealand perceptions and discourses of tolerance in wider society?

In the remainder of this introduction I address these questions. First I take a closer look at how belonging is broken down into two main themes in my chapters, showing how I place my research within anthropological frameworks of belonging, place and identity. Then I explain my approach to New Zealand perceptions of Somali women. I conclude with an outline of the thesis.

\section{Belonging}

"Belonging should be seen neither in existential terms (as primordial attachment to some kind of face-to-face community) nor as discursively constructed, but as a socially constructed, embedded process in which people reflexively judge the suitability of a given site as appropriate given their social trajectory and their positions in other fields" (Savage, Bagnall and Longhurst 2005:12).

Belonging in this thesis is broken down into two themes. Belonging through place making and belonging through identity. In each chapter that discusses these themes, the aim is to show how belonging is something that is constructed or performed by the Somali women in different ways, depending on intersectional differences like age, marriage status, religious adherence and social standing. In this way Cohen's (1982:14) ideas of belonging as mediated 
through fundamental structures like kinship, friendship, neighbourhood, sect, crew and so forth can be witnessed, implying a belonging that is cohesive because of these fundamental structures. However as will be seen in the narratives of the women I spoke with, belonging is more complicated than being part of a neighbourhood or community ${ }^{6}$ (Strathern 1982). It is subjective, with boundaries of belonging depending in part on the person who claims them as well as how these claims are received (or not) by others (Blenkinsop 2010). By thinking of belonging in this way, this thesis takes into account its complexities and the flexibility with which claims of belonging are made at different times and in varying contexts" (Blenkinsop 2010: 127).

\section{Place}

As stated above belonging, does not simply mean being a part of a community or group. For the women I spoke with belonging highlighted how "in a fluid world of movement, place remains a deeply contested and symbolically rich site in which to constitute the self" (Bönisch-Brednich \& Trundle 2010:1). Their narratives at time touch on ideas expressed in transnational theories where as refugees they maintain shifting and contextual affiliations to not only Somalia, but also to other Somali refugee receiving nations like England and America. In this way their stories express the "dynamic flow of ideas, political and social networks, goods, remittances, 'tradition', capital and investments that destabilise the very boundedness of host and home spaces (Bönisch-Brednich \& Trundle 2010:2, also see Marcus 1995, Massey 1995, Cliggett 2003).

\footnotetext{
${ }^{6}$ As Catherine Trundle (2014) discusses, community is a "commonsensical term used ubiquitously in a wide range of social settings within contemporary life" (2014:69). In this thesis, community is used to create a focus on how ideas of it are used instrumentally by my participants to create identities, boundaries and a sense of belonging (see also Cohen 1985, Mitchell 1998). However, as Brigitte Bönisch-Brednich and Catherine Trundle (2010) point out, community is not just a constructed symbolic tool, it is also experienced and lived in the everyday realities of people. In this way, while viewing community as an instrument used to create belonging, I also aim to show how my participants experience being part of a community as a lived reality of social interaction (Amit 2002) and how this impacts their sense of place, identity and belonging in Wellington.
} 
Yet this thesis is not only about their transnational links, but rather how these are part of the process of creating a sense of place and 'home' in New Zealand. Finding comfort within their physical locality or 'habitus' as Pierre Bourdieu terms it is based on context and relations in their localities (Appadurai 1995:204). In this way belonging is "constituted through discourse, narrative and imagination as a nostalgic and fictive anchor in a sea of movement (BönischBrednich \& Trundle 2010:2). Home becomes "neither here nor there...rather itself a hybrid, it is both here and there - an amalgam, a pastiche, a performance" (Bammer 1992: ix). Viewing home in this way also reflects Doreen Massey's (1995) idea of places having unclear boundaries that shift and change, hosting multiple and divergent identities within them. Place in this way can be seen to be intimately linked with the second theme of belonging, identity.

\section{Identity}

As the last point mentioned, place is intimately linked with identity. The home represents a visible space of belonging, where identity is expressed and enabled (Bönisch-Brednich \&Trundle 2010). In this way home provides a place for Somali women to perform and enact their identities, both as a way to define and align themselves with the community around them. Relating back to Doreen Massey's (1995) idea of multiple and divergent identities in the changing boundaries of place, the women perform multiple identities depending on situational, contextual and relational factors. Utilising ideas of performativity, identity in these situations is not analysed as fluid or forever changeable but is produced, embodied and performed with social and political consequences (Bell 1999, also see Butler 1988, 1997). Identity in this way is a complicated process.

In an anthropological framework of identity and belonging ${ }^{7}$, the Somali women's narratives represent on one hand the core tenant of identity politics where the point of asserting an identity is to 'erect and maintain stable boundaries between groups' (Trundle 2014: 69; see also Caldwell 2004; Banks 1996; Rapport 1997).

\footnotetext{
${ }^{7}$ See Afshar 2007; Akpinar 2006; Dobson 2011, 2012; Dwyer 2000; Hall 1996)
} 
While on the other they represent the agentic ${ }^{8}$, subjective and individual decisions of Somali women as they carve out positions for themselves in New Zealand society. Identity in this way fits within a feminist approach as well, with intersectionality ${ }^{9}$ playing an important role in the identity they create and are recognised as holding by those around them. By looking at identity articulation in everyday life, we can see how they expose a range of "creative transformations, contradictions and competing social impulses (Trundle 2014:71, also see Povinelli 2002) where maintaining a sense of Somaliness is prioritised in certain contexts, and a Kiwi ${ }^{10}$ sense of self in others.

In this section I have situated my research in anthropological frameworks of belonging. I have broken it down into the two main themes of place and identity that are expressed in the narratives of the women I spoke with, to show how anthropological analysis can highlight what a sense of belonging entails for Somali women in Wellington communities. Following on from this, the section below will show how a sense of belonging for Somali women is not just built on their own sense of place and identity but is also related to the perceptions of New Zealanders around them.

\section{New Zealand Perceptions of Somali Women}

The last point made introduced the third theme of this thesis, how belonging for Somali women is also impacted by the perceptions of those around them. I placed this analysis in anthropological frameworks of interpretation, power and ideas of the 'other' as seen in the work of Clifford Geertz (1973), Michel Foucault

\footnotetext{
${ }^{8}$ Agency in this thesis is the active actions Somali women take to change their realities (See Ortner 2006; Leckie 2002)

${ }^{9}$ Intersectionality is a feminist theory and method. It analyses oppression through the intersections of multiple forms of domination that impact individuals in society, like race, class and gender (see Brah \& Phoenix 2004; Kimberle Crenshaw 1991)

${ }^{10}$ Kiwi is a contentious term. It represents colonial endeavours to class all New Zealanders together. However, in reality it does the opposite. I use the term in my thesis because the Somali women themselves employed it, but I want the readers to be aware that I do acknowledge the issues that are inherent in using the term. (Refer to Jo Smith 2007 for an in-depth argument around the problems with the term Kiwi.)
} 
(1977a, 1978a) and Edward Said (1978). The power of perception differed depending on the perspective that was being analysed. For Somali women, perceptions revolved around stereotypes. Stereotypes in anthropology are "simplistic representations that portray group characteristics as fixed and homogenous, in contrast to the complexity and contradiction that in fact exist within social fields (Trundle 2014:50, see also Herzfeld 1992; McDonald 1993; Brown \& Theodossopoulos 2004). They provide political categories of 'identity taxonomies' that are used by those in institutions of power to achieve particular ends (Caldwell 2004: 128) or as Lorena Gibson (2011:150) discusses in relation to Muslim Indian women, stereotypes have also been used to analyse how they become self-fulfilling prophecies. However, as will be seen in later narratives, Somali women do have power and agency that is used to change stereotypes and shift perceptions, reflecting Sherry Ortner's ideas that "people in positions of power 'have' - legitimately or not - what might be thought of as 'a lot of agency,' but the dominated too always have certain capacities, and sometimes very significant capacities, to exercise some sort of influence over the ways in which events unfold (2006:144).

Yet when perceptions were analysed through the narratives of New Zealanders who had worked with the Somali community, the power of those in dominant positions was emphasised. Utilising Foucauldian ideas, discourse in these narratives formed bodies of knowledge around how to perceive 'others' in society. They particularly enforced a dominant discourse of tolerance around accepting Somali women as belonging, reflecting what Ghassan Hage (1998) terms a discourse of tolerance. Through using this analytical framework, the stories shared by those that work with Somali women highlight the inherent separation between those that tolerate and the tolerated, the hidden sense of 'putting up with something' that the term tolerant implies (Hage 1998). This ties together how Somali women both see, and are seen in Wellington society and how the discourse of power and tolerance effectively work to hinder their sense of belonging. 


\section{Thesis Outline}

In this introductory chapter I have created the bones that this thesis will grow from. I have introduced my overall goals and motivations and have situated the important themes of place and identity within the wider anthropological understandings of belonging. I have examined the importance of perception, linking it to discourse and power in the dominant community, acknowledging how belonging is a two-sided process that occurs between Somali women, the individuals around them, the communities they live in and wider society.

In the chapter two, I discuss the theoretical foundations for my research methods. I show how feminism and intersectionality have influenced each step in my research, and outline the fieldwork process and methods used in this thesis. This chapter allows for consideration of my role as a researcher, as I provide insight into my experience as an outsider interviewing women from a closed community and how this shaped my interviews and analysis. I also introduce the participants in this study and explore the process of recruitment, interviews and my analysis.

In 'Somali Civil War, Historical Context and Refugee Resettlement in New Zealand', I provide important details about the Somali civil conflict, Somali culture - particularly the contentious role of clans - and how this particularly impacted Somali women. I then connect Somalia's past to the refugee processes in New Zealand. I outline how New Zealand categorises and accepts refugees and the resettlement process once they arrive in the country. I argue that with new waves of refugees coming in, support is lost for those that have been here for long periods of time highlighting how it is still important to look at Somali women within our communities to see what their experiences reflect about wider structures and policies in New Zealand.

In chapter four, I examine how Somali women create a sense of place through physical belonging and 'home'. I argue that home is not just a 'house' but is instead based on emotional and physical attachments to locations across space 
and time. Generational differences are acknowledged and their role in creating feelings of liminality and belonging in 'betwixt and between' spaces is discussed. This chapter introduces ideas of reactive citizenship and the agentic choices these women make when it comes to putting down roots, with narratives demonstrating the importance of family and community in creating a sense of place for Somali women.

Belonging does not just rely on a sense of place. In chapter five I address how a sense of belonging also relies on the individual ideas of identity. I argue that the term 'Somali woman' is a complicated concept that introduces the reader to the importance of power relations in identity formation. This chapter introduces ideas of Somaliness and the ways that women negotiate maintaining this in New Zealand. Here, narratives demonstrate either an active preservation of a Somali identity, or a balancing of Somali and Kiwi aspects of self through dress, language and the 'house'.

'Hindering a Sense of Place: Perceptions and 'Tolerance" discusses both the ways that stereotypes impact how Somali women are perceived in wider society and how narratives of non-Somalis show a discourse of tolerance in New Zealand. I argue here that rather than becoming self-fulfilling prophecies, Somali women utilise their power and agency to transform the perceptions they face. This chapter combines the voices of Somali women and individuals that have worked with them to show how interpretation, power and discourse shape experiences in social spaces. It explores how these processes work to hinder, rather than create, a sense of belonging. 


\section{Methods}

Young, white female

What do you want with me?

My stories, my life -you want me to share

But young, white female

Why do you care $?^{11}$

This research project evolved out of a desire to have a collaborative process between the research participants and myself. Therefore my readers need to be able to understand how the methodology employed provides the bones of the thesis' structure. In the nature of ethnographic research I wanted the work to be malleable, unfolding out of what was discovered during the fieldwork journey; not only through what was shared with me, but also make visible my own reflexive moments of insight and reflection. In doing so I locate myself within a feminist anthropological framework as seen in the work of scholars like Lila AbuLughod $(1987,1993)$ with my focus being on creating a project that could benefit Somali women ${ }^{12}$. I was acutely aware at all times that my presence in the field

\footnotetext{
11 The poems in this chapter are all written by me, they represent reflexive moments in my field experiences where the ideas I held were challenged, changed or reinforced. Using poetry also creates a form of creative literature that reflects further the use of a feminist framework (Schrock 2013). I chose to only use poetry in my methods section as it reflects the intensely personal experience of doing ethnography (see Abu-Lughod 1987 Visweswaran 1994; Behar 1996; Teaiwa 2004), where I was required to step outside of my own comfort zone and meet new people. By sharing personal poetry that was written as a reaction to the fieldwork experience, I place myself in the fieldwork moments. I remind the reader through sharing 'vulnerability' that as an ethnographer my gaze and view is not a privileged ' $\mathrm{I}$ ' or a distant gaze looking in on a foreign 'other', I do not hold a form of ethnographic authority (Behar 1996:21). Instead, as ethnographic poet Toni Flores (1982:18) explains, "The self-revelation entailed in doing poetry makes a person think about other people in a slightly but significantly different way. I must observe myself, I must begin to think of myself as an observed "me," I must recognize that others too are being forced to think of themselves as observed "me's" ...but, more importantly, I have put myself in the same framework with the "objects" of my observation and am no longer under the damaging illusion that I am, somehow, a being apart and distinct from them".

12 This is not to deny the importance of working with Men or to minimise the importance of Male Somali experiences for community adjustment in Wellington but it is important to be aware from the beginning that this research only focuses on the experiences of women. At times this was contentious - one Somali man I spoke with did comment that 'I must hate men' to be only focusing on women, but in reality I believe that women can often be the silenced voices in
} 
would affect the way the women responded to me. In this chapter I introduce the participants I worked with and discuss the difficulties I faced accessing the field. I then discuss how these problems led me to an awareness of my position as a researcher and the importance of intersectionality in my research. I also outline the interview process and lastly discuss my inductive approach to creating my chapters.

\section{Breaking Down Walls, Meeting New Faces: Participants and Problems}

I decided to recruit participants who represented a broad slice of the female Somali community. I knew they could, and should, not be representative of the female Somali community, but I did want to get a range of experiences that showed how differences between the women could mirror different lived experiences in New Zealand. After my ethics application was approved ${ }^{13}$, I placed flyers around the university with my contact details and a link to a Facebook page I had created ${ }^{14}$. I also shared the Facebook page and details about my project on Facebook pages that were run by the Somali community. Alongside this, I reached out to the Wellington Somali Council and other community groups in the Wellington region. However, unbeknownst to me at the time, the Somali council and community were going through an internal crisis and this affected my ability to find participants. I also gained minimal to no contact from flyering and Facebook ${ }^{15}$.

minority communities and focusing specifically on them can provide important information for the ways women in particular need support or adjust to living here (See Leckie 1995, 2007).

13 Ethics approval was granted by the Victoria University Human Ethics Committee on 17 July 2015

14 I created a Facebook page to outline exactly what my project was about and provide a place to share more personal information about me, including sharing details about my time in Somalia, to foster a personal connection to the research. I also thought that it would provide a talking point that might pique interest and create a greater chance of contact.

15 I did have women comment on my Facebook page but they either did not reply after the first comment or were too busy to be involved. 
Turning the lens back in

Desiring to hear their voices

Reaching out, what I felt was a helping

hand

Caught in structures of difference

Western approaches - all that I know

Interviews, pushing boundaries, trying to

bridge a lack of trust

Coffee instead

I am an unknown, a stranger in their

midst

And they are just as strange to

me...feeling alone and unwelcome

Welcoming intersectionality, a tool, a

guide

Understanding and wanting their voices

But now I need mine too

Running alongside one another

A complete picture - or as complete as

narratives ever allow a voice to be

This poem represents how the methods of recruitment I employed were not suitable for finding Somali women in Wellington. As a participant informed me later, "an academic approach does not appeal to Somali women at all. Don't try and communicate through paper, because the Somali language has only been recorded for a very short space of time compared to other languages. A lot of the women who have learned to write, also have learnt in Arabic so written communication is not necessarily the way they would choose to communicate. As a form of cultural communication they also value face-to-face conversation, so don't give them paper" (Max). I was employing methods from my western, academic perspective when instead I needed to find a culturally sensitive form of recruitment. ${ }^{16}$

In light of this I decided to expand my pool of participants to include individuals from organisations that had worked with Somali women. I did this for two reasons. First, the methods for contacting individuals from organisations were

\footnotetext{
16 See Langellier 1999, 2010; Fraser 2004; Hopkins 2010 for other examples of how to conduct research with Somali women.
} 
familiar to me, I used the internet to search for key organisations involved in the female Somali community and then emailed either individuals or organisations about my research. If they wanted to be involved we arranged an interview, while those that did not simply replied 'no'17. Through this process I recruited four individuals to interview ${ }^{18}$. The second reason was to see if other people had faced the difficulties that I had in trying to talk with Somali women. It turned out that they were a very closed community who did not easily open up to outsiders. By talking to individuals that were respected by the community, I managed to find a gatekeeper who contacted women that she felt would talk with me, and this led me to two Somali women who would speak with me. I met another two women through my volunteer work at the Victoria University Refugee Drop-In Centre; in one case I met her face-to-face when she wanted help with an assignment and the other was introduced to me through an acquaintance ${ }^{19}$. This gave me a group of eight participants, four Somali women and four organisation participants.

\section{Demographics}

The Somali women were aged between 18 and 60. They had been in New Zealand from the first immigrant wave in the early 1990's through to a recent arrival in 2009. Jamilah, Fadumo and Miski were mothers, two attended university and one owned a café. Three of the four arrived in New Zealand as refugees, while Hibo came with her family through reunification. They all came from different parts of Somalia; one was from Berbera, another from the South and one from the North (in one interview place of origin never arose). Two of the four had fled through Kenya and another through Ethiopia, while one left directly from Somalia. Three had spent time in refugee camps and all of them had

\footnotetext{
${ }^{17}$ In most cases if an individual said 'no' they would still put me in touch with other people who they felt could be of more use to the project.

${ }^{18}$ I also spoke with four other people, but they were quick coffee meetings and did not end up being key for the thesis.

${ }^{19}$ I also spoke with two other Somalis, one man (Axmed) and two women (Ayan) but they were both brief coffee meetings that did not evolve into interviews.
} 
lost family at some point during the conflict. I did not ask about clan affiliations because I did not feel in a position to do so $^{20}$.

The other four participants were between the ages of 25 and 55. There were three females and one male, Zoe was American while the other three were from New Zealand with Max identifying as part Maori. Rachel worked as a lawyer and for the Family Reunification Trust, she had over 20 years experience with the Somali community. Sally had worked with Mclass, a multicultural learning and support service, from its beginnings and now worked as an ESOL teacher; she also had over 20 years experience with the community. Zoe had worked as a Social/Cultural community worker for 2-3 years but she no longer had strong connections with the community. The only male to be interviewed was Max who is currently a principal of a primary school who had a long history of working with refugee students. He had worked with the community for over 10 years and had been instrumental in providing work at different times.

All names are pseudonyms to help maintain anonymity.

\section{Framework: Feminism and Intersectionality}

Ethnography is informed by the personal politics you hold (Atkinson et al. 2001), as seen in the strong feminist ideals I hold when it comes to the research I want to do. By this I do not mean that I simply want to focus on women, the category of woman is not a universal (Visweswaran 1997) nor is there a universal woman experience (Abu-Lughod 1990). I am also not standing on a moral and cultural high ground, wanting to "save" these women; I am not creating a rescue narrative (Mohanty 1988). This research falls within a feminist framework because it foregrounds the question of inequality vis-à-vis the lives of Somali women, or if not their lives, their shared experience (Visweswaran 1997). It looks at the role of the everyday in contributing to the maintenance of power,

\footnotetext{
${ }^{20}$ The next chapter clarifies this but clan affiliation is a contentious issue in the Somali community and because there had not been enough time within the scope of this research to develop strong relationships of trust, I did not feel in a comfortable or educated position to ask.
} 
and understanding that my position in relation to those I want to work with could also be a reflection of the structures of power I am researching (Skeggs 2001). The research process, in this feminist framework, views the interactions of structure, agency, and historical sociocultural contexts as a co-production between participants and myself. It allows for the understanding and analysis to come out of both what the participants identified as important and needing to be heard, and my own academic analysis and understanding.

\section{Women}

As one

But different.

We are not all one

Intersections of life - race, a coloured

lady, a veiled face, religious difference,

educated, street raised, class awareness

Women are not all one

Blanket identities

Similarities

A voice

But...

We need to recognise - difference

Intersectional voices

Intersectional context

Intersectionality

A theory, a framework, a method

A way to acknowledge a complex whole

A feminist methodology allows for this by using tools like intersectionality. Doing so enabled me to see how important it was to acknowledge that women are constructed differently depending on factors like race, class, and religion (Hochreiter 2014). Intersectionality gave me a way to understand how these multiple grounds of identity could relate to the way Somali women constructed their lived worlds. Analysis of this nature highlighted the questions underlying feminist research, and in turn this methodology, by making me think about who was being constructed as different, for what purpose, and with what consequences (Hochreiter 2014). With my focus on disadvantage, intersectionality provided a tool to analyse how belonging simultaneously to a 
range of stigmatised or devalued categories could amplify negative experiences in the social world (Werbner 2013). But intersectionality has done more than clarify my focus on gender and the use of a feminist methodology; it also played a role in the formation of my reflexive voice and the awareness of my positionality as a researcher.

It became increasingly important to me to be conscious of how I was "I witnessing" my own reality constructions, the ways in which I was interpreting culture through my self-reflections and cultural refractions of identity (Spry 2001). This was important because "what happens within the observer must be made known, if the nature of what has been observed is to be understood" (Spry 2001:711). It helps create transparency in the research by allowing reflections on the intersections that create my identity and sense of self, how my whiteness and class membership could restrict the social freedom and personal development of others through what I chose to write in my thesis (Spry 2001). I needed to recognize that I was an active agent with narrative authority over the project, and that if I was not careful I could reinforce dominant and hegemonizing cultural myths (Spry 2001).

What ties together my use of a feminist methodology, self-reflection, and the methods and analysis I chose was the interweaving of reflexivity, positionality and intersectionality in my ways of thinking about the research. They have helped me be alert to the politics of positionality, that any one representation of an "other" is just that, only one way of seeing things. It has made me aware that while I strive for transparency between my participants and you as the reader, I am not striving for an ideal truth in my research. What I share is not fact. It is a creation evolving from my academic, feminist voice, and the voices of my participants as they are heard in the short snapshots of time that we connect. As Geertz (1973:140) frames it, "ethnography...involves owning up to the fact that, like quantum mechanics or the Italian opera, it is a work of the imagination".

It is truth, but it needs to be seen as partial truths (Madden 2010). Feminist reflexivity calls for these partial truths as a way to combat totalising, 
essentialising representations (Madden 2010). This form of reflexivity has allowed me to acknowledge that I am never entirely objective in my work, as I have constantly been in a process of engagement with the different positionalities of my participants and myself (Madden 2010). It is the recognition of what can be termed personal-political reflexivity, or the awareness of the influence of 'me' on the research and representations of 'them' in the write-up process. Without this, my research could not be seen as a reliable ethnographic account and transparency could not be achieved (Madden 2010).

\section{Interviews}

The main concern I had was that participants felt comfortable and at ease during our interviews, as this would be more conducive to creating the in-depth conversation I was aiming for. For Somali women this meant that most of the interviews were done at their homes, while I interviewed community workers at their office or work locations.

\section{Somali Women}

Interviews for all but one of the women were carried out at their homes. I met Jamilah and Fadumo once each and arranged through phone calls to visit their homes during the day. While Jamilah was happy to be recorded, Fadumo made it clear that she was not. This could have been to protect her anonymity but could also relate to distrusting me as a relatively unknown stranger interviewing her. Fadumo's interview was also the only one that was translated, she did speak English but preferred for her niece to translate most of the interview. I feel this impeded dialogue as writing by hand slowed down the process, making it difficult to create a flow between Fadumo and myself. It felt like a formal interview with a set list of questions, over a conversation. Jamilah was happy to be recorded, although I noted that she spoke more freely once the interview was over. Hibo was the most expressive when recorded and was happy to be interviewed at the university ${ }^{21}$. Miski was the only participant that I talked in-

\footnotetext{
21 I feel the ease of our conversation was due to being close in age and having previously met before the interview.
} 
depth with twice. The first time we met for coffee, I wanted her to get to know me a little before we had a recorded interview ${ }^{22}$. After the first meeting we arranged for me to go to her house. I had planned to record an interview but instead I had a lesson on cooking laxooh ${ }^{23}$ and tried other Somali dishes, then we sat and talked over cups of Somali tea. During the talking we covered all the areas that I was interested in so rather than create a forced interview that repeated what we had already discussed, I decided to write down from memory what we had conversed about.

At the start of each interview I made it clear to the women that they did not have to answer any questions that they did not feel comfortable with. I also reiterated why I was interested in talking with them. At the end of the interviews conducted in homes I was offered tea; during this time I talked further with the participants and often learned more than I had while recording 24 . I feel that having the tea and talking more about my times in Somalia helped to create the relaxed, informal atmosphere I had been striving for in the interviews because it aided in creating in-depth conversation.

\section{Community Workers}

All four of the interviews with the individuals who had worked with the Somali community were carried out at their offices or in rooms at their work. All of them were happy to be recorded. At the start of the interview I also made it clear that they did not have to answer any questions that they felt uncomfortable with, and introduced who I was and what the project was about. All of the interviews were semi-structured; I had a list of questions that I was interested in having the participants answer such as 'How has the group you work with interacted with Somali women?' or 'Do you think that New Zealand attitudes have an impact on how these women feel coming and living here?' But I made it clear that I was

\footnotetext{
22 Originally, I wanted to do this with all my Somali participants, but due to time restraints, I was only able to do this with Miski.

${ }^{23} \mathrm{~A}$ pancake made from fermented batter

${ }^{24}$ I took notes retrospectively from these conversations and used the information as data in this thesis.
} 
happy to let the interview flow where it would and that the questions were simply a guide.

In all of the interviews I strived for an in-depth conversation. While my relationships may not have formed over a long period of time, in most situations enough trust and rapport were created to shape a meaningful dialogue that did not flow from a list of questions, but instead emerged from conversations that we constructed together.

\section{Data to Thesis}

In this section I discuss how I analysed the data I collected during my fieldwork. Beginning to make sense of everything I found was the start to the analytical process, it was the summarising, sorting, translating, and organising of information (O'Reilly 2009). The first step was to figure out how I wanted to transcribe the spoken interviews. Did I want to remain completely true to the minute phonological details, or smooth out the voices to form edited and clean spoken transcripts (Skinner 2012)? For authenticity ${ }^{25}$ I decided to extend the concept of listening carefully and respectfully past the interview situation, to the 'listening' I carried out when analysing the audio data (Atkinson et al 2001). I approached transcribing as a way to capture as closely as possible the spoken conversation. This meant including silences, pauses and repeated words, as well as the utterances of agreement to show support for things that were said, such as yes, ah huh and so on. By doing this I showed respect to the interpretation of the story we had co-constructed, by simply attending to the words that were spoken (Skinner 2012).

Transcribing however is only one part of transforming interviews into the chapters of this thesis. Coding is another important process that helps to clarify

\footnotetext{
${ }^{25}$ Authenticity here relates to accuracy, "transcribing spoken data inevitably loses information as the concrete event or emotional response is translated into written language--a symbolic form inherently less rich and authentic. Thus transcription can result in the loss of pragmatics--the role of context and inflection on speech." (Markle, West and Rich 2011:5).
} 
the themes in the interview data. Coding for me became a process of deep reading' where I started by pulling out moments that leapt out at me, such as Miski's thoughts on family. Once I had a selection of important moments, I went back through the interviews, looking for information that would add to the arguments that I was starting to see in the quotes that had stood out to me. Once I had all this information I started to see that while there were clear themes of belonging, identity and acceptance, that specific participants stories spoke more loudly about these themes than others. The data then have created chapters that revolve around key participants, with the themes of belonging, identity and acceptance flowing out from their words. While all my participants have played a part in the chapters, three in particular have created the foundations that my analysis has been built on.

These foundations come from the data analysis and represent what is termed feminist standpoint ethnography ${ }^{26}$. In this framework the analysis of the chapters revolve around one key person, with the words of Miski, Hibo and Sally who worked for Mclass, speaking out more loudly than many of the other participants throughout different points of the thesis. In particular, it is the juxtaposing of these key women at times that creates tensions and insights into the Somali community within the chapters. Intersectionality not only illuminates my position in relation to my participants but also their positions to each other. What will become clear is that Miski's responses became the foundations for thinking about belonging in chapter three, Hibo's stories showcase thoughts on identity in chapter four and Sally's experiences working with the community inform chapter five. By interweaving and contrasting the women with one another, strong, coherent narratives demanded my deep listening and grasping

\footnotetext{
26 "Feminist standpoint epistemology is a unique philosophy of knowledge building that challenges us to (1) see and understand the world through the eyes and experiences of oppressed women and (2) apply the vision and knowledge of oppressed women to social activism and social change. Feminist standpoint epistemology requires the fusion of knowledge and practice. It is both a theory of knowledge building and a method of doing research-an approach to knowledge construction and a call to political action." (Hesse-Biber \& Leavy 2007: 45, also see Ramazano \& Holland 2002)
} 
the themes while more quiet voices have helped me deepen the analysis of the key themes of belonging, identity and acceptance in this thesis.

\section{Conclusion}

Strong Somali woman

Your resilience astounds me

I am silenced by the words you choose to

share

Strong Somali woman

New Zealand has so much to learn

You are more than a religion

Though being Muslim is important to

who you are

You are more than a different skin colour

Although you will never forget the

desert, or the soil where your roots still

yearn to grow

Strong Somali woman

You are more than a media image on a

screen

New Zealand has so much to learn

You are more than the "other" tick box

on our western forms

Strong Somali woman

I hope that others will get to share your

stories

Your experiences

And to see you for whom you are

Strong Somali woman

This chapter represents my thoughts on the fieldwork process. Through poetry I have shown my vulnerability in the field and a burgeoning awareness of the importance of intersectionality for my research. This highlights the use of a feminist point of view in my writing, where transparency about my position in the research is just as important as that of my participants. Reflecting on the fieldwork process also clarifies the methodology underlying this research and 
how the data have become my chapters. Following on from this chapter is a history of the Somali civil war and refugee resettlement, after which the use of feminist standpoint ethnography will become clear as the voices of my participants begin to speak. 


\section{The Somali Civil War and Refugee Resettlement in New Zealand}

This chapter provides the context for why Somali women have been resettled in New Zealand. It explores the impact of the civil conflict on their lives and important aspects of Somali culture, particularly the clan system to express how they flow on to effect Somali women's experiences of belonging even after forced migration. In this way connections are made between their experiences of war and the New Zealand refugee process. I then briefly introduce the resettlement process, arguing that Somali women's narratives express a loss of support for refugees who have been settled for long periods of time, reflecting larger issues in New Zealand's resettlement policies.

\section{The Somali war and its consequences: Flight, Refugee Camps and Trying to Survive}

The beginning of the Somali conflict can be traced back to the colonial era from the 1880's until 1960. Before this time no concrete boundaries existed between the different clan groups that made up Somalia, instead they functioned through a segmentary lineage system (Hopkins 2010). This system can be summarised by the Arab Bedouin saying "My uterine brother and I against my half-brother, my brother and I against my father, my father's household against my uncle's household, our two households (my uncle's and mine) against the rest of the immediate kin, the immediate kin against non-immediate members of the clan, my clan against other clans and, finally, my nation and I against the world!" (Samatar 1991: 25). What this means is that prior to colonial contact Somalis did not have permanent enmities with one another. Conflicts were context driven with friend and foe alike shifting and changing depending on the situation, while elders of the clans watched over and finalised any agreements and affiliations between groups (Samatar 1991, Hopkins 2010). 
After colonisation 27, Somalia became separated into five regions. French Somaliland, now Djibouti, the Ogaden region (which is controlled by Ethiopia), an area that is now situated in Northern Kenya, the British Somaliland protectorate in the North, and an Italian-administered area in the South (Hopkins 2010). However, these colonial boundaries were not representative of already existing splits in Somali society. In line with the fluidity of the segmentary lineage system, the clan boundaries were also fluid, reflecting the nomadic nature of the pastoral Somali system and the need for shifting boundaries as seasonal grazing availability changed (Gardner \& El-Bushra 2004). After increasing pressure from Somalis, the British-held Somaliland and the Italian-administered south gained independence; on July $1^{\text {st }} 1960$ they joined to form the Somali Republic. It was during this period of time that Somalis came to believe that all five areas that had been separated through colonialism should be joined back as one. This was symbolically represented by the white star on the Somali flag, with each point of the star representing one of the five points of colonially separated Somalia (Lewis 1994). Although it was not until the rise of Siad Barre in 1969, that this desire was to be fully embraced.

Siad Barre came into power on the $21^{\text {st }}$ of October 1969 through a military coup. By the following year he had declared Somalia a socialist state dedicated to Scientific Socialism, where he was the 'Father' of the nation and revolution was the 'Mother' (Gardner \& El-Bushra 2004). During this time he placed members of his own clan family (Marehan/Darod) into key government positions. This both exploited the centralized government system, and drew on the power of the traditional clan system, to form allegiances with a large number of the population who belonged to both his and his wife's clan groups (Hopkins 2010). By doing this Siad Barre had effectively combined the clan system and the centralized system of governance to secure his position of power over the entire country. He then proceeded to make the concept of 'clan' illegal, effectively

\footnotetext{
27 Somalia was colonized by Italy and England - English territory was called Somaliland and the Italian area was Somalia. Refer Ioan Lewis (2008) and Mohamed Diriye Abdullahi (2001) for more information.
} 
disempowering other clan and sub clan leaders (Hopkins 2010). Over the following years Siad Barre created a national campaign against tribalism. He symbolically burnt effigies made to represent tribalism, corruption, nepotism and misrule; but at the same time he continued to manipulate his own clan ties, creating a tighter web around himself of loyal followers and giving small benefits to other clans. This continued the process of disempowerment of other possible leaders, minimising the chances of an uprising and ensuring continued support from non-clan members of the population (Gardner \& El-Bushra 2004).

It was in 1977 that Siad Barre made his greatest push to unite all of the points of the Somali star back together. He launched a major offensive inside the disputed Ogaden region effectively creating a war with Ethiopia, however with the loss of Soviet Union ${ }^{28}$ support he was forced to retreat by 1978. This led to an upsurge in tribalism, or the reforming of loyalties along clan lines, as different groups vied to provide a victim to condemn for the debacle that was the Ogaden failure (Lewis 1994). With this shift back towards internal politics, the beginning stages of what would become the Somali civil war had started (Hopkins 2010). Within the year, on April 9th 1978, an ineffective coup was attempted to displace Siad Barre in power by disaffected Majeerteen ${ }^{29}$ officers. They would later come to form the Majeerteen-based opposition movement, the Somali Salvation Democratic Front (SSDF). However repercussions for civilians were severe, with the government implementing a 'scorched earth' policy between 1978 and 1979 against Majeerteen's in the regions of Muduug and Hiran, killing thousands.

At the same time that this was occurring, there were between 400,000 to 800,000 refugees from the Ogaden region flowing into Somalia and being settled in the Northern regions. They were given preferential treatment over the Northern clans (such as the Isaaq) that were already settled in the area, creating the beginnings of mass internal displacement; but even more dire was the use of Ogaden refugees by the government to form paramilitary groups and increase

\footnotetext{
${ }^{28}$ Coinciding with the Cold War, America and the Soviet Union played large parts in the conflicts in Africa. This has impacted how the war has occurred in Somalia, as support would change inline with what was happening in the American - Soviet conflict.

${ }^{29}$ A clan in Somalia
} 
Siad Barre's army through the use of forced conscription (Gardner \& El-Bushra 2004).

From the late 1970's through to 1990 there was a rise in clan-based opposition movements, including the Somali National Movement comprised largely from the Isaaq clan (who were being increasingly targeted by the government), the United Somali Congress (USC) of the Hawiye clan, and the Somali Patriotic Movement (SPM), which was, comprised of disaffected Ogadeni soldiers. In August 1990 these three movements, despite being formed from separate clans, joined together in opposition of Siad Barre and his government. In December of the same year the government lost control over most of the countryside and the USC entered the capital and government base of Mogadishu on the $30^{\text {th }}$ of December (Gardner \& El-Bushra 2004). However, it was not until the $26^{\text {th }}$ of January 1991 that Siad Barre fled Mogadishu and the USC forces completely captured the city. It was at this point that the civil conflict reached a point of escalation. With the removal of Siad Barre, clans began to vie for control over areas and resources (Hopkins 2010). As Awa Mohamed Abdi (2006:232) explains, "the overthrow of Siad Barre's regime in January 1991 culminated in a Hobbesian state of war of all against all in Somalia". It became a bloody process of revenge killings and mass displacement of civilians caught in the crossfire.

At its height between 1991 and mid 1993 it is estimated that 400,000 people died from the violence and man-made famine, with over a million Somalis fleeing to neighbouring countries such as Kenya and Ethiopia to escape the atrocities (Abdi 2006). Since 1991, and until the present, southern Somali has been in continual conflict. International aid and intervention attempted to create peace through internationally-organised peace talks, however, often fuelling the conflict with its own agendas and ideas of what can be helpful and for the foreseeable future, southern Somalia looks set to remain a refugee producing nation (Hopkins 2010). One glimmer of hope for those looking in from the outside is the Republic of Somaliland to the north. Somaliland claimed independence from Somalia on May $18^{\text {th }} 1991$ and currently remains an unrecognised state. After initial skirmishes between the dominant Isaaq clans 
and sub-clans in the early 1990's, Somaliland ${ }^{30}$ has effectively implemented grassroots level peace movements to form a stable government and society. They have achieved this with no international aid, instead utilising the traditional roles of elders to maintain peaceful connections between the clans in the area (Gardner \& El-Bushra 2004).

\section{The Importance of Clan for the Understanding of the Somali Civil Conflict}

The concept of the clan runs through the civil conflict and has commonly been used to analyse the fall of the Somali nation. Somalia is often falsely stated as being an ethnically, culturally and linguistically homogenous society; although the dominant population are ethnic Somalis (of Hamitic origin) there are also significant amounts of non-ethnic Somalis in the Southern parts of the country (Gardner \& El-Bushra 2004). While these groups identify themselves as Somali, there has been a long history of discrimination against them by the ethnic Somali community and it was their lands that have been some of the most ravaged throughout the civil conflict (Besteman 1999). However for the majority of the country religion, ethnicity, and language is the same and it is not the separation of ethnic and non-ethnic Somalis that comprises clan difference. Instead it is the breakdown of shared lineage between ethnic Somalis ranging from the broadest level of clan group through to the narrow diya-paying level ${ }^{31}$, which makes up the complicated Somali clan structure.

This structure is divided into six clan groups comprised of Ethnic Somalis; these are the Isaaq, Daarood, Dir, Hawiya, Digil and Rahanweyn. These six clans can be

\footnotetext{
30 These movements have been led by the elders, the traditional leaders in the clan system who have a history of maintaining peace in times of conflict between clans.

31 The diya-paying group was an alliance formed by related lineages within a clan by means of a contract, traditionally oral but filed in written form with district officials during the colonial era, at least in British Somaliland. The contract explicitly stated the rights and duties of members of the group with respect to the burdens of payment and the distribution of receipts of blood compensation, that is, distribution of the camels or money received, when the parties were members of the same or different diya-paying groups (refer to Ioan Lewis $(1994,1999)$
} 
divided into either pastoral or agricultural modes of subsistence, with the first four most powerful clan families being primarily pastoral and widely dispersed, while the last two are largely agricultural and concentrated in the riverine region of Southern Somalia (Farah \& Lewis 1997). Every ethnic Somali will recognise, through patrilineal descent, that they belong to one of these six kin-based clan families that make up a confederation of genealogically related clans; thus a clan in simple terms can be seen as a group of people that recognise descent from a common ancestor and who trace their blood relationships through the male line (Gardner \& El-Bushra 2004).

Each of these six principal lineages or clan families can be broken down into a number of clans, which in turn can be broken down into smaller sub-clans, then primary lineages and the all important diya-paying groups (Gardner \& El-Bushra 2004). For example Daarood can be broken down into the clans Ogadeni, Marehan, Marjeerteen, Dulbahunte and Warsengeli, which in turn can be broken down again into smaller sub-clans (in some cases as many as 10) known by the names of common ancestors, as seen in the Dulbahunte who have four sub-clans, the Muuse Si'iid, Ahmad Si'iid, Malbammad Si'iid and Yuunis Si'iid. These subclans are comprised of primary lineage groups containing the diya paying groups (Gardner \& El-Bushra 2004). Diya-paying groups are the basic political and jural unit of the sub-clans. The members are bound strongly by their agnatic ties with four to six generations between them and a common ancestor, with membership varying between a few hundred to a few thousand members (Farah \& Lewis 1997). The importance of the diya-paying unit is summarised best by Farah and Lewis (1997: 353) who state that "its enduring social solidarity is also further cemented by the collective obligation to pay and receive blood compensation and payments regarding other acknowledged delicts. Here both principles which define social solidarity and political action, agnation and contract (or xeer in Somali) neatly supplement each other to produce a cohesive and stable political unit which provides the protection and security of the pastoral Somali".

While this description can appear to make the concept of clan appear concrete, it is in fact not a stable entity. As Harper (2012) discusses clan is actually a 
dynamic and infinitely adaptable aspect of Somali society, a malleable part of identity that is remoulded with each shift in the political situation of the country. Alongside this malleability it is also a highly contentious issue. There are those in the Somali community, both abroad in the Somali migrant/refugee communities and at home in Somalia that deny that clan, as a category, even exists. For those who do acknowledge it, they argue amongst themselves over its importance and role in their society, as well as which clans and sub-clans actually exist (Harper 2012). What can be recognised is that these ambiguities and dissentions occur because Somali clans are fluid in nature. The divisions are not well defined due to the fragmentary nature of a segmentary lineage system, and the role of bloodlines telling people who they are and where they stand in relation to others (Harper 2012).

The clan system is significant for understanding the Somali civil war, but it is important to not be reductive. It is incorrect to view the conflict as simply a tribal society carrying out clan versus clan warfare, and it has been a common misconception to view Somalia as purely a country of nomads prior to the civil war. The reality however, was that by the 1980's Somalia had one of the fastest growing urban populations in Africa, with an increasingly urban and educated middle class (Gardner \& El-Bushra 2004). The conflict arose out of an intricate set of issues relating to the distribution of resources and power, economic marginalisation in the global economy, long-term corruption and exploitation, oppression, and uneven development (Gardner \& El-Bushra 2004). Alongside the failures of the state itself, Western contact also played a pivotal role in the formation and continuation of the conflict in Somalia. Bilateral aid was a key resource abused by Siad Barre and following warlords throughout the conflict, as well as the flow on effects of the legacy of superpower rivalry between the United States of America and the Soviet Union contributing heavily to the military hardware that was available during the conflict (Waldron \& Hasci 1995).

However because war-makers like Siad Barre have effectively utilised clan as both a weapon and a shield, civilians' fates have largely been determined by his or her clan identity (Gardner \& El-Bushra 2004). An emphasis on the power of 
kinship and the solidarity of lineages captures an important reality in Somali society (Besteman 1999). Where individuals may deny the existence of clans, the existence of lineages cannot be denied, as Dahabo expresses "even though you don't want to believe in tribal or clan things, you have to. It is like a passport" (Gardner \& El-Bushra 2004:185). Kinship bonds created safe networks for individuals during the conflict by drawing on the emotional connections that family ties create, and it has been recognised that many of the revenge killings that occurred after Siad Barre's ousting were clan orientated in nature (Besteman 1999). Different warring factions effectively manipulated clan sentiment during the conflict along with the promise of food and expensive goods to rally support, with larger militias also claiming to represent clan interests and even today Somalis living in exile can still be divided along clan lines.

When thinking about how best to analyse clan within the conflict Ioan Lewis (1998:105) describes it best stating that "clanship is and was essentially a multipurpose, culturally constructed resource of compelling power because of its ostensibly inherent character 'bred in the bone' and 'running in the blood' as Somalis conceptualise it. The reality is rather that Somali kinship although ideologically endowed with supreme moral force and conceived as 'natural' fact (blood), is, as elsewhere, deployed tactically as a multipurpose, culturally constructed resource".

\section{Biri-Ma-Geydo and Xayn Iyo Xiniin: Gender, Displacement and War Consequences}

Prior to the outbreak of civil conflict, inter-clan conventions existed that defined who was to be protected in times of war. Those who were termed Biri-ma-geydo or spared from the spear were immune from attacks and included women, children, the sick, elderly, men of god (wadaad), poets, honoured guests and community leaders (Gardner \& El-Bushra 2004). Fighting during the civil war has largely ignored these conventions making it highly risky for anyone to live 
outside their clan's territory, but for women in particular this has made the war especially difficult (Gardner \& El-Bushra 2004).

The clan connections for women are more complicated than for men, with the saying 'Xayn iyo xiniin', or 'the cloth worn by women and the testicles' expressing how paternal relations are like the testicles; they are essential to a man, whereas links through women are like a cloth that can be thrown off without diminishing the whole (Lewis 1969 cited in Gardner \& El-Bushra 2004). A woman will always belong to her fathers clan, whether she marries or not, with clan identity being patrilineal and for life. Yet women have more than just their patrilineal clan connections, as reflected in the popular saying 'a woman has ten very close relations in society: her mother, mother-in-law, father, father-in-law, daughter, daughter-in-law, son, son-in-law, paternal uncle and maternal uncle (Warsame 2001 cited in Gardner \& El-Bushra 2004). This creates a 'dual' clan identity for women, which has created a specifically gendered problem during the civil conflict.

The following diagrams represent visually the differences between male and female clan connections. 
Content not available. Please consult the print version for access. 
Content not available. Please consult the print version for access. 
While a man's clan loyalty is inherently only identified with his paternal clan, a woman, depending on the situation, can be identified by either her paternal or maternal clan (Gardner \& El-Bushra 2004). This 'dual' identity has throughout the civil war created a risky ambivalence during points where clan loyalty may be put to the test, where it causes men to question whom a woman will be loyal to (Gardner \& El-Bushra 2004). Women had historically been used in conflict as messengers and intermediary negotiators of peace because of this 'dual' identity, emphasising the positive possibilities of the multiple connections they hold to different clan groups; but during the civil war, being at the centre of multiple and potentially conflicting loyalties is precisely what put women at the core of suffering during the post-1991 inter-clan wars (Gardner \& El-Bushra 2004). Gender thus played an essential role in the decision for or against flight in the Somali conflict situation, as can be seen by the cases of Somali women who were facing double persecution because of the clan dynamics they lived within (Hopkins 2010). Many women were sent out of the region by family members because of this fear of reprising clan violence and sexual abuse, prior to and during the flight out of the country. It is as Hopkins (2010:524) says, "to ignore gender dimensions of experience and response to experience is to ignore the ways in which flight, migration, resettlement and transnational connections produce, reproduce and alter gender, cultural, and ethno-national identities."

While gender might create a sense of homogeneity among all Somali refugee women, it is erroneous to treat them as one cohesive whole that have experienced the civil war in the same way. As essential background to understanding how war has affected Somali women, you must locate their experiences within the context of each individual's social position in Somali society (Gardner \& El-Bushra 2004). The experience of the civil conflict will differ dramatically between women who have close family members in the diaspora or business connections and those who have no links and survive on the bare minimum distributed by international aid regimes, which counts for most of those in refugee camps such as Dadaab (Abdi 2006). It is the particular circumstances of Somali refugee women which influence the type of resettlement experience they have, how they relate to the receiving society, and how they will 
integrate into the Somali community they enter into in the diaspora (Hopkins 2010). For Somali refugee women, gender becomes an organising principle of social opportunities and relations through its embodiment in roles, relation and hierarchies in their society (Hopkins 2010).

An example of this in lived reality is the experiences of Hibo and Fadumo. While both of them are female Somalis, their experiences of coming to New Zealand differ immensely. Fadumo came from Berbera originally and was married at the age of 16 . When the civil war broke out in 1988 she already had 3 sons and was pregnant. Her husband died in the fighting and she fled to Ethiopia where she stayed in a refugee camp from 1991until 1999. During this time she was shot and after one year ended up in Djibouti for medical reasons. It was at this point in time that the United Nations intercepted, deciding to send her to a country that could both help her medically and benefit her children. On February $10^{\text {th }} 1990$ she came to New Zealand.

Hibo in contrast came from the north of Somalia and was only young when the war broke out. She came to New Zealand with her Mother through family reunification. Her family was lucky enough at the time to have an uncle already situated in New Zealand and he arranged for the family to come here. While they still faced difficulties through this process it appeared that she did not remember suffering any specific forms of violence. Instead she remembers the frustration around having to sort out the visas and travel documents, which involved travelling to places like South Africa where the closest embassy was, as she says "it was long travelling". Hibo also came straight to Wellington and has had minimal contact with the Somali community here, while Fadumo was processed through the Mangere Refugee Reception Centre in Auckland before being resettled in Wellington and has been an active member of the Wellington Somali community ever since.

Refugee Somali women were also not just affected on an individual level, almost all have suffered agonies of separation and loss (Gardner \& El-Bushra 2004). Family has become one of the most affected aspects of Somali society in the wake 
of the conflict, with children and parents being separated either because one or the other has been sent away for safety, or through the more devastating experience of being separated during the conflict while fleeing or through death. All of my participants had faced some form of separation or loss. Both Miski and Jamilah became separated from their nuclear families as they fled to Kenya. Jamilah relied on extended family and eventually made it to New Zealand in 1999 through an Aunt, while Miski was taken in by an unrelated family who cared for her until they were resettled out of the Kenyan refugee camp; because Miski was not their biological child she could not go with them, but they carried on supporting her, eventually she was reunited with her biological family in the 2000's but in the time apart her father had died. Fadumo and Jamilah suffered loss as well, with Fadumo's husband dying early in the conflict and leaving her a solo mother of three children and Jamilah's father died leaving her mother in a similar situation to Fadumo. These stories are not unique and a continuing result of the conflict has been women having to take sole responsibility for their families, "probably the most painful impact of the conflict to many is the disintegration of the household" (Accord 2001 cited in Gardner \& El-Bushra 2004:104).

\section{Consequences of Conflict: Refugee Camps}

Resettling in New Zealand though was the final part of the journey for the women I spoke to. Before they could make it here, they had to survive in most cases for years at refugee camps on the borders of Somalia. Fadumo who was situated in Berbera which is in the North-Western part of Somalia fled to Ethiopia, while Miski and Jamilah who lived further South fled to Kenya. The Kenyan reaction epitomises the African response to refugees in the 1980's and 1990's. Unable to financially support and politically cope with the flood of close to 500,000 individuals from a hostile neighbour such as Somalia, the Kenyan government created refugee camps (Abdi 2006). By creating these camps the Kenyan authorities transferred all responsibility for refugee determination, care and maintenance to the United Nations High Commissioner for Refugees (Abdi 2006). Restrictions were placed on refugee movements, and citizenship rights 
were not given to those entering the country. One explanation put forward for this heightened restriction on refugee movements is the political and economic turmoil host countries could be facing themselves, as was the case in both Kenya and Ethiopia at the time of the Somali conflict. Large refugee flows were seen as potential threats to already limited resources by citizens in the receiving countries, leading to hostile attitudes towards incoming refugees (Abdi 2006).

A refugee has been characterised as the 'achilles heel' of the nation state system, "they flee from their homeland because the basic bond between citizen and government has been broken, fear has replaced trust" (Adelman 1999:93 cited in Abdi 2006). By necessarily rejecting their 'mother or father land' in the process of forced displacement, they run into another state territory whose government predictably prioritises the rights of its members as citizens over outsiders, which by definition means excluding all others including the incoming refugees (Abdi 2006). "By the mere fact of being beyond the borders of her country, the refugee occupies 'no-mans' land or as Turton puts it, is out of place, relegated to the domain of the excluded or the object...the protection guaranteed for citizens albeit limited in many regions of the world, and always gendered, is denied them" (Abdi 2006:235). For Fadumo and Jamilah, the time in refugee camps was one of the hardest parts of their experience and fitted with this rejected citizen model. They had to survive with minimal support, relying on United Nations handouts in the worst of conditions, wary of sexual abuse and violence, which is rife in refugee camps and is reflected in the shooting of Fadumo. The only experience to break this mould was that of Miski who settled in Kenya and had only positive comments about her time there. The difference between Miski, Fadumo and Jamilah's experiences was the financial situation of those supporting Miski. As she put it, "Kenya provided more support and citizen related benefits to those Somali refugees that could afford it" (Miski).

\section{Refugees, Resettlement and New Zealand}

A refugee is defined as: "A person who, owing to a well founded fear of being persecuted for reasons of race, religion, nationality, membership of a particular 
social group or political opinion, is outside the country of his nationality and is unable or, owing to such fear, is unwilling to avail himself of the protection of that country" (UNHCR 1951 \&1957 cited in Dunstan 2004). The UNHCR seeks resettlement for less than $1 \%$ of the world's refugees. This is in recognition of the fact that the process of resettlement removes individuals permanently from their original nation, meaning that people must make major readjustments to their lives such as changing their language, way of life and livelihood (Altinkaya \& Omundsen 1999). For most people this is not a desirable outcome, as Dahabo expresses, “In my heart I wanted to be there (Mogadishu) - I didn't want to be a refugee. But I was scared to go back" (Gardner \& El-Bushra 2004). Resettlement will only occur if alternative options such as local integration or voluntary repatriation are not available or feasible. When this is the case, resettlement is offered to guarantee security or to provide humanitarian protection for refugees in "vulnerable categories" (Altinkaya \& Omundsen 1999). It is those refugees who are most in need that will be given the opportunity to begin a new life through resettlement. New Zealand is one of only 12 nations out of the 188 member states of the United Nations (UN) that accepts refugees through a quota system. In making this decision to accept refugees for resettlement, New Zealand has made a commitment to provide both a safe haven and a durable solution to their plight (Altinkaya \& Omundsen 1999).

New Zealand made this commitment when it signed the 1951 United Nations refugee convention and the 1967 protocol, relating to the status of refugees (Dunstan 2004). New Zealand does this through accepting an annual quota of 750 refugees, who are recognised as such by the UNHCR. Alongside this, New Zealand also considers applications from asylum seekers who claim refugee status when they arrive on our soil. This process takes into account the UNHCR's international protection priorities and New Zealand's capabilities and community needs. After this process the UNHCR refers cases to the Department of Labour, which makes the final call about who will be accepted based on credibility, risk, and settlement assessments (Dunstan 2004). As the global situations and humanitarian needs shift and change, so too does the geographic mix of refugees New Zealand accepts. The top five source countries for quota 
refugees coming in to the country recently has been Iraq, Somalia, Ethiopia, Afghanistan, and Burma/Myanmar. For convention refugees (asylum seekers) the top five source countries have been Iran, Sri Lanka, Afghanistan, Somalia and Iraq.

Quota refugees are composed of three main sub-groups. These are protection cases, women-at-risk and medical/disabled, with refugees being able to fit into more than one category (Dunstan 2004). This can be seen in the case of Fadumo who was both a woman at risk as a solo mother in a refugee camp, and also faced medical and disability issues after being shot. New Zealand has a high level of humanitarianism in the history of who it selects as a refugee, compared to other countries that often have highly selective and restrictive policies for refugee acceptance (McLean 2004). Out of the 750 quota refugees that we do accept, $10 \%$ are required to be women-at-risk and $10 \%$ need to be in the medical/disabled category.

How this affects the refugee populations we have was made clearer to me one day while having coffee with Axmed; he said that the first Somalis to arrive in New Zealand were women and children from the refugee camps (those in the women-at-risk category) and disabled Somalis. He believed that they had all come from the countryside rather than the urban centres and that this had influenced how the community had formed in New Zealand, compared to other parts of the world. He related it to factors like the ease of learning language, adjusting, finding work and so on, and felt that these original Somali refugees had brought family over once they were settled, leading to a community where all the groups were from the same areas. He then went on to compare New Zealand's choices to America, where it was often Somali men that were accepted because they could become skilled workers and added to the economy through this. While this was only one person's opinion, and the Somali refugee community is in fact comprised of both urban and rural refugees, it does help to understand that who New Zealand decides to accept does have an effect on how the community will form and fit within the country. 
Alongside the quota refugees with its three sub-categories, New Zealand also accepts an additional 200-500 asylum seekers, or conventional refugees as they can also be termed; while family reunification no longer counts as a category of refugee acceptance, it is still another way that refugees come into the country. These refugees however, will be recognised as migrants who are sponsored by a family member, even though in most cases they will be coming from the same refugee camps and experiences as their family member had (McLean 2004). Each of these refugee types will experience a different process when they arrive in the country. For an asylum seeker, they will initially be interviewed by border control staff and detained at the Mangere Refugee Centre. After a period of roughly a month they will be interviewed again by the refugee status branch of the New Zealand Immigration Services (NZIS), who will have a research team looking into what is going on in their country of origin and the reasons for them seeking refugee status (McLean 2004). Gaining refugee status as an asylum seeker is very hard, only $20-25 \%$ of individuals that apply will gain refugee status first time round. In comparison those who arrive through the quota system already have refugee status by the time they arrive in New Zealand and once here they receive six weeks of support at the Mangere Refugee Centre. For those who come through family reunification, the onus of support is placed on the sponsor/family who already reside in the country (Dunstan 2004).

The 750 quota refugees do not arrive all at once, they come in intakes of 120-130 at a time to the Mangere Refugee Centre (McLean 2004). This is a residential centre based at Auckland in Mangere at an old army base and is comprised of around five core organisations. These are: the NZIS which runs the facility and its services; the Refugee and Migrant Service (RMS) whose role is to resettle all the refugees, which is often difficult as there are frequently issues around where refugees want to live, and where they can actually live; Auckland University of Technology (AUT) which runs a centre for education where each refugee's language abilities are assessed in both their mother tongue and English, they also provide compulsory school facilities and run lessons that teach people how New Zealand services and systems work; there is also a counselling service through Refugees as Survivors (RAS) and a medical clinic that runs a medical screening 
programme (McLean 2004). While this might seem like a lot, the support services at Mangere are in reality small agencies with extremely large jobs, meaning they are often stretched too thin to provide all the services that refugees need (McLean 2004).

Once they leave Mangere, quota refugees are provided with the most support in comparison to conventional and family reunification categories. The government funds some refugee-specific community education and health programmes. They are eligible for a community services card to aid with the cost of health care and some aspects of day-to-day living. Community liaison staff and co-ordinators also exist to help with access to different services, particularly health services, as mental health is often an area of concern especially among the women-at-risk category (Dunstan 2004). For conventional refugees there is less support and they have a greater reliance on friends and government agencies for help. It is especially difficult prior to being granted refugee status, as they are expected to fund things like English language classes themselves. For those who have come through family reunification their biggest support network is obviously the family, who are expected to provide accommodation and financial aid. There is little government support for this group although they can gain some help through government institutions like Work and Income New Zealand (Dunstan 2004).

While New Zealand can be seen to have a high level of humanitarianism regarding those we accept as refugees, we have some of the poorest support systems in place once they arrive here (McLean 2004). After they are settled into a community it comes down to mainstream agencies and the kindness of everyday people to orient, befriend and help refugees (McLean 2004). Service providers themselves feel that refugees do not have a good enough understanding once they are sent out into the community, on how to access services that they need and what their entitlements are. There are also variations within the refugee populations over who needs help; Somalis for example often need support after living in New Zealand society for two or more years. Zoe worked as a Somali community social worker between 2010-2011 and had 
discussed how there were still many women within the community who had, in her words, 'fallen between the cracks' in terms of support. Often it was a mixture of a lack of understanding on behalf of the Somali woman, and a lack of cultural awareness on the New Zealand side. When dealing with doctors, police, or any organisation where the provider was viewed to be in a position of power, Somali women would often not speak up or go against their opinion, as there was a mixture of fear and lack of understanding of their rights in these situations. By making those in the organisations aware of this, and working with Somali women to make them aware of their entitlements, the women were able to more effectively utilise the support around them.

There are not only issues around accessing support but also around the type of support given to refugees with a need to cater for both ends of the refugee spectrum. For Sally, who was a support worker in the multicultural and support service group (Mclass) when it was first formed in the early 90's as a response to the incoming Somali refugees, one of the biggest problems they faced at that time was the lack of understanding about the women they would be working with. They were told to expect poorly educated women who had little English language proficiency and who needed everything. There were some younger women needing to be taught not only the basic language skills but also skills like using a New Zealand kitchen. However, conversely, one memory that had always stuck with Sally, was meeting a young woman who was incensed because her English was actually quite good and she said that she had lived in Mogadishu, where they had five microwaves and that she did not need to learn how to use an oven. So there was a wide spectrum of women to try to support and this is still the case today. What becomes important for New Zealand when looking at our refugee processes is the need for inter-cultural awareness (McLean 2004). The inflow of refugees is creating a diversification that can be seen as a two-way street, with refugees recognising us as the host society and being aware that they need to learn about our culture, but for better integration, New Zealand as a host society also needs to learn about their culture as well (McLean 2004). 
"People often say when looking at the refugee communities that have been here for the last 20 years, well how long do people go on being refugees? ...Surely they are now well integrated...these communities are not always so obvious and people assume that everyone is employed and getting on with their lives. But in fact, when you look at it, this is not the case for the whole community. So people ask me how long do people go on being refugees? I say you know, forever really, because it's a mix of things. The trauma stays with people and New Zealand has really been somewhat neglectful in terms of support that's needed and how little there is" (McLean 2004:25).

\section{Conclusion}

This chapter has provided the historical and cultural context behind forced migration faced by Somali women who have resettled in New Zealand. It has explored the importance of understanding their history and cultural systems like clan structures to recognise how they flow on to affect resettlement outcomes in Wellington communities. While Somali women have now been resettled for a relatively long period of time, there remains a need for support to create a sense of belonging in Wellington communities. Regarding New Zealand's refugee policies and support in the community it is imperative to acknowledge that the integration of refugees is a continual process that shifts and changes for each group that arrives in the country. With a focus on each new wave of refugees that come in, we risk forgetting about the refugees that are already in our communities. This is why, even though Somali refugee women have been here, in some cases since the early 1990's, it is still important to look at them within our communities and to see what they reflect about the wider structures and policies in place in New Zealand. 


\section{Belonging: Place-Making and 'Home'}

"Well it sounds awfully cliché, but it is really survival of the fittest. The ones who have gotten here, the ones who have managed to make it, the ones who have

thrived - it is an inner core of something that I think some people have and some people don't" (Sally)

Sally's words at first glance appear to be unrelated to how Somali women have created a sense of place and belonging in New Zealand. But thriving and "making it" relies strongly on a Somali woman's ability to create 'home' in Wellington communities; to carve out a place they can call their own after resettlement processes. Studying place-making in refugee Somali women's lives where movement has been constant through running, fleeing and forced migration, reminds us how "place remains a deeply contested and symbolically rich site in which to constitute the self" (Bönisch-Brednich \& Trundle 2010:1). The narratives in this chapter provide snapshots of the everyday experience of place, allowing glimpses into the ways that these spaces of belonging are constituted by Somali women through material forms, memory, imagination, flows and movement (Bönisch-Brednich \& Trundle 2010:3). Focusing on intangible aspects of belonging, such as memory and emotion, I argue that home is more than just a 'house'. Instead physical attachment occurs across space and time, relying on transnational and local connections in the lives of these Somali women. Generational differences are also examined and their role in creating belonging 'betwixt and between' spaces is analysed. Lastly ideas of reactive citizenship and the role of family are introduced, leading to a discussion of their importance for putting root downs and creating a sense of place for Somali women.

\section{Where is Home?}

"Home is here, not a particular place that one simply inhabits, but more than one place; there are too many homes to allow place to secure the roots or routes of one's journey" (Ahmed 2000:77). 
"She didn't want to, she said no I'm too old to go west. I don't know what they had against the west, they were like I'm too old to go there I'd rather die where I was born and be close to where a lot of my family members were buried. So I think its more to them... they feel like they don't ever want to leave, they know whose already buried there; I don't know my grandmother's thoughts but she'd rather be next to where all her family got buried. I don't know how she's going to manage though because she can't manage at the moment, because obviously the grave gets bigger every year. But it is the very same grave where her mum and her dad were buried and that means a lot to her, so she said no I'm not going I'm already at that time... she was already in her 70's, so she said no I don't want to go. " -Hibo talking about her grandmother's decision to stay in Somalia rather than come to New Zealand.

Hibo's story demonstrates the complex relationship between geographic mobility and attachment to place (Bonisch-Brednich \& Trundle 2010). Contradicting theorists like Zygmunt Bauman (1998, see also Castells 1996) Hibo's grandmother actively chooses to remain in stasis, bound to land around her. Arguing against migrating to New Zealand, she emphasises her connection to burial grounds where graves symbolically represent kinship ties. Home in this situation relies on site-specific and immobile symbols of familiarity, centred on family connections and a lifetime spent in one country. Somalia for Hibo's grandmother is what Bourdieu terms a "well-fitted habitus", creating a state of being that arises when one has a sense of familiarity, maximal know-how, and a sense of spatial and practical control (Hage 1997:103). Yet Somali women, who were forced to migrate, still express strong connections to the homeland. As Gupta and Ferguson (1997:11) argue, "immigrants use memory of place to construct imaginatively their new lived world", and for my participants creating nostalgic recollections of Somalia flowed on to affect their desire to create a sense of place and home in Wellington.

The power of nostalgic recollections in resettlement processes generationally changed in the narratives shared with me. Reflecting on the differences between 
herself and her mother, Hibo highlighted how older generations carry what she termed 'Somali baggage'. This is “where they never fully settle, if someone had grown up in Somalia or had an adult life in Somalia, once they come here they are just always packed, always ready to go home to Africa" (Hibo). This baggage leads to continual processes of 'waiting' for a woman like Hibo's mother, yet it is not a passive modality of being nor resignation about their place away from Somalia (Hage 2009). Energetically maintaining links provides an example where "agency oozes out of waiting" (Hage 2009:2). It is an active process of continually keeping links open with the homeland. Time and resources are put into creating a sense of home in New Zealand, but also maintaining homely belonging 32 in Somalia (Lakha 2009, Hage 1997).

Through actively waiting and maintaining homely belonging in Somalia, Hibo's mother and Fadumo convey a 'myth of return' where they imagine a homecoming that in most cases will not happen (Lakha 2009). This 'myth of return' is based on memories of Somalia before the war, where solidarity, sharing, reciprocity, trust and support are central to recollections. As Fadumo discussed this was the best time of her life. She reminisced about a vibrant, beautiful, abundant country where she was happily married and raising her family. Her memories create emotional attachments to Somalia, representing the "interplay of affect and emotion, knowledge and beliefs, and behaviours and actions in reference to place" (Low \& Altman 1992:5, see also Gustafson 2001). Fadumo has created a home in Wellington but acknowledges that she dreams of life in Somalia before the war, as she said, "the experiences you have change you and while it is fine here, it is not that previous life".

Home for Fadumo is still rooted in nostalgic imaginings of a past Somalia. She dreams of returning and would if she could, but acknowledges Somalia's current instability. Homecomings exist in a future fantasy, representing the futureorientation of a 'myth of return'. Fadumo situates her mythical return in the

\footnotetext{
32 Following Hage (1997: 100) we can think of "home" as made up of a series of affective building blocks, blocks of what he calls "homely feeling". For home to come into being, these blocks need either in themselves, or with others, to provide four fundamental feelings: security, familiarity, community and a sense of possibility (also refer to Velayutham 2007: 102-103)
} 
future, but discusses it in the present. Maintaining transnational links or buying property in Somalia are actions in the present that build towards creating the imagined future, representing how "the present is more than a fleeting moment in time; it is the space, place and way in which we think about and live in the world that is informed by the past, by current social and physical actualities, and that looks toward the future" (Gibson 2011: 13). Actively working towards returning 'home' creates a present full of moments of practical anticipations and retrospections that hold a sense of potential, or things to come (Bourdieu 2000:210).

As a form of practical anticipation, Hibo's mother's longing to return is being reformulated as a retirement plan. Re-imagining the 'myth of return' in this manner increases the sense of possibility ${ }^{33}$ that the imagined future will manifest into reality. Processes of this nature create what Dhooleka S Raj terms a 'neomyth', where the wish to return is shaped in response to changes in the homeland (Lakha 2009). Over time Somalia has had an increase in migrant returns and continued transnational support that provides, new infrastructure and increasing economic stability. Because of this, Hibo's mother views investing back in Somalia economically as providing for her retirement in the future. Waiting involves forward planning for this arrival in the homeland through active engagement in the present through return visits, supporting family through remittances and buying property (Lakha 2009). Experiences and memories could be seen to cast a shadow over the present, binding older Somali women to the past (Lakha 2009). However by maintaining transnational and economic links with Somalia, they actively carve out a future place that provides a strong sense of self and purpose in the now. Belonging in this situation relies on variable and contextual affiliations to both New Zealand and Somalia, where

\footnotetext{
${ }^{33}$ A sense of possibility is intimately linked with ideas of hope. While I have not framed my analysis in this framework, it is important to recognise that the women I spoke with create a sense of belonging as a way to maintain hope. Whether this is through imagined returns to Somalia or utilising all they can gain in New Zealand to give back one day, they represent forms of hope for the future. "Societal hope refers to the societal routes available for people to pursue meaningful and dignified social lives. It is about "one's sense of the possibilities that life can offer" (Gibson 2011: 15, also see Hage 2003: 20, 1997).
} 
home is centred on memories and emotions that are intimately linked to an imagined and future-orientated homeland (Bönisch-Brednich \& Trundle 2010:2)

Yeah, they just think home for them is Africa, home is Somalia. They all see it and they are all like we are going to invest in there, we are going to do this and we are going to do that. They have this idea that everyone lives here and yet they invest back in Somalia. But it's a good thing for the people who are living there, it's a good thing you are building schools and roads for them and you are giving them all this accessible [sic] ...but what about you? You're going to be here for how many years, god knows when you are going to go back, might be never. I don't think they will ever go back, but to them their homes there. They will always, especially when it comes to property, invest a lot of money and stuff... they will always put it in there, rather than here ... and for the elderly if you talk to them, they would say homes back home. To them homes back home, where they are going to retire, when they hit retirement age they are going to go back home. So to them retiring's like going back home and moving in to those properties of yours, where you can then live the life of luxury... yeah its different the way they see their life - Hibo talking about her mother and grandmother returning to Somalia.

\section{Where is Home? Betwixt and Between a Sense of Possibility}

The first time, when I was new it was really hard in New Zealand because of the English barrier. But after a few years, when I look back it has become like home, I feel like home here so now I think I am kiwi and also because when I went back home it was very hard for me to connect with the Somalis that are back home. So I have gotten use to it here, I mean this is my 17thyear so its, it has been quite long yeah...Going back, the first thing was it was really hot! From coming from here, it was really hot for me but it was really interesting to see so many Somalis there because I hardly see a lot together here, so that was one of my highlights. But apart from the heat, another thing that I didn't like was the living, where people live 
especially house, toilet, how they cook, yeah those things I never liked so it was hard going back. - Jamilah

Belonging for the younger Somali women I spoke with still relies on shifting and contextual affiliations between New Zealand and Somalia, but their narratives do not revolve around future-orientated imaginings of returning to the homeland. Instead young Somali women locate themselves within complex fields ${ }^{34}$ of belonging, where positions shift and change significantly between New Zealand and Somalia. For example Hibo discussed how she believes she would be received if she returned, "I don't consider myself a pure Somali. I wouldn't say I'm a pure Somali, so even if I did go back home people would look at me differently, they would feel 'oh she is from western she's here to learn the culture and stuff' - so obviously that gets stuck in your head, knowing that if you go back once in your life everyone would describe you from western".

In this moment Hibo is experiencing conscientização ${ }^{35}$, an awakening to the dispositions and structures that have shaped her life up to this point (Freire 1996). Reflexively she recognises that the way she acts has been shaped through living in New Zealand, the social structures around her have changed her behaviours to the point that she would no longer be deemed 'Somali' if she returned. Returning to Bourdieu's ideas Hibo can no longer play the 'game ${ }^{36}$ ' in Somalia because she is lacking the cultural capital ${ }^{37}$ necessary to be an active

\footnotetext{
34 The field is one of three analytical tools that Pierre Bourdieu discusses in relation to human practice (refer to Bourdieu 1990). It represents social spaces in society where social actors occupy and struggle over positions with other social agents. They can be "the various spheres of life, art, science, religion, the economy, the law, politics and so on, [which] tend to form distinct microcosms endowed with their own rules, regularities, and forms of authority" (Wacquant 2008:268).

35 Conscientização (translated from Portuguese into English as "conscientization" or "consciousness raising") is considered by many to be a key component of empowerment and community development; once people are aware of oppression and other structural factors they can begin to think, hope and act to change their circumstances (Gibson 2011:10)

36 The game is another term Pierre Bourdieu uses for the field.

37 Capital is the way individuals can 'invest' in the social world. It relates to the game and comes in three main forms: economic (financial and material assets), cultural (dispositions, know-how, information, cultural goods, skills and titles) and social (relationships, the sum of resources
} 
player on the field. The capital she holds, that gives her (albeit limited) abilities to play the game in New Zealand, holds no symbolic power ${ }^{38}$ in Somalia. It gains her no social recognition (Hage 2009).

Hibo's thoughts were based on a hypothetical return, yet they are supported through the narratives of Jamilah who has visited Somalia on more than one occasion. As she demonstrates, they exist in social spaces between both Somalia and 'the West', balancing positions in multiple fields that create belonging grounded in liminal positions. Her time in New Zealand has created visible markers of difference such as speaking Somali with an accent, but it has also created invisible markers as seen in her thinking about everyday Somali experiences, such as the way cooking is done, the household structure, hygiene and her place in society as a woman. Attachment for Jamilah now spans more than one location as she actively plays the game between two separate fields. However, juggling social positions and capital accumulation between two distinct social spaces, results in a sense of belonging that is both 'betwixt and between ${ }^{39}$. Recognition as Somali or Kiwi relies not only on Jamilah's sense of self, which recognises both New Zealand and Somalia as forms of home, but also on how she is received and recognised by those around her (Jackson 2012). In both cases this is partial. She is seen as 'other' in New Zealand through her birthplace, yet she is also 'other' in Somalia because of her absence from her place of birth.

Belonging in these instances is created within these spaces of liminality. Younger Somali women exist in a state of being "neither here nor there...betwixt and between" (Turner 1987:3). Nonetheless this does not imply passive existence in social spaces. The Young Somali women I conversed with do express desires to

accrued by virtue of membership in a network or group). These forms of capital become resources in given social space or field (Refer to Bourdieu, 1986; Bourdieu \& Wacquant, 1992:119; Wacquant, 2008:268; Hage, 2009).

38 Symbolic capital is the amount of social recognition individuals can gain through accumulating different types of capital (refer to Hage 2009).

${ }^{39}$ Victor Turner talks about betwixt and between states in relation to initiation rites where individuals exist 'betwixt and between, neither here not there, no longer a child and not yet an adult" (Turner 1987:3). In this thesis young Somali women exist in a betwixt and between state, no longer Somali and not yet 'Kiwi'. 
return, but within discourses of giving back in the future. As Jamilah said, "I would love to go back and live there so I can help just to contribute what I can" while Hibo feels it is important because "I think that's who you are because knowing you are from that side and you are the lucky ones, you should always help them. I do want to go back and help them but it's just not now". They are active agents constructing belonging and home in these in-between spaces. By dynamically seizing opportunities that New Zealand provides with a thought to giving back to Somalia through the skills they can learn, Hibo and Jamilah effectively balance increasingly 'kiwified' 40 senses of belonging with their desires to return.

Envisaging returning to Somalia is integral for defining ideas of home and belonging for the Somali women I spoke with. As they move and shift between social spaces across countries, their transnational aspects force us to reconsider what it means to be at home. They remind us that we construct a sense of home through particular places not simply a place (Hua 2011). They Illuminate belonging in liminal spaces as they navigate playing the game in New Zealand and Somalia. Memories and emotions create links to the past, but belonging is enacted in the present generating dialogue about how these women are fashioning meaningful futures for themselves (Hage 2003a). For Somali women, existing as they do in liminal spaces betwixt and between localities of belonging, home becomes a changeable construct where their attachments and lives are rooted in multiple locations (Hua 2011). So when asking the question, where is home? We see that it exists in a complex mix of spaces that are actively constructed to create links between a life that is centred here, and a life centred there.

\footnotetext{
40 I use this term to represent behaviour and action that would be recognized as typically 'Kiwi'. I originally created it when I could not think of another suitable way to word what I wanted to say, but after a quick Google search, I have discovered that it is a common colloquial term used in social media like twitter and Facebook to represent New Zealand identities. It has also been clearly used in the article "Is it a bird? Kiwi, not only flightless but also birdless" by Jan Bunting (2011:5) where she describes the increasingly Kiwi attitude expressed by a South African man, exemplified in his choosing of the All Blacks over the Springboks (New Zealand and South Africa's respective rugby teams).
} 


\section{Home within Community: Living in Newtown}

Up until this point belonging has been situated within and across geographical boundaries. I now shift my argument to focus on the construction of home and belonging by Somali women in smaller communal units, such as neighbourhoods and communities. When talking with Miski memories of her time in Kenya where she stayed after fleeing Somalia, clearly shone through to shape how she reflected on Somali community formation in Wellington. Reminiscing, she spoke about the way Somalis had created a flourishing community that was built on the foundations of what had originally been a refugee ghetto in Kenya. This area was now a fully thriving section that was accepted because of its ability to give back to the Kenyan community and economy ${ }^{41}$. It achieved this through the business Somalis brought into the country and the competition they created with Indians, who had previously maintained a monopoly over goods. She spoke not only of the thriving Somali community in Kenya but also about their existence in places like Minnesota, and even as close to New Zealand as Melbourne.

Through this reminiscing Miski is reflecting on strong patterns of Somali community building in one place ${ }^{42}$. When looking at Wellington she was clear in distinguishing Newtown as this community centre. After observing Wellington social spaces in my daily wanderings throughout the year, I could clearly see how Newtown is a hub for Somali activity. Somali women were visible at all times of the day, clearly recognisable in their bright dress and headscarves.

\footnotetext{
41 This could represent what Ghassan Hage (2003) terms as 'mutual obligation' where "when we have a society which, through bodies that govern it, feels 'obliged' to offer spaces that 'honour' its members as 'important' human beings, and when these members, in turn, experience an ethical obligation towards it which means nothing other than becoming practically and affectively committed to it, caring about it that we have a structure of 'mutual obligation'” (Hage 2003: 148). However, while Miski might feel this ethical obligation and even affection for Kenya, pointing out the economic benefits highlights how in reality it could represent neoliberal ideas of social contracts, where Kenya creates a calculated exchange of rights between 'homo economicus' and the state driven by self-interest over reciprocity (Trnka \& Trundle 2014:46). This idea is further enforced to me by a comment from Abdi where he notes that America purposefully chose male Somali refugees over women because they needed labour.

42 Refer to work by Gail Hopkins (2010) and Rima Mcgown-Berns (1999) for other examples of Somali's forming communities in one location once resettled.
} 
Whereas I barely saw any walking around areas like Lambton Quay or even Courtney Place, it was as Hibo commented, "every-time I go to Newtown, it is like you're in Somali town". What Miski explained was how Somalis actively ${ }^{43}$ choose to contain themselves in areas like Newtown. They prefer to congregate in one area where they can generate support networks inside bounded communal spaces. This could reflect the fact that most Somali women coming in to New Zealand were solo mothers, who relied on extended family and communal support to work and raise their children; but this pattern is also found in countries like America, where Somali refugees are mainly men. Instead it illustrates patterns found in refugee resettlement trends, where individuals will group together to form environments of familiarity, acceptance and support (Leckie 1995).

For Miski a sense of belonging was strongly centred on community locality, because it is associated with "a 'warm' place, a cosy and comfortable place...where we all understand each other well, we may trust what we hear, we are safe most of the time and...we are never strangers" (Bauman 2001: 3-4). She stressed her yearning to live in Newtown, a request she was not alone in voicing. Sally who has lived in Newtown over the last twenty years and has worked as an English and community support person, puts this congregating down to the social housing in the area but also feels it is linked to larger issues"4. "I know a

\footnotetext{
43 This represents Sherry Ortner's ideas on agency. Through actively choosing how they form a community, Somalis express intention and desire. These are the two spheres of meaning that form agency according to Ortner (2006). Agency in this way is also a form of power. By exercising their ability to create bounded communal units in Wellington communities, Somali women navigate relations of power that potentially could inhibit their community formation (such as government housing projects). In this way they illuminate how "agency is always embedded in webs of relations with other agents and things" (Gibson 2011:11). Creating a community within these webs is a form of strategic agency, that Ortner (2006:136) terms "agentive acts that intervene in the world with something in mind (or heart)". It also again links back to hope because by creating a community it "builds on individual or private hopes, shared hopes become collective when individuals see themselves as hoping and so acting in concert for ends that they communally endorse" (McGeer 2004:125).

44 This can relate back to Bourdieu's idea of 'well-fitted habitus'. Moving out of Newtown shifts Somali women, like the one Sally mentions, out of a comfortable habitus where they are surrounded by familiarity and can feel they have a semblance of control in the space they live in. The Newtown community represents a field that Somali women navigate, where the players represent social agents with similar behaviours and beliefs. When they are forced to live outside
} 
couple of students who have said to me that they know someone who got put into a council house up in Ngaio, or somewhere that is quite an unusual place. She hates it because it's just too white for her. She wants to be back in Newtown but she can't get back because she's got this big family and there isn't a big enough house in Newtown". However Somali Women do exercise their agency within relations of "social inequality, asymmetry, and force" (Ortner 2006:139) that impact their ability to live in the community, by remaining in poor housing conditions rather than leaving the Newtown area. In this way they maintain social connections and support that only exist in the community ${ }^{45}$.

I can remember quite clearly that this one family was getting evicted from their housing because there was an upgrade, so they needed everyone to get moved. She had five young children and a husband who worked fulltime, she was offered a brand new very flash apartment and I went with her to see it, but it was on the otherside of town, on the other side of Brooklyn, where as all of her family was in Newtown. She said I can't take this and the housing group just couldn't believe it because it was so much nicer than her current location but logistically it would be a nightmare for her to be separated from her community. It ended up going to court and the judge thankfully ruled that they'd have to come up with a more suitable housing option for her. So yeah, she would rather stay in a mouldy, cramped place where her families way too big for the house but she'd rather stay there because that is where she could get the support she needed. So yeah, it's just logistically really hard in Wellington because of the housing shortage. - Zoe

However, it cannot be generalised that all Somalis want to live in the community. For example, Hibo's family consciously decided to not live in Newtown, "I lived

of this community they shift to unfamiliar fields, creating an 'ill-fitting' habitus through lack of understanding and ability to fully participate in the new game.

45 Obviously exercising agency in these situations is based on a weighing up of the importance of community support with housing conditions, but a trend appears to be remaining in poor housing conditions, emphasizing the importance of support networks for the Somali women I spoke with. 
outside the Somali community. We were I think the first ones who lived outside that area, we first lived in Miramar and then we moved out to Seatoun where we still live... I think it was my uncles choice, knowing that we were young at that time he didn't want us to live where a lot of the Somali community were because when you are kids and you arrive and there's a lot of community in the area you don't interact with anyone outside of it...I think his idea was that he didn't want us to live with the Somali community because there was a lot of older children and he didn't want us to just live in the community, he wanted us to interact with other communities". Hibo's mother's ability to make this decision stemmed from the fact that she was not reliant on government housing or support. Her mother had greater power and agency to choose where she and Hibo would live, bringing to light the importance of recognising that not all Somali women have the same ability to be completely active agents in their choices.

Each woman exists within different class, economic and social structures, with varying amounts of kinship networks and support in New Zealand once they arrive. This affects their ability to decide where they want to live versus where they can live. Hibo's mother's choice was also not completely based on her own desires, instead it was her brother's choice as he provided the economic and familial support that she needed to survive as a solo mother in a new country. It represents one of the major functions of habitus, its ability to "bridge the gap between two opposing theories of human action: that humans either have unfettered agency (free will) or that human action is determined by and constrained by external structures" (Bourdieu 2000:138). Analysing the narratives of place-making as examples of 'free' choice expose how actions for Somali women in this research are shaped by structures around them, but also how as social actors they create, reproduce and transform society too (Gibson 2011: 10).

I have argued that community is vital for belonging, as expressed in the stories of Miski. Locality is stressed as important, but 'free' choice is limited by intersectional differences like class, economic and social positions. Creating home then relies on a process of negotiation between social structures and the active agency that Somali women in these narratives could exercise. By gathering 
together, Somali women work to weave a life within chosen bounded spaces that become representative of home. While home is often associated with the concrete symbol of a house, in this section it is related to the experience of dwelling, or building a sense of home that is representative of life negotiated between social structures and individual yearnings (Saegert 1985). Which as we will see in the following section can be seen and felt through communal networks of support in Newtown, mirroring the kinship and clan support networks left behind in Somalia (Saegert 1985, Lewis 1994, Cohen 1982).

\section{Home Through Family: Support, Isolation and Reunification}

$\overline{\text { For me to have asked about asking a man what he thought about rearing a child }}$ that was a wake up call for me because Somalis have these very specific roles. I think that's also where extended whanau comes through with those roles, in that we try to interpret family values through our understanding of what they should be in a nuclear modern family and so on, mum, dad, kids, well straight away you run in to problem for Somalis where they're thinking this is not family as we know it. You're encountering a loss of that family structure in many places... if you actually look at how the families are structured and Somalis aren't the only ones, a lot of our Asian community is the same, they've come from very clan based, very family based societies and we don't realise how much we've dissolved that in our society. In their society dad is the bread winner, dad is the supplier of resource, dad goes out and gets it, that's almost the hunter gatherer still; mum is the processor of resource, mum takes the food, runs the household, does the cooking and gets everything done. So mum and dad, their roles are very much work orientated and the raising of the little ones in a lot of these communities is done by elderly parents and youth. So it might be mums younger brother or sister who isn't quite old enough yet to be in the work force or whatever so it falls to them and grandma and granddad... but so many of our families didn't have grandma and granddad, they're 
still stuck in refugee camps or they've unfortunately been killed, so there is none of that support. - Max

Somali women are trying to recreate the family structures that Max witnesses as fading in his school environments, through creating communal support networks. Kinship and clan provided support networks in Somali society prior to the civil conflict, as physical proximity in Somalia created the possibility of an ethic of neighbourliness and reciprocity (McMichael \& Manderson 2004). But as Roger Rouse (1991:11) discusses, "migration...highlights the social nature of space as something created and reproduced through collective human agency and, in doing so, reminds us that, within limits imposed by power, existing spatial arrangements are always susceptible to change". As Max argues, traditional Somali spatial arrangements rely on interactions between extended family. Living in New Zealand changes these arrangements because of a lack of understanding about the importance of kinship networks by institutions of power ${ }^{46}$. Belonging for Somali women is mediated through the fundamental structure of kinship (Cohen 1982). It provides social networks that aid in reducing the negative effects of trauma suffered during the conflict and also promotes good mental health and resilience (McMichael \& Manderson 2004).

This is reinforced in Miski's narratives as she became noticeably emotional as she discussed her yearning for family reunification in New Zealand. As a Somali woman she argued that family would not only provide support in helping to raise her three young sons, but could also ease the extreme sense of isolation and loneliness she felt. With women and children making up ten percent of New Zealand's refugee quota, these feelings are not unique to Miski. Isolation is particularly problematic for refugee women who are forced to leave their families, emphasising the importance of family reunification in resettlement

\footnotetext{
46 An example of an institution of power in this situation would be the New Zealand government and immigration that decide who is allowed into the country. They represent institutions of 'discipline' as theorised by Michel Foucault (1977) where they enforce social control by acting as agents of normalisation. By not acknowledging the importance of extended family for Somali women, these institutions reinforce kinship norms, where nuclear family is emphasised and extended family is not recognised as important.
} 
processes for refugee mothers in New Zealand communities. Both Jamilah and Fadumo, who are also mothers, stressed the importance of their children in their actions and decisions since coming to New Zealand. For Somali women "children are their most precious asset...it is almost inevitable I suppose that the ones who come as a refugee, that generation, is sort of a lost generation. They had to sacrifice so much, but they do it for the next generation coming through...but that is just my impression as a practitioner, and I suppose we would do that too if we were in a similar situation, it's for a better life, for your children" (Sally, English teacher and community support person).

It is critical for their resettlement to have family members here, especially if it's their children, or sometimes it parents or very close family members. The criteria for bringing family members to NZ is very, very tight so not all refugees can bring family members to NZ but if they are eligible they might not meet the eligibility criteria so many of them can't bring their family members here, but the ones who can try to. If you talk to the mental health providers for refugees they will all say that the mental health condition of a refugee here is vastly improved when they have the family members back together again, especially if the family were in a dangerous or bad situation in refugee camps it's critical to get resettlement to have their family here if they can get them here...I don't know if going anywhere else would enable them to bring their family here but some refugees have said to me they would prefer to go back and live in the refugee camp with their family than be separated from them, especially if its children. Although when they are here they can earn some money and send it over and support their family over there, so it's a double-edged sword. The mothers especially with children left behind in refugee camps, they're desperate to be with their children but they know, and they go back sometimes to visit them but they know here they can earn some money, and a little, even little bit of money from their benefit or from their job will go a long way over there to support them with food and health and all those things so its really, really difficult. - Rachel 
I claim in this section that belonging for the Somali women I spoke with relies on the formation of social networks, that mirror kinship and clan ties in Somalia. Family reunification becomes a key process to achieve this, however it is extremely difficult in New Zealand ${ }^{47}$. Institutions of power, like immigration, fail to recognise the importance of extended family in the resettlement process; producing altered spatial arrangements for Somali communities, and increased isolation and loneliness for Somali women. Nevertheless as the next section shows, Somali women are actively pushing back against these boundaries. Through the desire to be surrounded by kinship networks, Somali women are becoming reactive citizens, challenging the limitations of their inclusion in New Zealand society.

\section{Laying Down Roots: Citizenship and Jumping Across the Ditch}

"Passport and citizenship is seen as a means to an end, to being able to go somewhere more supportive, rather than as a final confirmation of citizenship and belonging" (Bhabha 1996).

Family reunification creates a choice for Somali women. Fadumo, who has successfully navigated the process, can settle in New Zealand surrounded by her support networks and family. Yet for Miski, who is currently navigating the reunification process, bringing family into the country becomes a make or break

\footnotetext{
47 Fadumo, who has gone through the process twice, has been one of the lucky ones. The first time she was put in contact with Rachel who as a lawyer has worked as a refugee advocate, helping with immigration and family reunification over the last 15 years. Rachel and Fadumo are now very close because the process was long and difficult. There have been instances of applications taking over ten years, but for Fadumo who started in 2001 to bring her mother, brother and children here, it took three years with them arriving in 2004. She then did a second application for another brother and children. This time she was aided by a psychologist who helped families who were applying, by writing letters to assist with the immigration process and taking the women to make appointments with doctors, who would also write useful letters. As Fadumo commented there are a lot of people involved in the reunification process. It requires the woman to have knowledge of her rights, the immigration and reunification process, as well as being able to hire lawyers and use doctors and psychologists. They also need to have the financial means to not only pay for all of that, but to also pay the fees to have the family members come over. In some cases this can lead to the women making big sacrifices, with Miski currently in the process of selling her shares in a café she owns to be able to fund a family reunification application.
} 
point. To create a feeling of home Miski is relying on being able to have her family around her. To not bring family here, even in the nuclear sense, challenges her desire to put down roots. This reflects the states use of family reunification as a tool to control the Somali community and its physical growth in New Zealand (Bhabha 1996). Miski's struggle to bring her mother into the country, leads her to think about alternative possibilities as explained here, "when I finally get a passport, it is no longer to be a citizen here, it is a means to move elsewhere". Gaining a passport and citizenship becomes a means to an end, a vehicle to travel somewhere else that is viewed as more supportive, rather than as a final confirmation of citizenship and belonging.

Miski clearly articulates that she has a choice once she gains a passport. She demonstrates a reactive form of citizenship or what has been termed 'nomadic citizenship', where "as both an imposed condition and process of negotiation, nomadic citizenship suggests the ambivalent, lucrative, unconscious, and itinerant ways in which migrant subjects live in relation to the state. Nomadic citizenship delegitimises the state as arbiter of identity and citizenship" (Joseph 1999: 16). It counters the neoliberal idea of reciprocal citizenship that exists in New Zealand (Trnka \& Trundle 2014). Reciprocal citizenship to me is the process where those who gain citizen status are believed to then have to give back through being active members of society; there is "an idea of being given a list of rules that you have to follow to be able to fit in New Zealand, that you need to do this to be seen as a 'contributing' member of society" (Ayan).

However this is problematic when looking at Somali women, because as Ayaan experienced "it creates a double bind, because you need to be a contributing member to be accepted but this is not made easy, since there is little support around how to be a New Zealander". As a reciprocal citizen Miski is viewed as needing to give back to the country, 48 yet as she says, "why would I want to be a participating citizen if I cannot also have my family, why would I want to put down roots, if I have no one else to share them with"? Belonging for Miski relies on more than being legally recognised by New Zealand as a citizen, it is trusting

\footnotetext{
48 This also relates to ideas of responsibility as discussed earlier. Refer to 'Competing Responsibilities: Moving Beyond Neoliberal Responsibilisation' (Trnka \& Trundle 2014).
} 
that her recognition will be confirmed through being able to set-up a family network in New Zealand. In short she wants to have both the obligations and the rights of citizenship.

Looking at citizenship in these scenarios highlights how as citizen-subjects, Somali women exist between legal, cultural and political forces that affect their everyday experience (Joseph 1999). Citizenship for Miski, and women like her, extends past the national boundary to be influenced by their kinship, migrant and displaced needs (Joseph 1999). This creates a positionality that stems from positions of vulnerability, but recognising this vulnerable positionality does not create victims out of Somali women. Instead we can see how identity becomes situational and is used strategically to achieve particular needs (Abdi 2015). By being a reactive citizen, Miski becomes an active agent. She utilises her identity to push back against the state structures that she sees as limiting her ability to create kinship networks. By appearing to follow the list of rules that enable her to fit into society, she effectively manipulates the system to gain the coveted passport. In this way we are able to see the "performed possibilities available in different arenas of the everyday, through which communities and individuals access (successfully or not) the experience called citizenship" (Joseph 1999:2). Through this performance, women like Miski are able to create a better reality for themselves, even if this means leaving New Zealand for perceived greener pastures.

For Miski, New Zealand transforms into a gateway rather than a place of belonging. It provides what Ahiwa Ong (1999) terms flexible citizenship. Being a Somali citizen created a subject who was allowed minimal global movement through belonging to the Somali nation-state. Holding a Somali passport results in having the least access to visa-free travel around the globe, because they are ranked last in the worldwide travel index (Abdi 2015). In contrast, New Zealand passports are ranked as one of the top on the same index. This allows Somali women who become New Zealand passport holders, visa free access to around 170 countries. By (re) locating and (re)aligning themselves as citizen-subjects in New Zealand institutional contexts and webs of power, Somali women become flexible citizens (Ong 1999). 
In this way Somali women like Miski intentionally become flexible citizens in New Zealand, to gain access to easier travel (Abdi 2015). As a dispersed population, Somalis can have family connections around the globe. They desire to be able to carry out transnational lives and gaining a New Zealand passport allows this. Their mobility is greatly increased because barriers that they faced previously are removed (Abdi 2015). What Miski is seeking through being a reactive citizen is to gain this flexible citizenship, "these coveted Western documents permit refugees to seek economic opportunities and physical and psychological security, providing the ability to lead the transnational lives necessary for families scattered around the globe" (Abdi 2015: 234).

This is also reflected in patterns of migration to Australia once Somali women gain citizenship. While perplexing to Sally she does highlight what this movement demonstrates, "I mean they can go to Australia, god knows why they would want to, but as most of them are New Zealand citizens now they have that movement". By becoming a New Zealand citizen Somalis are automatically granted access to Australia, where it is perceived to be better in terms of achieving family support and reunification. The impact of this movement was recognised not only by Miski who believes the population to have dropped from around 300 families to about 90, but also from those who work in organisations that have had contact with the community. According to Zoe who worked as a Somali community social worker, all of her contacts in the community who worked in groups like the Somali Council have left. It comes down to a need to be providing for not only themselves, but also for the family left behind and spread around other parts of the world. For many of them, this is not possible in New Zealand. As Jamilah explained, "in New Zealand I think that it is financially hard because most Somalis are either a cleaner or taxi driver and you don't see cleaning as earning much, you don't earn much, just enough to do your living".

I've maintained email contact with my colleagues from the Somali council but they've all moved every single one of them have moved away, mostly Australia some Italy, some back to Somalia so its been really interesting to follow their 
journeys... and as far as I know right now, there was just this huge mass exodus to Melbourne of all places. They move because they want to be making lots more money, to have more job opportunities, they really just want to work and be able to provide for their families both here and back in you know the refugee camps and things so there's a lot of pressure to go. You don't get enough money on the benefit to survive here, let alone the expectation that you are in this wealthy country now so you have got to be providing for them, so yeah there's a lot of pressure and so I think a lot of people jump over to Australia. - Zoe

These narratives express how a pattern of exodus from within the Wellington community is linked to a lack of support in relation to the family reunification process. As Somali women continue to feel that they do not receive the same rights as other New Zealand citizens, they will continue to actively push back against a perceived lack of recognition and support. For women like Miski who attempt to work the system to gain flexible citizenship, it is not inherently about wanting to leave New Zealand. It is instead about wanting to be heard. She wants to receive the rights of citizenship, not just the obligations. While economic factors are involved in leaving, it still comes down to a need to provide for family. These narratives show how putting down roots and become participating and active citizens, relies on Somali women being surrounded with both nuclear and extended family. In the words of Miski again, "why would I want to be a participating citizen if I cannot also have my family? Why would I want to put roots down, if I have no one else to share them with?"

\section{Conclusion}

This chapter outlines three key factors that create a sense of belonging through place and 'home' for the Somali women I spoke with. The first factor was how belonging across generations is intimately linked to returning to Somalia. Older women expressed this through a 'myth of return', shaped by nostalgic and emotional recollections. Hibo's mother framed this in terms of retiring, where she actively engaged in preparing for the imagined return, over passively 
waiting. While future-orientated, these imaginings are enacted in the present, as seen through buying property and sending remittances to kin that have remained in Somalia. For younger generations, returns were framed through discourses of giving back in the future. Unlike their parents, they did not recreate a mythic return based on memory. Instead they navigated belonging 'betwixt and between' the social spaces of New Zealand and Somalia. Secondly I argued through Miski's narratives, Somali women try to create bounded communities in areas like Newtown to recreate their missing support and kinship networks. This highlighted the importance of family reunification in the lives of Somali women, and led into my third and final point that laying down roots relies on this reunification. To gain the same rights as other New Zealanders women like Miski are utilising flexible and reactive forms of citizenship so they can either be reunited with their family or leave. This chapter has argued that belonging is found through a home that is situated not in $a$ place, but in places that can exist across space and time (Hua 2011). Moving forward, the next chapter shifts away from place and 'home', to analyse belonging through individual and group Somali identities. 


\section{Belonging: Identity and Somaliness}

"I have that Somali side of me and I have the kiwi side of me as well, it kind of goes together" (Hibo)

The narratives in this chapter explore the role of identity in the construction of belonging. Through analysing constructions of self, I argue that the label of 'Somali woman' is in fact a complicated term that is created through navigating multiple power relations. This leads into an analysis of how a sense of Somaliness is a multi-layered construct, reflecting the fuzzy, shifting boundaries of identity and its dependence upon situation and context in creating feelings of belonging in Wellington (Kiely et al 2005). For women in this section, a sense of self is formed in relation to intersectional factors like age, marriage status and time spent in New Zealand, creating differing ideas of how 'being Somali' is enacted and performed. Through this we can see Judith Butler's (1999) ideas of performativity where the performance of identity through words, acts and gestures is modified depending upon where the women are, and who they are trying to identify with. Using Bourdieu's theory of practice (Refer to Bourdieu 1972; Bourdieu \& Wacquant 1992), we will come to see that 'Somali woman' is a complicated identity, created through both the individual agency of the woman and the structures around them.

\section{'Somali Woman'}

"What it means to be a Somali woman is shown to be a dynamic state interacting with locations of origin and resettlement, and with other ethnonational and sociocultural locators which act to define the bounds of Somaliness in a shifting ideological context" (Hopkins 2010:519)

I don't know anything else about when you say Somali woman, I'm like what does she mean a Somali woman? Does she mean Somali-kiwi as an adult and the kind of 
struggle they have gone through? I think it's a different... it depends on the age you were when you came here and also how you came here, for example someone like my mum would always have a Somali side, she would always think as and would always be Somali, so you should always do this the Somali way, you should always be doing this as a Somali. But for example for me I don't think it should always be a Somali thing, its just a thing, long as I consider myself a good Muslim and I be nice to everyone else I don't see how culture has something to do with you. - Hibo

In the moment above we can see how 'Somali woman', a term I believed to be a fairly innocuous aspect of identity, was in reality a complicated concept. For Hibo 'Somali woman' is a loaded signifier that represents a complex, intersecting way to look at Somali identity and ideas of belonging. As a process of identity work ${ }^{49}$ or "the on-going existential process of constructing a meaningful sense of selfhood" (Trundle 2014: 44), discussing being a 'Somali woman' expresses how they construct and assert their personal identities (Snow \& Anderson 1987:1348). For example, Hibo denies the role of culture in identity processes, arguing that "culture has nothing to do with someone, it is just you saying 'oh I am from there, once upon a time we were from there', that has no impact on me because, while I was kind of brought up for some part of my life there, it is more from being here". Instead, Hibo's identity talk ${ }^{50}$ constructs self around complex interplays of time spent in Somalia, time spent here in New Zealand, and the other parts of her life that made her who she is as seen through her: age, education, community experiences and religious adherence.

Importantly, identity talk only provides spoken formations and declarations of personal identities (Snow \& Anderson 1987: 1348). Hibo's narrative is only characteristic of how she constructs her identity as a 'Somali woman'. For

\footnotetext{
${ }^{49}$ Identity work is the "range of activities individuals engage in to create, present, and sustain personal identities that are congruent with and supportive of the self-concept" (Snow \& Anderson 1987:1348).

50 Identity talk is one of the four processes of identity work as outlined by Snow and Anderson (1987). It is the "verbal construction and assertion of personal identities" (Snow \& Anderson 1987:1348).
} 
instance, culture was not important in Hibo's identity talk, but for Miski identity is grounded in her culture and the support it offers her in New Zealand. Recognising that her identity construction is limited by the social constraints of her position within New Zealand society ${ }^{51}$ (Anthias 2001), Miski emphasises a Somali identity as a strategy to ease her struggle against the boundaries of New Zealand social fields (Bourdieu 1975). By stressing her Somaliness, Miski's identity talk communicates a process of embracement, where she verbally expresses "acceptance of and attachment to the social identity...a set of social relationships" (Snow \& Anderson 1987:1354). In this way identity comes to be relationally based on a feeling of familiarity and family, which can only be achieved when Miski positions her self as Somali.

\section{Edgewalking Somali and Kiwi Identities}

For Hibo identity was not as easy to define in terms of being either Somali or Kiwi. Instead she can be seen to exist in a state of in-betweeness amid cultures, languages and landscapes through identifying with both a Somali and a kiwi sense of self (Ibrahim 2008). She feels that "I am a bit of both. I am kind of all of them because I don't see myself being only Somali. I mean technically I am a Somali, but to be honest I was brought up here more than I was brought up in Somalia, so I have spent more years here than Somalia. So obviously I have that Somali side of me, but I have the kiwi side of me as well and it kind of goes together". For her, identity is positioned around both a sense of where she has come from and her years spent in New Zealand, as Hibo explains, "you kind of have to think about it, like am I 100\% kiwi, or am I 100\% Somali? No, I think I'm $50 / 50 "$. Identity is relationally and situationally formed from her position in a third space of neither being Somali or Kiwi (Ibrahim 2008). Effectively she is an

\footnotetext{
51 Miski is aware that by not being born in New Zealand limits her agency around being able to produce an accepted New Zealand identity. This relates to the previous chapter and her issues around bringing family here. Miski's identity is intimately linked with having family connections and support, so by not being able to bring them in to the country creates a reason to reject a New Zealand identity in favour of a Somali one. In this way she can still draw on kin ties and the sense of oneness being born in Somalia can create (refer to work by Marilyn Strathern $(1992,2005)$ for further information about the role of kin and relations in the formation of belonging and identity)
} 
'edgewalker ${ }^{52}$ ', constantly navigating between intersecting aspects of Somali and kiwi identities (Ibrahim 2008).

Explaining how she managed edgewalking between two different identities, Hibo discussed how her time in New Zealand has created an altered sense of Somaliness. As an example she explained how her ideas about education and politics have changed, "when it comes to education and a lot of politics I see myself as more kiwi, and one of the guys I'm studying with said to me while we were doing work that 'you're more like a republican' and I have no idea where I get the republican part of me! But he could not see how I would be like this, since I came from Africa and he saw the politics over there as being crazy. But then its just not who I am, its just the way I've been brought up. I mean being brought up in New Zealand, you kind of think about Somali politics and stuff, and you obviously would disagree with them, but a Somali would then say 'ah, your republican', just because I don't support a lot of the policies and stuff they use". Her time in New Zealand enables Hibo to reflect critically on her cultural identity and the history of where she came from. As she stated earlier, "I don't think it should always be a Somali thing, its just a thing, as long as I consider myself a good Muslim and I be nice to everyone else I don't see how culture has something to do with you". Hibo's time in New Zealand has created a changing, and sometimes ambivalent, relationship with Somalia that flows on to shape how she identifies herself (Hopkins 2010).

I think my mum kept the cultural side. She has gone back to visit, she went there a couple times, so she's still kept that Somali tradition and stuff. But yeah, I don't think we've actually become more traditional, really we might have become less with the Somali, I can tell you that we don't speak Somali at home and my younger sister can't even understand it. She was only 2 by the time we left, so even now days

\footnotetext{
52 An 'Edgewalker' is a person who is "resilient to cultural shifts and able to maintain continuity wherever he or she goes, walking the edge between ... cultures in the same persona" (Krebs, 1999: 9). It is used in research on multiple identities, particularly with youth of minority groups and has been studied with reference to Pasifika youth in New Zealand by Anne-Marie Tupuola (2004). Hibo's narratives often mirrored the same thoughts and ideas as the Pasifika youths.
} 
if my mum says Somali she wouldn't reply in Somali, she would always reply in English so she wouldn't pick it up...Yeah it kind of gets washed away. Like my mother always says 'oh you guys don't consider yourselves Somalis because you always say when you see Somali shows or something on Somalis in NZ omg this persons Somali'. My mum says 'why do you always say everything that's different, that the person has to be Somali', just because we walk past in Newtown and see them standing on one corner and another's crossing to the otherside of the road and they're shouting at each other and at the end of the day they walk together, I'm like laughing about it, like why can't they just come together on one side of the road and just talk in normal voices, rather then going to the other side and shouting at each other with their hands and everything going up. They'll stand on the otherside of the road and shout at each other, why don't they just cross over the road, like that's the kiwi way... -Hibo.

Thus being a 'Somali woman' involves a "weaving of their 'I' through a web of many different voices, which they encounter and to which they react, creating 'Me' voices that take up different pitches and differing intensities at various times in their lives" (Hajdukowski-Ahmed 2008:37). Identity relies not only on a Somali woman's positionality in relation to structures, but also on a process of identification formed from both from their own sense of who they are, and their acceptance by those around them (Ibrahim 2008, Bourdieu 2000). In this way belonging through resettlement entails a continual negotiation of self where women like Miski strive to hold on to a sense of Somaliness, and others like Hibo become edgewalkers, traversing both Somali and Kiwi worlds.

\section{Staying Somali: Dress and the House}

Miski's desire to maintain Somaliness represents the performative aspect of identity. She generates an 'enacted fantasy' or "the idealization of coherence that is a result of bodily signification - words, acts, gestures - which work to produce 'the effect of an internal core' of identity...It is the acts which generate a core identity and not identity which generates acts, although a choice to maintain 
group belonging may be exhibited through adopting certain acts" (Butler 1999). This 'enacted fantasy' is analysed two ways through the narratives in this section. The first is through the visible marker of dress and the second is the recreation of Somalia through interior decorating.

\section{Staying Somali: Clothes}

Dress became a visible sign that I used to identify my participants as Somali when we first met. Each of the women, apart from Hibo, were dressed in patterns and colours that vividly worked to remind me of the women I had seen walking down the streets during my time in Hargeisa ${ }^{53}$. Through my recognition of the style of clothes that the women wore, the performance of a Somali identity in that moment could be confirmed. Clothing for the women I met with became a way to either enact or openly resist presenting an image that represented a 'Somali woman'. Through visually consuming the image the women enacted in their dress sense, I saw how the body was transformed into a sign that is culturally visible and readable to members of a community ${ }^{44}$ (Paulicelli 2006).

\footnotetext{
53 During my time in Hargeisa, I visited the main market or Suuq in the center of the city and had garments made for me. Through this process, I was introduced to what was acceptable and unacceptable in clothing for women. I also experienced a cultural difference in taste, when the seamstress repeatedly refused to listen to my adamant no about embellishing my dresses with decals and shiny details. It was common for the women to wear bright, tie dyed materials (that they often dyed themselves) and to embellish them with bright and shiny sequins and decorations. This reflects Bourdieu's (1984) ideas about taste. In saying no to the embellishments I was making a distinction, I was making a choice in opposition to the culture around me. This reflected my aesthetics and the social factors that created what I found pleasing or not. Embellishments to me had a social meaning associated with tackiness and vulgarity, leading to negative judgments about the people who wore them. As Bourdieu (1984) says, the social world functions simultaneously as a system of power relations and as a symbolic system in which minute distinctions of taste become the basis for social judgement.

${ }^{54}$ When talking with Jamilah, the interlinking of religion and Somali culture was also made clearer through the mode of dressing. She claimed, "I think that's Somali culture, but as Somalis we also tend to live in a way that is right based on our religion as well. So wearing the scarf is another important piece of clothing". The choices that the women make to wear what they believe to be modest attire and to cover their heads, was not only a way to show belonging to the Somali community but was also a means to show their adherence to their faith. In the same way that identity can be multi-layered, its expression can also represent more than one part of the individual's identity. Faith for Somali women is intricately linked with a sense of self, with a rejection of Somali clothing and modest attire being taken as a rejection of faith, not just the community itself. Looking at this double meaning of dress and its links with faith highlights the interesting juxtaposition between individual choice and community expectations (as will be seen
} 
Dress provides a personal means to express being a 'Somali woman' that as an extension of the body can 'speak' more loudly about individual identity and belonging, than other symbols of material culture like flags and monuments (Akou 2011).

As I saw in Hargeisa alongside style, the colour, patterns and embellishments of a dress were just as important in marking it as Somali. Compared to other Islamic groups 55 that might live in Wellington communities, such as Palestinian immigrants, Somali women are clearly recognisable through a penchant for much broader ranges of patterns and hues. They step out in vivid colours like sky blue, yellow, eggplant and maroon, embodying what Akou (2011:112) describes as, "a more individual, improvisational, recognizably African sensibility about colours". Choice of dress, colour and pattern are distinctions of taste that reflect where Somali women have come from (Bourdieu 1984). It is part of a symbolic system of social meaning where dress preserves Somaliness in a decidedly darker, and less flamboyant, Wellington aesthetic (Bourdieu 1984). By adhering to a bright palette and shiny embellishments, Somali women are visibly able to recognise one another in public. Dress becomes a performance of symbolic forms of taste that mark the boundaries of belonging in the Somali community.

Creating distinction through Somali dress however is carried out in opposition to the wider communities' tastes (Bourdieu 1984). It visibly marks Somali women as 'other' in dominant social spaces. It creates a conflict in how these women accumulate being, as their interest in the social world and space is negotiated between two separate forces: the Somali community and New Zealand (Bourdieu 2000). As cultural capital, dress is only recognised in social spaces by fellow Somalis - it has no value outside of this field (Bourdieu 1986; Bourdieu \& Wacquant 1992). Because of this, playing the game through dress in Wellington social spaces can push Somali women to modify their dress sense. Miski and

later in the discussion of Hibo and the wearing of pants); where the individual may reject what they feel is a cultural aspect of Somaliness that does not go against their religion, but those in the community see it as a rejection of both community and faith.

55 I have chosen to compare to other Islamic groups here because they would also be recognizably different through the wearing of headscarves and the covering of female bodies to maintain modesty in public. 
Jamilah both discussed wearing more muted colour choices to balance expressing a sense of Somaliness in their clothes, while still visually presenting themselves in ways that allow movement and acceptance in Wellington social spaces.

You do stand out, especially when you are Somali and then you wear bright colours, but I do think they overdress to be honest. A lot of Somali women do overdress, there's so many times, so many people who come over to me at my work and one of my co-workers went to Newtown the other day and said 'I think I saw one of your people', and I was like 'what do you mean my people', and she said 'I think I saw one of the Somali woman, she was wearing all this bling bling stuff and bright colours'. So they do like walking around in all that kind of clothing, and a lot of the elderly, they overdress or they wear all the colours and stuff and you know that you stand out obviously, you do stand out. I think about them in Newtown when I'm on the bus or going home, I always see them like that, bright coloured head cover or bright coloured dress and I'm like oh god! But yeah, they do stand out a lot and I think they are known for that. -Hibo

So far I have argued that dress is a form of taste, a point of distinction that separates Somali women from wider Wellington society (Bourdieu 1984). Exploring this has illuminated how dress choices act in two ways in the lives of the women I spoke with. On the one hand dress is an active performance and embodiment of Somali identity. Yet on the other it is a visible sign of difference, creating an identity of the 'other' in social spaces where their dress as a form of cultural capital is unrecognised. Both of these identities however rely on a clear Somali, or Kiwi, sense of self. This will be explored in the next section through the experiences of Hibo who, as an edgewalker, uses dress as a marker of an inbetween identity (Tupuola 2004). 


\section{Between Clothing}

"As many Somalis see it, a young woman who does not resist assimilation is endangering not only herself but her future children, threatening the integrity of the entire culture. She might be able to get away with small touches of the Westnail polish or a fancy cell phone- but daring to wear a $t$-shirt or a pair of jeans without a skirt calls into question her respectability as a woman and ultimately her long-term commitment to upholding Somali culture." (Akou 2011:112)

As an edgewalker, the way Hibo chooses to dress makes a powerful statement about how she sees herself fitting into society (Akou 2011, Tupuola 2004). Existing in-between Somali and New Zealand social spaces means her decisions are judged by the tastes of both the receiving society and the Somali community (Bourdieu 1984). By trying to balance a personal desire to fit into work and university environments, while also adhering to the rules of Somali female dress, Hibo finds herself in a position of not quite fitting in either social space. This creates a point of uneasiness where discrimination is experienced in both communities. She particularly feels this from within the Somali community, who place pressure on her to project her loyalty to their culture and faith through dress (Akou 2011). By rejecting traditional Somali clothing, Hibo is seen as rejecting Somaliness itself by the community.

$\overline{\text { You do dress up different to be honest, I wear jeans at work and you are not meant }}$ to wear jeans ${ }^{56}$ at work. You know you're meant to wear-I mean I do wear jeans to work on Friday or sometimes if I'm not feeling well, I'm like who cares, as long as I

\footnotetext{
${ }^{56}$ Akou (2011:111) discusses why pants are not viewed as acceptable attire for Somali women: "Pants are almost universal among Somali men, but for women they are a controversial garment. Close-fitting pants have become common among women living in the refugee camps as an undergarment (worn under a skirt), but pants by themselves (without a skirt or another outer garment such as a shuka) are generally considered unacceptable because they look too much like clothing for men". It also relates to how revealing pants are of the female form and that this contradicts the ideas of modesty found in Somali dress related to religion. An excerpt from Akou (2011:111) again reinforces this, "She has only taken off her skirt and wears trousers, nothing else. But they may say that if she is wearing trousers, she has given up on her faith, or that she has changed from a decent girl into a whore."
} 
wear something black on the top and then I feel more formal. But I think back home you kind of have to wear skirts and stuff, but saying that for example I was wearing jeans the other day in Newtown and I just went through the butchers to get meat and I felt like I was kind of like an outsider. They all were just staring at me, there was a couple of other guys that walked into the shop and they were all staring at me. My little sister was with me and I'm like is it just me or are they all staring at us, and we kind of noticed they were all staring at us just because we were wearing jeans... so even inside your own community, you don't fit the culture if you don't wear the appropriate clothing that you're meant to. But I don't know who says that you have to wear skirts all the time...you just wear what makes you feel comfortable. - Hibo ${ }^{57}$

Rejecting Somali forms of dress as part of her identity mirrors the rejection of ethnic and cultural identities young Samoan women feel are imposed on them by their elders and peers (Tupuola 2004:88). For Hibo, her taste in dress aesthetic had been greatly influenced by not living within the Somali community. While her mother originally felt sad about what she saw as a loss of Somaliness through Hibo not wearing traditional clothes at school, she recognised that to adjust accordingly, her daughter needed to fit-in through dressing as closely as possible to her peers. “She doesn't mind what I wear, I think we all wear whatever is comfortable in our own mind. But then she never feels kind of like, I think first when we were in high school she thought it's sad and non-traditional if we don't wear normal Somali traditional clothes, but we never actually were, just because we never actually lived within the Somali community. We just wore what everyone else in our circles were wearing". In this scenario Hibo and her mother were acknowledging that as a young woman at school she felt more pressure to fit-in and not stand out, than to adhere to the Somali community's ideas of dress acceptability. The social field she was navigating at school emphasised their form of dress as the acceptable cultural capital. Thus to belong and acquire

\footnotetext{
${ }^{57}$ Hibo worked in a Somali run organization, so her dress sense needed to fit in with the Somali idea of acceptable work attire. She also talked about feeling that she stood out in non-Somali roles when she wore skirts all the time and that wearing jeans was a way to fit in.
} 
recognisable cultural capital, Hibo rejected the more Somali aspects of her dress (Bourdieu 1984). She changed her taste to imitate the New Zealand norm, enacting an identity situated in a Kiwi sense of self through dress that is accepted by the judgements of taste around her.

These judgements of taste however shift and change as Hibo navigates between different social fields (Bourdieu 1984). In Newtown, Hibo's dress loses its cultural capital, instead it becomes a point of judgement as the normalizing taste transforms from Kiwi to Somali (Bourdieu 1984, 1986). In this situation Hibo's rejection of Somali aspects of dress, such as a denunciation of bright colours and wearing pants, becomes symbolic to the older generation of moving away from traditional female Somali identities. Hibo, as an edgewalker, embodies the flux and change of migration, signifying changing forms of Somaliness. As a refugee community, Somali women have been forced to consider what it still means to be 'Somali women' (Akou 2011). Hibo's negotiation of Somali and kiwi senses of self, through dress, is part of this process. It ties back into the community's idea that dress is a way to express loyalty, where "little things like a hairstyle or the pattern of a headscarf can mean the difference between assimilation and the preservation of Somali culture" (Akou 2011:94).

Yeah I think a lot of the elderly generation or the mothers have the big mouths of talking. They will always say I saw her, her and her wearing jeans, or I saw her and her wearing this! I get it so many times, when I go out with people and then my mother goes 'did you see this person' and I'm like 'who?' and she is like this, this and this. I might not even know who they are, or they might have seen me at the bus stop, or on the bus and I'm wearing my work clothes and what am I meant to wear, I can't wear skirts every single day... but once you got in with the Somali community, they always have that judgement. They always be like, 'oh she's wearing that!' 'Oh she has been being do this!' or 'she was with this person!' So you do hear that kind of stuff, they still have that judgement. But you don't really notice that until you go out of the community and then you go into that situation where they all treat me like I'm some kind of outsider. - Hibo 
I have argued so far that Somali dress is a complicated marker of identity. In the right circumstances it can be seen as an on-going commitment to Somali culture (Akou 2011). For the older generation it offers a symbolic and visible marker of Somaliness, a form of cultural capital as they navigate Somali social spaces in Wellington (Bourdieu 1986). Yet for edgewalkers like Hibo, modifying Somali dress represents a negotiation of judgements of taste to fit into the wider New Zealand society (Bourdieu 1984). Her shifting identity represents a process of change for being Somali (Tupuola 2004). While it is important to not generalise, it can be seen from what I saw and what was shared with me that dress is an important aspect of identity. Through its adherence, manipulation, or rejection it clearly gives a visible image of how a Somali woman identifies herself, and how she will be identified by those looking at her. Moving forward the following section moves past visible symbols that can move between social spaces, to analyse the role of the house as a geographically bounded visible symbol of Somali identity.

\section{Staying Somali: The House}

I was struck as I visited the Somali women by similarities in their home interiors. After losing their households in Somalia, where interiors "once constituted and supported their family structure, status, social relations, culture, traditions, religion, and sense of self - or, in one word, their identity" (Hadjiyanni 2007: 13), it could be seen that interiors of Somali homes in Wellington have become mirrors for what they have lost. While in each of these cases the women were living in government housing where there was little room for redecorating or structural changes ${ }^{58}$, the women utilised their agency to change the interior surfaces within the restrictions they faced. The government house has become a blank space that they have used as a canvas to recreate the home that they lost in their resettlement. The house for these women remains the primary site of social and cultural practices, underlining how the choices they make in decorating their

\footnotetext{
58 Somali homes are architecturally different to those in New Zealand. The layout of the house reflects the traditional roles of men and women, with design accounting for the separation of genders. This is not done in New Zealand homes and at times creates issues for Somali families.
} 
homes personify the interaction between human behaviour and the built environment (Hadjiyanni 2007). Social belonging for Somali women can be seen as intrinsically linked to the house through its interior, instead of locale. The decisions they make in decoration and use of space reflect cultural understandings and traditions. By making over the house to reflect a Somali sense of self, the women actively create the house over as a site of resistance against the normalized New Zealand interior aesthetic (Hadjiyanni 2007).

After my time spent in Hargeisa ${ }^{59}$, walking into my participant's homes was like being taken back to Somalia. In each house I was welcomed by the distinct smell of unsi, a traditional incense made of sugar, perfume and spices that is used to freshen the house, and also to let visitors know that Somali people lived there (Hadjiyanni 2007). At the time while visiting my Somali participant's homes in New Zealand I noted that the curtains were layered in different thicknesses in different rooms to create spaces of varying light. While some rooms appeared to be very dark, the lounge in the three homes I visited remained relatively well lit. What this reflected was a Somali aesthetic where dark and shady rooms were preferred, "[We like] large windows with heavy curtains. We like the room dark. It is a custom to have curtains" (Hadjiyanni 2007:19). In contrast to the desire for a darker lighting aesthetic, the furniture and floor coverings were bright, in velvety fabrics and ornately patterned. In most of the homes the women had brought furniture over from Somalia that reflected these taste preferences. Walking into these homes was like being transported back to Somalia, representing the active choices by these women to create an authentic home away from home in their interior spaces.

She still has a lot of Somali culture, like a lot of traditional stuff like the house decorations and stuff. Every year she goes back and we clean out the house, like yes! We got rid of all the stuff! And then she comes back with a full suitcase... we're

\footnotetext{
${ }^{59}$ During my time in Hargeisa I visited a variety of households (both traditional and more modern dwellings). This provided me with a template that I was able to use to gauge the sense of Somaliness found in each of the houses that I visited here in New Zealand.
} 
like again?! This stuff keeps coming back, so it's a way to maintain the Somali side for her, through having these weird old house decorations. To me, I think they look like really weird, I'm like why would you keep this thing?? And she's like 'oh but this is like what most Somali women make inside their house', so this is what some of them do- maybe to us it doesn't make much sense, but to my mum it means something to her... -Hibo

Identity in this case is being presented through the decorating of the house. While individuality plays a role in how a person will decorate their home, in the case of Somali women a collective sense of identity could be seen in their lack of individualization, and variability around how their homes are decorated and arranged (Hadjiyanni 2007). The women here present their sense of Somaliness through the home, and while it cannot be generalised to an entire population, this pattern has also been found in resettled Somali communities in other locations (see Hadjiyanni 2007; Hopkins 2010). Alongside the larger furniture and adornments, there were also smaller more intimate decorative touches in each home, such as hand-made fake flower baskets and religious adornments. Hibo also commented on her mother's collection of traditional wooden spoons in their home, with each of these touches representing another way that the women are maintaining a connection with their homeland. It also acts to provide a clear identifier to anyone entering their home that they are Somali. For these women who are active in the Somali community, the home becomes a signifier to others that visit about their attachment to their culture. In a group where impromptu visits are the norm, keeping up a sense of Somaliness in the home aids in creating a welcoming and clearly familiar space for others in the community (Hadjiyanni 2007).

Like a wooden spoon! We are like how can a wooden spoon have something to do with someone! I think they had something to do with them being bought up this way, it kind of connects them to that part of their life even though living in New Zealand you can buy a less horrible spoon for like less than 10 bux but they still 
have the wooden spoon. I mean who would want a wooden spoon, and another one, oh god the curtain... I hate those curtains they are the only things that makes us stand out from everyone in the neighbourhood. They love their curtains. I think that's the only couple of things in my house, apart from furniture... Oh yeah she actually bought furniture, why would you want to spend all this money buying furniture, its just about how Somalis think they have to have the best one. Who cares, I don't actually care whether I sleep on the floor or not as long as I have a bed to sleep on, but to them it's a big deal. With that I think it's a big deal for a lot of the elderly, for them, for their house to be the more fancy one. -Hibo ${ }^{60}$

Through looking at how the women I spoke with articulated ideas of Somaliness in relation to dress and the home interior, we can see how they negotiate their 'Somali woman' identity through the resettlement process. What became clear is that these two areas are key for how the women perform a Somali identity. They provide the visible, audible and communal ways to embody the 'Somali woman' sense of self, to embrace or reject being part of the Somali community in Wellington. Resettlement creates a continual negotiation around what the words 'Somali' and 'woman' mean in the New Zealand context, with a generational difference appearing to play a role in a Somali woman either using these areas to hold on to a sense of Somaliness, or trying to walk between both worlds. By observing the changes in dress and home interiors, we can see how their identities are navigated in an existence between the parameters of Somalia, New Zealand society and the local Somali community.

\footnotetext{
${ }^{60}$ Hibo's comments also remind us that recreating a Somali interior is not always wanted. For Hibo, her mother's desire to uphold a Somali interior for their home in Seatoun was almost a point of embarrassment. Instead of creating the sense of community and identity that it could be seen to produce for her mother, this interior transformation created a marked point of difference between her home and others in the neighbourhood. Growing up in a neighbourhood dominated by the New Zealand housing aesthetic has changed her sense of taste, leading to a rejection of Somali interior aesthetics (Bourdieu 1984). The home then as a form of identity is a contested site, based on how a Somali woman wants to embody and enact both a sense of Somaliness, and a sense of Kiwiness.
} 


\section{Conclusion}

The very act of living abroad frequently enables people to think about their identity and their history in new ways" (Cassanelli 2001: 272)

Through forced resettlement in New Zealand, Somali women have had to rethink what it means to be a Somali woman. Belonging in New Zealand rests on their ability to be able to preserve and reproduce Somali culture, as seen through their choice of dress and actively redecorating their home interiors in traditional Somali styles. Navigating these areas through the narratives in this chapter has resulted in the realisation that they exist within webs of conflicting influences. They need to juggle the pressures of living in the Wellington community with the pressures of the Somali community (both in New Zealand and afar) to perform an accepted identity. But what has come through clearly in the words of the women I spoke with is that rather than striving to alter their identities and sense of self to adjust to New Zealand society's norms and expectations, they instead focus on reinforcing and confirming their sense of Somaliness. As Jamilah has commented, “'It depends how you want to socialise with New Zealanders but we don't like, as Somalis, I don't have to adapt to Kiwi culture. We can just communicate in a way that we can bridge what we wanted to know".

As Sally commented, "My impression of Somali women is that they are resilient. They are here now, they strike me as a people that make the best of where they are and make sure that their next generation coming through can have the advantages of the lifestyle or safety". The way that they have approached belonging through maintaining a strong sense of Somaliness in the face of increasing pressures to adapt, to me, reflects what Sally is saying. The push from the community and older generations to perform a Somali identity is a sign of their strength and desire for the younger generation to make the most of the opportunities here, but to not forget where their roots have come from. With the changing attitudes of the younger generations, and edgewalkers like Hibo, what we are witnessing is their active choices to shift and change what Somaliness is. Whilst it might come up against barriers at this moment in time, only the future 
will tell exactly what a 'Somali woman' will be, and how they belong in their resettled countries. 


\section{Hindering a Sense of Place: Perceptions and 'Tolerance'}

Belonging so far has been analysed from the standpoint of the Somali women I spoke with. However, analysing belonging for these women in Wellington relies not only on how they construct home and identity, but also on how those constructions are perceived in the society around them. Following that line of thought, the narratives in this chapter need to be read in two specific ways. The first part follows on from the last two chapters, it centres on the experiences of Hibo. Through her narrative, I argue that the stereotypes she faces do not become self-fulfilling prophecies. Instead her stories represent moments of agency and power, where she is actively working to change the perceptions held by those around her. In the second part, I move away from a Somali woman standpoint. Instead I draw on the experiences of my participants who have worked with the Somali community. I argue through these narratives that a strong discourse of tolerance can be felt around the acceptance of Somali women in Wellington communities. Through analysing moments of misinterpretation and misrepresentation in the lives of the Somali women I spoke with, and the individuals that have worked with them, I claim that belonging is hindered - not created in New Zealand.

\section{Part One - Hibo's Story: Perceptions and Stereotypes in a Wellington School}

I think people do accept us, but in saying that I remember times that make me question if we really are. I remember when I first started high school going into my history class and the lady who was my history teacher at that time was the dean of all of us year 9s. She needed to sign some papers for me and was like, "are you a Somali?" as she read the documents, obviously I was like "yes", well, her reaction was to say "you're not one who is like the other girls!" which caused me to ask her what she meant, she then went on to say that I hadn't skipped any time off or been 
caught fighting. This was difficult because I knew that girls in Somali families often had time off to help out their family as they would back in Somalia, but there was also a lot of Somalis who were there that had been fighting each other at school, there had been all this tribal sort of stuff going on around the school. So the teachers had decided that all the Somali girls were all as bad as each other, nevertheless they needed to know who I was before they judged me like that. I can also remember another time having to justify that I was actually Somali because the teachers could not believe that I was, I had to keep saying no I am a Somali. They thought that I had to be Malaysian because a Malaysian friend was staying with our family at the time and all the teachers just assumed we were all Malaysian because I did not fit the stereotype of a Somali girl that they were use to. They kept saying "you guys are not Somali", I had to keep saying no we are Somali! So I had to kind of convince them of my Somaliness because I was nothing like the image of Somalis that they had in their mind, I was nothing like the Somali girls fighting over school canteens and stuff, so I think that stereotype was always around especially at a lot of the schools where a lot of Somali kids go. Yet I don't necessarily feel that it is New Zealand's fault that they have these images of Somali girls, I don't even think it's the teenager's fault. Its just like the way that if one group of people behave one way, then the groups after them also behave that way, then the ones who follow after will also be labelled in the same way and this is what I think has happened at that school when it comes to Somali girls. I remember my dean telling me once about how all the teachers in the staff always talk about us as Somalis. They see us as the trouble makers but then when they saw my friends and I they had to change their thinking because as they said "you're nothing like them, you're nothing like the ones in year 11 and year 12," and I kind of understand why they were labelling all of us Somali girls in the same way. There was this group of girls that hung out as a group in the school who were all from the Newtown area, even as a Somali I didn't fit in to their group because I was not from their community, I was an outsider and I can't describe them properly, but that's how they were, one group that the teachers thought represented all Somali girls. It comes down to the way you present yourself in the school and this group of girls were from one part of the Somali culture, not all Somali's are the same even though we are all Somali. But because they were before me and I was following on from 
them, the teachers and students thought 'oh here comes a Somali girl, she will just follow in the same footsteps as the other ones'; except you actually don't want too, like you are completely different from them... - Hibo

Hibo's story presents the complex creation of labels and stereotypes in her school around what a 'Somali girl' is. As discussed by Keith Brown and Dimitrios Theodossopoulos (2004) stereotype analysis can be broken down into two categories, liberal and deconstructionist. For a liberal analysis, the stereotypes produced through the school institution become an object of alarm, underlying a latent ethnic prejudice held by the labeller (Brown \& Theodossopoulos 2004:3). But this analysis holds the actor in thrall to the stereotype, unable to see past the categories that they have created around the "other". However, as seen in Hibo's story, the perceptions the teachers hold, while strong, were changed through their interactions with her in the school structures. For deconstructionists, as seen in the work of Edward Said (1978) on Western views of the Orient, stereotypes are formed in relation to power. They come to be reinforced in the production of knowledge about the "other" 61 , as can be seen in the refusal of Hibo's Somaliness when it does not match the image held by her teacher, even though the teacher is not Somali herself. This provides the recognition that "their sources and discourses constitute a self-contained and self-serving domain of fiction masquerading as truth" (Brown \& Theodossopoulos 2004:4). The stereotype of a 'Somali girl' in Hibo's school resides not in the wider world, but instead exists only within the eye of the beholder, her teacher(s).

Hibo's experiences can be more effectively understood when analysed in a third way, through what Brown and Theodossopoulos (2004:4) term an "interpretive" approach to stereotypes. It draws heavily on the work of Clifford Geertz (1973) and as can be seen by Hibo's own inquiry of the stereotypes that she has faced, its analysis focuses on the "play of different orders of interpretation of social life"

\footnotetext{
61 Also, refer to the work of James Faubion (1993) and Michael Herzfeld (1987) for further critical analyses of how power relations reinforce the production of knowledge about "otherness".
} 
(Brown \& Theodossopoulos 2004:4). For Hibo, the stereotypes that she dances between in her school years have illuminated the different ways that individuals read a situation, it demonstrates the different social models that people live within in the social order (Brown \& Theodossopoulos 2004:4). For her teachers, the image they have constructed in their minds of Somali girls comes from previous experiences that reinforced negative stereotypes of aggression, tardiness and 'wagging'62. There is a tension here that Hibo recognizes; on the one hand, she understands how teachers have come to form this negative stereotype. On the other, Hibo knows from her own experiences and knowledge of Somali cultural norms, why Somali girls are more likely to not come to school, or be involved in school-yard conflicts.

It is important to look at what the stereotypes expressed in Hibo's story create in context (Geertz 1973:5). For example, the label of 'Somali girl' gains importance in two ways, but only when analysed within the context of the school setting. Firstly, it represents a stereotype held by certain teachers, which when expressed negatively (as heard by Hibo on more that one occasion) can aid in maintaining prejudice (Herzfeld 1992). It does this by acting as a modelling device with enormous potential for harm when coming to think about Somali girls (Herzfeld 1992:73). It places any Somali girl automatically into a category that defines who they are, based on a supposed 'truth' formed from the teachers shared knowledge and experience of prior contact with them (Herzfeld 1992:70). Secondly, through this process the label of 'Somali girl' becomes essentialising (a term that will be expanded further later in this chapter) ${ }^{63}$, as encountered by Hibo when she forcefully defended her identity as Somali in the school environment. Being a 'Somali girl' becomes dependent on its recognition by her teachers and fellow students in the social map of the school. Since her behaviours fall outside those that are seen as familiar for Somali girls, or that define the self/other, us/them boundary between female Somali students and teachers, her identity as Somali is challenged (McDonald 1993: 228).

\footnotetext{
62 Colloquial term used by students when talking about missing classes on purpose

63 This can also be seen in stereotypes of Muslim women that create a perception of a homogenized identity (refer to Hasan 1996).
} 
In this situation stereotypes act as more than just words, they symbolise knowledge that creates the true or false boundaries of what a 'Somali girl' is (McHoul \& Grace 1993). For example, school becomes a place of 'discipline' as theorised by Michel Foucault (1977). It is an institution of social control, where teachers act as agents of normalisation through the establishment of stereotypes like the 'Somali girl' (Foucault 1977). In the school context, Hibo can be seen to be caught in webs of power that act to define who she is; "in the case of those normalising judgements which determine an individual's level of 'deviancy ${ }^{64}$ ' one person has the capacity to judge someone else on the basis of knowledge that only the former possesses" (McHoul \& Grace 1993). In this way, the stereotyped image becomes normalised, creating an influential and predominate way to think about Somali girls in the school context or a hegemonic form of (mis)representation (Said 1978). ${ }^{65}$

\section{(Mis)Representation}

" Realising that social actions are comments on more than themselves; that where an interpretation comes from does not determine where it can be impelled to go. Small facts speak to large issues, winks to epistemology or sheep raids to revolution, because they are made to" (Geertz 1973: 23)

Hibo's experiences at school can be interpreted as a system of construable signs that speak loudly about the wider social systems that schools exist within (Geertz 1973:14). By reading the actions of Hibo and her teachers within a wider context, Geertz's (1973) idea of small facts speaking to large issues can be realised. Hibo's experiences with stereotypes express the reality that "what is

\footnotetext{
${ }^{64}$ Deviancy in the case of Hibo is not meaning negative behaviour; instead it is her deviancy away from the stereotype of the Somali girl that the teachers have created. This also relates to the idea that what a discourse does, whom it acts upon, how it is distributed and the forms of resistance it meets (if any) are all open to transformation (Foucault 1977)- Hibo is the catalyst for transformation around the discourse of 'Somali girls' as she provides a new way to think about them.

65 See work by Stephanie Dobson $(2012,2013)$ for work of a similar nature on stereotypes and perceptions of Muslims.
} 
commonly circulated is not 'truth' but representations" (Said 1978:45). By drawing on the analytical distinction between civil and political society 66 (Gramsci et al 1971), it is possible to see that these representations do not form in a vacuum. Instead the teacher's representations are created around what they personally experience and what they are exposed to in wider society. Through the use of tools like the media, political society spread their image of who a Somali is into wider society. Talking with a previous immigration officer, friends and family, the dominant discourse around Somalis appears to be mainly negative. They are one of the least wanted groups by New Zealand immigration and are seen as aggressive and continual liars ${ }^{67}$. This creates a discourse ${ }^{68}$ in society that dominates thinking about Somalis. In the same way that teachers exerted hegemony over the 'Somali girl' image, political society creates a hegemonic construction of the 'Somali' image in everyday society (Said 1978).

Moving into part two, the narratives shared express the thoughts of individuals who have worked with the Somali community. By analysing their stories, we gain another perspective on the how perceptions and stereotypes are produced. I

\footnotetext{
66 Civil society represents citizens voluntarily affiliating themselves with certain social responsibilities (Edward Said (1978:31). Said (1978) terms voluntary as rational and noncoercive when talking about Gramsci's distinctions and I feel that is a useful way to understand the term in this context. In Said's (1978) thinking, affiliations represent institutions like schools, families and unions, while Political is state institutions like the army, police or central bureaucracy.

67 They were deemed as liars because of on-going issues with false or inaccurate information being provided during immigration processes. The flow on effect of this discourse was apparent in conversations I have had over the years with family and friends representing its expression in civil society. More than once I have heard negative stereotypes being espoused about Somalis in Newtown and Wellington, and even at times by those who have not lived in areas where Somalis are found (such as Nelson). In these conversation's Somalis were discussed in relation to their positions in New Zealand as a whole and how their actions and behaviours (such as dress) did not fit into the New Zealand ways of being.

68 In this way, we can also see Foucault's (1977) idea of systems of power, rather than the general idea of power itself. By looking at the structures in political and civil society that all work to reproduce representations of Somalis, we are looking at the ways that power is exercised throughout the different layers. It is also important to note, as Foucault (1977: 194) discusses, that power does not have to only be viewed in negative terms. While in this case it is being analyzed as a system of repression, as Hibo showed in her experience of school, power also produces. It produced a moment of agency for Hibo where she could not only solidify her identity as Somali but it also provided a moment of possible transformation as she changed the boundaries of what being a female Somali student was.
} 
argue in this section that the consequences of misinterpreting Somali women, such as essentialising them into one homogenous group, leads to a hindering of their ability to belong. Lastly, I explore the subtle influence of the discourse of tolerance. I claim that while Somali women may exercise agency to push against barriers in their lives, such as Hibo's school experiences, that agency remains shaped by the wider institutions of power that surround them in Wellington communities.

\section{Part Two - (Mis)interpretation}

"Some people might find that it's not the typical New Zealand way. We are so reserved, we hold back and don't express our opinions so much; so I think there is a difference between our cultures that possibly makes it harder for them to fit in" Rachel

The process of fitting in that Rachel ${ }^{69}$ mentions, offers a way of exposing how images viewed in daily experiences provide the visible markers of boundaries of either belonging or not (McDonald 1993). By not 'fitting in', an observable marker of difference and thus of judgement is created (McDonald 1993:232). In the case of Somalis, as Rachel discusses, it is not just clothing that creates a visible marker of difference, "they are also very expressive and vocal, they can be really loud and for some people that might seem to not be the typical New Zealand way". This expressiveness becomes an expression of an ill fit into a New Zealand cultural system where being reserved is a recognised form of acceptable behaviour (Chapman 1982). By not observably enacting acceptable behaviours, Somalis place themselves on the outside of these cultural categories, emphasising their otherness in the eyes of the majority. Through this the ways that individuals define themselves can be seen to rely on the recognition of either fitting, or not fitting in, where "the more powerful centres of self-

\footnotetext{
69 Rachel is the lawyer who has worked with the Somali community for over 20 years.
} 
definition...generate the more powerful and persuasive images of order for themselves, locating disorder on their margins"70 (McDonald 1993: 225).

This is problematic when the boundaries of acceptable and unacceptable behaviour clash; as will be seen later in this chapter in a story shared with me by $Z^{7} e^{71}$, about a young Somali woman's experience of negotiating her cultural beliefs in a situation where they conflicted with those around her. In this instance the judgements of the Somali woman's behaviour led to a moment that elucidates how a lack of fit between categories of knowing can easily give rise to misinterpretation $^{72}$ (McDonald 1993:222). It is a story where relationships of power are at play. The dominant groups voice frames the Somali woman's behaviour as negative, drawing on their power to enforce her behaviour as wrong (Said 1978). It is important to also acknowledge that the 'truth' of this moment, and what it represents, shifts and changes depending on who is interpreting the interactions. It signifies a complex interplay of relationships of power and domination where varying degrees of complex hegemony can only be acknowledged in light of New Zealand's complicated and contentious past, with its colonial roots and uncomfortable indigenous recognition ${ }^{73}$ (Said 1978).

\footnotetext{
70 Important to note that Somalis who come to New Zealand will also have their own culture categories and in conversations with the women there was a clear recognition of the process discussed above, but in reverse. The women instead judge New Zealand behaviour through their eyes and saw the private and reserved behaviour as a negative, representing the closed and noncommunal ways of New Zealand society. This highlights how Malcolm Chapman's (1982:133) point is still relevant where "most of the events, however, within which such judgments might be formed, are the product of events occurring in a multi-dimensional social space, with many different orders and systems of category intervening".

71 Zoe is the woman who worked as a social/cultural worker with the Somali community for over two years

72 By not understanding Somali (and in this case also Muslim) ideas around acceptable contact between an unmarried woman and men the groups involved in the story were unable to understand her behaviour from her perspective. Instead, they misinterpreted it through judging her behaviour through their ideas of what contact was acceptable.

73 New Zealand's history stems from a complex series of roots linked to the experiences of indigenous Maori, colonial settlers and 'alien' immigrants. The impact of colonialism on incoming migrants, including refugees, cannot be downplayed due to its integral role in the understanding of New Zealand's 'national culture' and the politics around this. In New Zealand, historical power relations can be seen to have been manipulated by national governments to construct an idea of a purely New Zealand, or 'Kiwi' culture (Arneil \& Macdonald 2010). This is important because a national culture can be viewed as a construction of cultural power. Signifying more than merely a point of allegiance, attachment or representative identification, it can shape how incoming migrants, including Somali women, will be recognised, received and accepted by the wider New
} 
She went to her university and they had a welcoming powhiri where you have to do a hongi and this was a real problem for her because traditionally, you know, not all Somali's but some, especially with the women, its very sensitive about touching men. So in her view from her family viewpoint and the way she was raised, if she had any kind of physical contact with a strange male that would make her unmarriageable. So everyone is waiting in line and getting ready to do this hongi and she had to sit aside and she really had a problem with her school not understanding - they said she was not being culturally sensitive towards the Maori and it was really a shame, I mean we had to do some work with that because you know there's some compromises that you can't make, like you can't sacrifice your marriageability to go through a line, and I think the Maori community would understand that if they were, if it were explained. So I think there are just a lot of misunderstandings and judgements made where its, its a lot more complicated than I think people think - Zoe

The misrepresentation of Somali's comes down to a lack of recognition of different ways of being. To belong Somalis as a whole need to 'fit in', but not fitting in represents what has been seen through Hibo's school experiences, the power of dominant discourses in society to shape ideas about who a Somali is (McDonald 1993). By looking at how Somali behaviour is observed and how Somalis in turn observe others, you are able to see how cultural practices when viewed through unfamiliar lenses can promote imagery of "volatile, unpredictable, irrational, inconsistent, capricious, or even dangerous 'others'” (McDonald 1993:229). It becomes another tool for those in society to define

Zealand society (Arneil \& Macdonald 2010). Our colonial history not only plays a powerful role in the formation of policy and government tactics, but also filters down into the everyday experiences and lives of individuals and community groups. Settler colonialism has been resolute in acting to normalise the settler subject as the most significant agent of history; but postcolonial interpretations of New Zealand's past can destabilise and deconstruct this view (Byrnes 2009), highlighting how the indigenous population and those pushed to the periphery of our history have been active agents in its construction (Smith 2011). This leads to an understanding that colonization is more than a relic of our past, instead it needs to be acknowledged as an on-going, continuing process, with consequences not only reaching into today, but also towards the future (Byrnes 2009). 
themselves from those around them, it reinforces the dichotomy of 'us' and 'them' and creates an essentialised category of 'Somali' based on the dominant discourse of what they are 'really' like as a group (McDonald 1993:231).

\section{Essentialization}

"Once you dig below the surface there is as many different possibilities as there are people" - Sally

What this essentialising creates is a construction of the Somali community as a collective whole, who speak with one voice and represent one homogenous identity ${ }^{74}$. However, this can mask internal differences and power struggles within the minority collectivity and their respective communities (Yuval-Davis 2011). In the same way that feminists have come to problematize the word 'woman' for hiding intersectional difference, like class and ethnicity, grouping Somalis together under the word 'Somali' can be seen to have the same effect (Arneil \& Macdonald 2010). Dominant discourses and cultural stereotypes in society then promote the Somali community as an essentially bounded ethnic unit, with unchanging essential components and minimal internal conflict (Rattansi 2011). Yet it is a common fallacy to view the Somali population as one collective whole, when the reality is a much more complex situation. For the women I spoke with, it was clear that they recognised different issues within their society as impacting how cohesive the Somali community was, as shown in the stories below.

Its nothing to do with tribes, I remember there use to be two communities in Lower Hutt and two in Wellington and the reason for that was because the previous one that was there was not doing the job it was suppose to do and they were not wanting to step back so that was maybe the issue, but I don't think its about tribes because one of the guy's that was actually leading in Wellington was a

\footnotetext{
${ }^{74}$ This has also been researched in Muslim communities, see Gibson (2011) and Hasan (1996)
} 
Somalilander, and for Somalilanders back in Somalia they don't assume that they are Somalian, but in here they do, they think that they are Somalian. I don't see anybody that had that issue with him but they did have an issue with how the community was running, because as I told you, there was no activities for kids to do during holidays, there was no Eid celebrations, there was not any language classes or cultural anything like that, so especially mothers, we were demanding to get those ones because that is the main priority for them... but yeah, I don't think its about tribes and things like that. - Jamilah

The thing with the Somali community is that each one of them has got their own politics, so they all have like, what we did back home. So they have all brought their old baggage with them and they can't be one group as is seen for example in Newtown, where it's like you're in Somali town... and I noticed it when I was working with them, there was another council who was trying to open and they were competing with us and I remember telling the lady who was manager at that time, why are you guys competing with each other? You are a small group why don't you work together? Maybe this guy has a different knowledge then what we have, why don't you just sit with him and say 'listen, you want to help us, you want to help the Somali community so do we, just come, come and join us' but no its all about I'm in charge, I've got the power, all this...I think they all got their own politics and sometimes it is all about self-interest, sorry I have to say that...I feel like they've got their own self interests where they want to say I've got the power, I'm in charge of this place, I should be running for this, or this group should be the one group. - Hibo

"You have a wound and it is hard to heal, because of the fact that a person or a persons clan killed half of yours, or your family members because you were not their tribe, their sub-clan... I am wounded and cannot forget what their clan/s have done to me, when we leave Somalia, like when I fled to Kenya this changes and we can help one another and not focus on our differences, but once we are settled and safe again, like here in New Zealand, these problems become bigger again and we become super divided again". - Miski 
When commenting on the community not all of the women acknowledged conflict; only Fadumo talked positively about her experiences and place within the community. This could reflect a desire to not share Somali problems with someone who is not from the community, preferring to present a united front to those looking in from the outside, but it could also reflect the impact of individual differences on how Somali women fit within their community. It is not just the recognition that wider society cannot view communities themselves as cohesive wholes, but also that individual members will have different views on the community and their place in it, based on their own identities and sense of self. As the stories above show, each of these women hold different ideas about how the Somali community works as a group and their place within it. Each of these woman need to be looked at intersectionally to understand how they come to conceptualise their experiences of the community, and their place in wider society, because aspects like gender, class, religious adherence and ethnic identity all intersect in different ways to create their individual experiences and understandings ${ }^{75}$.

\section{(Mis) interpretation: Consequences for Community Support}

"In general, well working here I'm in a little bit in a bubble. I get all these wonderful volunteers here so they kind of self select to be the right people. But no, working in the Somali community over at the Somali council I can say that it is a mixed bag - so for the most part I'd say yes, sometimes you come across people in different agencies and organisations where they work with Somalis and find it a bit difficult and I think a lot of that is due to misunderstanding of the culture...it has them forming all sorts of judgements where I think they just really don't understand how complicated it is" - Zoe

Essentialising the Somali community through using the term Somali as a collective noun that converts them as a subject of experience, into objects of

\footnotetext{
75 This has also been discussed in relation to Muslim women; refer to Hasan and Menon (2005). Both Muslim and Somali groups have shared interests as distinct groups (see Mohanty 1988), but the individual differences of the members need to be acknowledged.
} 
knowledge, has consequences past how they are perceived in society. It affects their support from organisations and institutions in the community around them (Jackson 2002). Through not understanding divisions in the Somali society, organisations and institutions set themselves up to misinterpret, and misunderstand, the communities behaviours and positions of their members. Zoe who worked as a social/cultural community worker, explained how the conflict found in the Somali community is not unique to Wellington or New Zealand, “it is typical of Somali communities who've resettled in all parts of the world, I've seen it happen in London, Sweden and looking on the internet you can see it in places like Minnesota and Seattle as well." By not recognising the existence of two distinct tribes, 76 the problems they can create are misunderstood, "they have these two tribes and it gets carried over everywhere and the problem again is that a western kind of New Zealand, Wellington, community doesn't understand that"(Zoe). By not fitting the homogenous image of a collective community that New Zealand uses to construct the boundaries of what a community is, the social category of Somali comes to be problematized and misunderstood.

It is again a moment of recognising that the boundaries of what a 'community' is, acts as a social category that is formed by the dominant, or powerful group in society (Crenshaw 1991). To gain support Somalis need to be able to show that they can work as a community in a way that is acceptable in New Zealand society. Zoe illustrates this in her discussion of the difficulties faced by groups like the Wellington City Council when trying to provide funding: "so there were these two different groups when I was working there, I don't know what's happened since but there was the Wellington Somali Council and the Wellington Somali Community which both had the same initials which made it really confusing! But both claimed to represent the whole Somali community when really they didn't, it was very tribal based and so we'd sit down with the Wellington City Council and be like look we are giving grants to both you guys

\footnotetext{
${ }^{76}$ In reality, it is more than two, but the biggest splits that can be seen and cause tension are the Somaliland/Somalia divide or the North and South divide. For more information refer to Fox (2007), Ahmed (2010) and Elmi et al. (2010)
} 
which one is it and each group would say its me, its me and it was really confusing for the western society to understand that actually its not a Somali community all as one, they're separate tribes and that's part of the reason why they're here and why they now need this support and help". In this way Somalis face the consequences of two separate, but closely linked, forms of power: firstly, the ability to be categorised in the first place, and secondly the fact that being in or out of those categories, can have social and material consequences as seen in the issues around funding and community support (Crenshaw 1991).

It was really disorganised a lot of things happened that we here would consider unprofessional, there was a lot of political things happening too so the Somali cross cultural worker, the male one who was from the other side, ${ }^{77}$ he would receive threats, people would physically threaten him saying 'you shouldn't be working for them'. There were times when people on the board would get a letter in Somali and go up to the western kind of organisations working with refugees going 'look what they've wrote it says this and this and this' but it isn't actually what it says - so there was some unprofessional kinds of behaviour going on that really reduced the credibility of both groups. That kind of stuff showed how really hard it was to try to say 'look in here this is how it works, this how a board works' and all of those things, so yeah just the lack of knowledge of how it works in a western kind of context was hard. And you know it was very political in their organisations, they would call the chair person of the board president, they'd say you're the president now we've elected you and it was almost treated as if this was a political campaign and they were really able to make all these you know very powerful decisions. But of course they were very poor so yea I guess... how do you say it...there was just unmanaged expectations of people on the board. - Zoe

\footnotetext{
77 The cross cultural worker was seen as being from a different tribe to the majority of Somalis that he worked with - I feel this particularly highlights the splits within the community, where even when they are trying to help one another the tribal aspect still plays a big role in how willing they are to accept help.
} 
While it is easy to see how the Somali community could be negatively impacted by their categorisation by New Zealand society, the reality as seen in Zoe's experiences is that the past conflicts and the on-going problems in Somalia also impact how well they adjust in New Zealand. There needs to be a balance between New Zealand recognising the role of history, and personal trauma, in the actions and cohesion of the Somali community, and the community itself acknowledging its impact on their ability to function within New Zealand society. Forward movement in this situation means moving past thinking that the 'New Zealand' way is the only way to work with members of community to find ways that satisfy all that are involved. In the same way that members of the Somali community could have unmanaged expectations of people who were on the board, New Zealand can be seen to have unmanaged expectations of how easily Somali's will adjust and 'fit in'. While their actions may be tolerated, for the women I spoke with, this had not created an easy position of acceptance in the community around them.

\section{'Tolerance'}

"But that's not the New Zealand way" - Rachel

“We are very lucky in New Zealand because while we are not as welcoming as we could be we are certainly not as restrictive or as unwelcoming as I think some countries are, but yeah, inevitably its going to have an effect on the people that come here" - Sally

"We have got to be very eclectic and very open to have so many people here and understand them. It relates to one of my hobbyhorses where I hate the term culturally tolerant, because if you're tolerating something it means you're putting up with something you don't really like." - Max

Talking with Sally inadvertently highlighted what Ghassan Hage (1998: 79) terms a discourse of tolerance that underlies how New Zealanders think about 
their acceptance of immigrants. Tolerance in this instance implies two important points. Firstly, it implies an inherent separation between those who are doing the tolerating and those who are being tolerated, with the separation creating a platform to clarify the unequal power relations between the tolerators and tolerated in society (Berns-McGown 1999). Second, as Max mentions above, by using a discourse of tolerance you create a stance of "putting-up-with-something, a holding-one's-nose-and-taking-no-contrary-actions" (Berns-McGown 1999). Through a discourse of tolerance, instability is created because tolerance inherently co-exists with intolerance (Hage 1998:81). In this way, if a person is able to tolerate another, they fundamentally hold the ability to withdraw that tolerance when that 'other' crosses a line, or acts in a way that does not fit in-line with their idea of acceptable behaviours (Berns-McGown 1999).

I think we're tolerant, I mean it is generalising but I think we're tolerant but we don't go out of our way to invite people into our lives and that works both ways. Yet I think apart from the obvious or key groups in New Zealand that sponsor refugees like the church groups or the English language partners, people who work with them one on one which is fantastic but in fact I think generally as a country while we're not hopefully racist or prejudiced, I do think that while we're tolerant and not unwelcoming, I don't think we go the extra mile that we could to make the new migrants, new arrivals and former refugees (because once they arrive here they're not refugees anymore) but refugee background women and men obviously it would be nice if as a society we did more. You know we're better than some countries and not as good as others, but I guess we kind of...my impressions are that we are kind of in the middle really. My view is probably a bit distorted because I work in an area where people are sympathetic and you know we do our best to try but just from my interaction with other people in my own community, people aren't outwardly racist or anything like that but they don't...but I know there are probably pockets of New Zealand that won't welcome them but you know we kind of get a little bit protected in places like this where we hang out with people that think like us. I am very aware that there are pockets of people out there that will not be accepting but I think generally New Zealanders are a more tolerant society 
than others I can think of like Australia...We have got to kind of not defend New Zealanders but when faced with something so unusual, just from my own reaction you know, when you see something that is that different it almost like this alien species and I support their right to wear whatever they choose to wear, I think that's really, really important but on the other hand they need to be aware of the impact that that has on the observers, which they kind of get in the education sort of process and if they are in full of possession of all the facts and they still choose to do that then that's absolutely fine, that's their choice but it's a two way thing - Sally

Sally, who worked for Mclass, expresses the double-edged reality of a discourse of tolerance in New Zealand. She does claim that New Zealanders do not go as far as they could to welcome other people into the country; yet, she places the onus of acceptable behaviour back on to individuals, like Somali women. For example, she argues that dressing differently is their right, but in the next moment, she contradicts this point by highlighting how it can be confronting for New Zealanders because it is an unrecognisable form of dress. This expresses how tolerance still relies on Somali women needing to be 'in full possession of all the facts', about what is acceptable or unacceptable in New Zealand. The statement, 'that's their choice but it's a two way thing' emphasises this point. It illuminates the relationship between New Zealand as a 'host society' and Somalis as a 'minority community', confirming how power is embedded in the position of the 'host society' to tolerate the differences of the 'minority community' (BernsMcGown 1999). In a sense, Somali women can only dress how they desire in New Zealand because of the tolerance of New Zealanders. ${ }^{78}$

\footnotetext{
${ }^{78}$ Forms of tolerance are also linked to social group differences - in the same way that intersectional differences are apparent between the Somali woman and impact how they view and interact with their community, intersectional differences like class and ethnicity also play a role in forms of tolerance. As Douglas Grbic (2010:125) discusses "positive or negative attitudes toward immigration, therefore, have different meanings depending on broader social and cultural divisions in society." Having liberal or xenophobic attitudes towards Somalis or other immigrant groups in New Zealand then relies on different understandings that form between the broader social and cultural divisions in society (Grbic 2010:126). For example, Maori and Pakeha members of society both hold strong reservations about increased immigration but for separate reasons (Refer to work by Fleras \& Spoonley 1999).
} 
Sally also stressed more than once that New Zealand was not as bad as other countries when it came to tolerating and accepting immigrants into the country. She uses tolerance to mask the problems that New Zealand does have with immigrants and refugees, through emphasising that those problems could be worse. Advocating for tolerance in this manner represents the way that dominant groups can work to "mystify the element of coercion, and to present tolerance as if it were a mere benevolent choice on their part" (Hage 1998:101). Comparing to another country encourages the continuation of tolerance in New Zealand, because it maintains the current structures of power that keep the dominant groups tolerating and the minorities tolerated (Hage 1998:99). Reflecting this, tolerance as a concept was only emphasised by non-Somali participants. While Somali women faced challenges that exposed the consequences of a tolerant discourse, such as discrimination around dress and their religious ideals, they did not specifically relate it to tolerance ${ }^{79}$. A focus on tolerance then reflects the fact, that those who talk about it the most, are the ones who are in the position to feel entitled to tolerate (Hage 1998:87).

Absolutely there are still too many people who pass judgement on people when you don't even have to. Some people are very overt and say terrible things like 'go back to your own country' and things like that, some people convey it with a look and some people do it inadvertently by avoiding contact and the person on the receiving end can discern when someone is going out of their way not to see them or talk to them. Lots of people do that to be fair from embarrassment, they don't know what to say to someone who is different from them - so that again comes back to the more we know people the less we might need to cause problems ourselves, you know - Max

\footnotetext{
${ }^{79}$ The women all felt that they were tolerated/accepted in New Zealand. However, I feel that in some cases they did not feel comfortable enough with me to express how they truly felt about their place in New Zealand because I represented the dominant society. In other cases, like Jamilah, the tone of their voices and body language contradicted what they were saying as well.
} 
While overtly discriminatory acts, like telling people to 'go home', represent obviously intolerant forms of behaviour, avoidant actions and awkward looks are acknowledged as tolerant. However, these practices of tolerance are still forms of symbolic violence, hiding acts of discrimination under a veneer of egalitarianism and acceptance (Hage 1998:87). As Max argues, those who face this symbolic violence are aware that they are being treated differently. This is reinforced in Hibo's experience of applying for a job at the New Zealand Defence Centre $^{80}$, "I started talking to a guy next to me who was Chinese and started asking if we had gone through more scanners than the others had gone through, and he was like 'I think we did', and then one of the guys who was an accounting student who had also applied (and was from New Zealand) who was also sitting with us said, 'I think you guys go through more, you took longer than we did' and I kind of made light of it joking that we are not going to blow up anything and then I saw the security guys face change and I was like oh no, I'm not going to get the job. But yeah its different when you go through that kind of situation...It does have impact on you when you go to a job interview and stuff, people look at you when your head is covered and they will ask you questions and you don't feel like you fit the job description". Hibo's lived experience represents a process of symbolic violence, where she is caught in structures of power. She recognises that she is not being treated equally, but is unable to change the situation because of her position as a Somali woman.

Belonging for the Somali women I spoke with, is positioned on a precarious relationship of existence, where existing is in many ways reliant on being tolerated by wider society (Hage 1998). This does not diminish the agency of Somali women, but highlights how their agency is in part shaped by the freedom they are given through a discourse of tolerance. As tolerators, the dominant New Zealand community exercises a form of power that allows them to position individuals as they feel is right, within a space that they consider to be their own (Hage 1998:90). As Rachel states at the start of this section, "but that's not the New Zealand way" and we can now see that the New Zealand way, is an imagined construct held by society that is used to create boundaries of belonging. By

80 She may have meant force, but center was the term used. 
listening carefully to what is spoken underneath narratives, like Rachel's and Sally's, that on the surface appear to be about supporting others in New Zealand communities $^{81}$, we discover that acts of exclusion can be subtle, based on a perceived act of transgression by those being tolerated, past the majorities or individuals limit of tolerance (Hage 1998:92).

\section{Conclusion}

By combining the voices of Somali women and the individuals who have worked with them, this chapter has negotiated between both the understanding and production of stereotypes. As seen through Hibo's stories, Somali women are not passive victims of stereotypes and discourses of tolerance. As they traverse multiple social spaces, they actively utilise their power and agency to challenge the boundaries placed around them, creating new understandings of who a 'Somali woman' is. Yet, they still face considerable misrepresentations and misinterpretations from individuals around them. As narratives of women like Sally showed, acts of exclusion can be subtle and often unrecognisable to those that are sharing them. In this way the power of dominant discourses, like the discourse of tolerance, has been explored. It does not diminish the agency of the Somali women I spoke with, but it does highlight how this agency is still shaped by the institutions of power in wider society. This chapter then argues that while Somali women are pushing back against the boundaries that can impede their belonging, the wider discourses of power and tolerance still work to hinder how they can achieve this.

\footnotetext{
${ }^{81}$ This is not to say that their narratives were not about support - both women have provided on-going and amazing support for the Somali community, and want to help as best they can. Instead what their narratives highlight, is the pervasiveness of discourses of power. The insidious way that they can underlie apparently innocent ideas, such as the 'New Zealand' way, to reinforce positions of power and control between the dominant and minority groups in New Zealand.
} 


\section{Conclusion: It is ok, maybe we are not the majority, we are the minority - but look into the needs of Somalis}

Content not available. Please consult the print version for access.

I began this research with the aim of understanding identity and its transformations for Somali women through resettlement processes. After taking the time to make connections to the community and listening to the experiences of the women, I realised that identity was only a small part of a larger process of creating a sense of belonging in New Zealand. What has unfolded is a thesis that prioritises the voices of Somali women. I depart from previous research that subsumes these women into other categories of being, instead analysing how being a Somali woman interacts with other aspects, like religion, to create who my participants are in society today. Situating myself in feminist and intersectional frameworks has given me the ability to side step essentialising or homogenising identity for the women I spoke with. Instead this research provides insights into the diversity of strength and resiliency of these women. Narratives emphasise the agency of these women who, in the face of adversity, strive to maintain their Somali identity or to navigate between the boundaries of Somali and Kiwi senses of self.

The biggest contradiction I faced in this research was around identity. As Somali women arrive in New Zealand, they encounter a cacophony of voices that try to label them. They are called Muslim, Refugee, African, foreigner, 'Other' - yet narratives shared with me reinforced at all times a Somali identity. Belonging in New Zealand is not based on becoming 'kiwi', instead for my participants it relies on maintaining Somali aspects of self. Faced with outside pressures to conform, they still wear traditional clothing and decorate their homes in Somali styles. Physical location, 'home' and a sense of place are intimately linked with their identity as Somali. Across space and time, memories of the 'homeland' are still integral to belonging. Being Somali in New Zealand means maintaining intimate, transnational ties to kin, family and support networks in Somalia and children 
growing up here are reminded of their Somali identity through all five senses. Their homes smell of unsi, they drink traditional spiced tea, eat laxooh, wear traditional clothes, sit on furniture that is imported from Somalia and hear their language through the sound of Somali TV being on day and night. In all of these ways, which were discussed with me in the stories they shared, Somali women reinforce who they are in New Zealand, carving out a sense of belonging that is as distinct and unique to them as they are to New Zealand.

Generational differences play a big part in the importance of Somaliness for a sense of belonging. While all the Somali women emphasised Somali aspects of self, one participant stood out through trying to navigate between Somali and kiwi identities. This reflects the constant weaving in and out of cultures that younger Somali women can experience, positioning themselves as edgewalkers in a way that older generations do not (Tupuola 2004). Somali women across generations showed resiliency, but it was particularly obvious in the narratives of younger women who balance expectations of older generations and the New Zealand society around them, traversing tense boundaries of acceptable and unacceptable behaviour in both cultural realms. Through analysing these generational differences, this thesis has demonstrated how younger Somali women use their plurality of identities to create a sense of control over how they construct their own sense of belonging. For older generations holding on to Somaliness is a way to preserve their roots. Yet as the younger generations push back against these boundaries, we can see how roots that are placed in New Zealand soil start to grow differently producing a new sense of what Somaliness is, and who Somali women are in a New Zealand context.

Nonetheless creating a sense of belonging in the New Zealand context is also impacted by the perceptions of New Zealanders. The consequences of this unfolded in two ways through the narratives in this thesis. Stories shared by non-Somalis who have worked with the community exposed the underlying and subtle consequences of dominant discourses created by those in institutions of power. Their words insinuated a discourse of tolerance, an acknowledging of a begrudging acceptance in wider society, that flows on to impact how Somali 
women are viewed in Wellington. As part of the majority, these participant's voices are valuable for pointing out the role of discourses of power to marginalise minority groups in New Zealand. Belonging for Somali women in these narratives relied on their behaviours being recognised as tolerable, demonstrating the power relations between Somali and non-Somali members of society, or the judged and judgers. Society in these accounts is inherently unstable for Somali women who apparently exist as an object to be recognised as belonging or not on the whims of wider society.

Yet, Somali women who encountered discourses that produce stereotypes of who a 'Somali woman' was, emphasised their agency and power in these situations. They spoke of moments of change, breaking down barriers in thinking about who they were and how they should behave. Listening to first-hand accounts of Somali women provides insights into the consequences of discourses of power, but instead of presenting narratives of dislocation and marginalisation these women present moments of strength, power and change. While it cannot be generalised to the entire female Somali community, there are pockets of resistance to the essentialising categories New Zealand discourses create, moments of contradiction and awareness of their own power within their communities. This does not remove the fact that dominant ideology can have negative consequences, or the fact that discourses of tolerance exist, as shown in the narratives of non-Somalis but it reminds us that these Somali women are not passive victims of discourse. They are active agents in the creation of their place in New Zealand, whether they are accepted or not.

Creating a sense of belonging was one of many significant ideas that were raised in my interviews. While it was outside the scope of this research it is important to note that both Somali women and those that worked with them discussed areas where the women could use more support, such as help with family reunification processes, support for teaching Somali culture and language to their children and the possible power of friendship for greater acceptance and understanding. This highlighted the importance of working with Somali women in research projects, as I have done here, because what the women say they want 
and what community support workers, lawyers and English language teachers discuss can vary considerably. As Jamilah said, “they have a woman's group but they were not actually targeting Somali women. They had sewing classes and stuff like that, but that was not important for Somalis. So when you are setting up organisations you need to know what their needs are". Any research that focuses on Somali women needs to include them in the process. As seen in the discussion above and in the quote by Jamilah, to actually understand their wants, needs and thoughts you need to speak with them directly.

Speaking directly with these women has created a thesis that contributes to anthropological studies about belonging. Through using an anthropological, feminist approach it has particularly added to discussions about how they belong. As New Zealand's demographic continues to grow and the make-up of communities becomes increasingly multi-cultural, anthropological studies of this nature will become increasingly important. While it can be argued whether Somali women are accepted or not, research like this creates an awareness of them in communities. It opens up a dialogue where knowledge can be shared to change the dominant discourses that exist in society. As more than one participant commented, a lack of knowledge about Somali women in their communities adds to the misconceptions and problems they can face. The more individuals learn about each other, the more informed opinions they can make.

This promotes the use of an ethics of care lens for future research on Somali women, or other minority group projects, that focuses on creating respect and care for all in the analysis (Yuval-Davis 2011: 196). Overall, I hope that readers of this thesis go away from it with a deeper understanding of Somali women, their history, place in New Zealand and their ideas and thoughts about life here. In this way I want to contribute to promoting love for one another through respecting differences to the extent that one is able to, rather than rejecting a person because they are strange or 'foreign' (Assiter 2009:102). As bell hooks (1994: 243) says, "Without love, our efforts to liberate ourselves and our world community from oppression and exploitation are doomed. As long as we refuse to address fully the place of love in struggles for liberation we will not be able to 
create a culture of conversion where there is a mass turning away from an ethic of domination".

To repeat the opening quote of this section, "you are terrifying and strange and beautiful, someone not everyone knows how to love" - A poignant epitaph written by Warsan Shire, an up and coming Somali poet, that I believe captures the thoughts and attitudes toward Somali women in Wellington communities. They are strange, unknown, an 'other' that people do not know how to love but through research of this nature I believe that blind spots held by individuals in society can be challenged, expanding "our concern about politics of domination and our capacity to care about the oppression and exploitation of others" (Hooks 1994:244). Learning about Somali women through their narratives not only explores how they belong in New Zealand, but also what is important to them. As Jamilah said, "it is ok, maybe we are not the majority, we are the minority - but look into the needs of Somalis and all the other refugees, and maybe as you learn more, you will see how maybe we should be a priority for what we have been through."

"Everyone in our culture desires to some extent to be loving, yet many are in fact not loving. I therefore conclude that the desire to live is not itself love. Love is as love does. Love is an act of will - namely both an intention and an action. Will also implies choice. We do not have to love. We choose to love." (hooks 1994:247). 


\section{Bibliography}

Abdi, Awa M.

2006 Refugees, Gender-Based Violence and Resistance: A Case Study of Somali Refugee Women in Kenya. In Women, Migration, and Citizenship: Making Local, National and Transnational Connections. Evangelia Tastsoglou and Alexandra Dobrowolsky, eds. Pp. 230-251. Aldershot, Hampshire: Ashgate Publishing.

Abdi, Cawo M.

2015 The Somali Diaspora and a Borderless Muslim Identity. Minneapolis: University of Minnesota Press.

Abdullahi, Mohamed Diriye

2001 Culture and Customs of Somalia (culture and Customs of Africa). Westport: Greenwood Press.

Afshar, Haleh

2007 Women, Wars, Citizenship, Migration, and Identity: Some Illustrations from the Middle East. Journal of Development Studies 43(2). Informa UK: 237-244.

Ahmed, Ismail

1999 The heritage of war and state collapse in Somalia and Somaliland: Local-level effects, external interventions and reconstruction. Third World Quarterly 20(1). Taylor \& Francis Online: 113-127

Ahmed, Sara

2000 Strange Encounters: Embodied Others in Post-Coloniality. New York: Taylor \& Francis.

Akou, Heather Marie M.

2011 The Politics of Dress in Somali Culture. Bloomington: Indiana University Press.

Akpinar, Aylin

2006 Discourses of Islam/secularism and Identity-Building Processes among Turkish University Youth. In Muslim Diaspora. Gender, Culture and Identity. Haideh Moghissi, ed. Pp. 133-149. New York: Routledge.

Altinkaya, Judi, and Helen Omundsen 1999 "Birds in a Gilded Cage": Resettlement Prospects for Adult Refugees in New Zealand. Social Policy Journal of New Zealand(13): 31-42.

Altmann, Irwin, and Setha Low

1992 Place Attachment: A Conceptual Inquiry. In Place Attachment, Human Behaviour and Environment. Advances in Theory and Research (Vol 12) Pp. 1-12. New York: Plenum Press.

Anthias, Floya

2001 New Hybridities, Old Concepts: The Limits of "Culture." Ethnic and Racial Studies 24(4). Informa UK: 619-641.

Appadurai, Arjun

1995 The Production of Locality. In Counterworks: Managing the Diversity of Knowledge.

Richard Fardon, ed. Pp. 208-29. London: Routledge.

Arneil, Barbara, and Fiona Macdonald

2010 Multiculturalism and the Social Sphere. In The Ashgate Research Companion to Multiculturalism. Duncan Ivison, ed. 
Assiter, Alison

2009 Kierkegaard, Metaphysics, and Political Theory: Unfinished Selves. London: Continuum International Publishing Group.

Atkinson, Paul, Sara Delamont, John Lofland, and Lyn Lofland

2001 Handbook of Ethnography. London: SAGE Publications Ltd.

Bammer, Anjelika

1992 Editorial. In The Question of "Home”, New Formations (Vol.17). Anjelika Bammer, ed. Pp. vii-xi. London: Lawrence \& Wishart.

Banks, Marcus

1996 Ethnicity: Anthropological Constructions. New York: Taylor \& Francis.

Bauman, Zygmunt

1998 Globilization: The Human Consequences. New York: Columbia University Press.

Behar, Ruth

1996 The Vulnerable Observer: Anthropology That Breaks Your Heart. Boston: Beacon Press.

Bell, Vikki

1999 Mimesis as Cultural Survival: Judith Butler and Anti-Semitism. Theory, Culture \& Society 16(2). SAGE Publications: 133-161.

Besteman, Catherine

1999 Unraveling Somalia: Race, Violence, and the Legacy of Slavery. Philadelphia: University of Pennsylvania Press.

Bhabha, Jacqueline

1996 Embodied Rights: Gender Persecution, State Sovereignty, and Refugees. Public Culture 9(1).

Duke University Press: 3-32.

Blenkinsop, Heather

2010 “She"s from Bothy Sike' Challenges to Research and the Experience of Belonging. Sites: A

Journal of Social Anthropology and Cultural Studies 7(1). University of Otago Library: 123-142.

Brigitte Bönisch-Brednich, Catherine Trundle

2010 Local Lives: Migration and the Politics of Place. Surrey: Ashgate Publishing.

Bourdieu, Pierre

1975 The Specificity of the Scientific Field and the Social Conditions of the Progress of Reason. Social Science Information 14(6). SAGE Publications: 19-47.

1972 Outline of a Theory of Practice. 21st edition. Cambridge: Cambridge University Press.

1984 Distinction: A Social Critique of the Judgement of Taste. Cambridge, MA: Harvard University Press.

1986 The Forms of Capital. In Handbook of Theory and Research for the Sociology of Education. J.E. Richardson, ed. New York: Greenwood Press.

1990 The Logic of Practice. Stanford: Stanford University Press.

2000 Pascalian Meditations. Stanford: Stanford University Press.

Bourdieu, Pierre, and Loïc Wacquant

1992 An Invitation to Reflexive Sociology. 3rd edition. Chicago: University of Chicago Press. 
Brah, Avtar, and Ann Phoenix

2004 Ain't I a Woman? Revisiting Intersectionality. Journal of International Women's Studies 5(3): 75-86.

Brown, Keith, and Dimitrios Theodossopoulos

2004 Others' Others: Talking about Stereotypes and Constructions of Otherness in Southeast Europe. History and Anthropology 15(1). Informa UK: 1-22.

Bunting, Jan

2011 Is It a Bird? Kiwi, Not Only Flightless but Also Birdless. NZWords 15: 4-6.

Butler, Judith

1988 Performative Acts and Gender Constitution: An Essay in Phenomenology and Feminist Theory. Theatre Journal 40(4). JSTOR: 519.

1999 Gender Trouble Feminism and the Subversion of Identity. 10th edition. New York: Routledge.

Butler, Judith P.

1997 Excitable Speech: Contemporary Scenes of Politics. New York: Taylor \& Francis.

Giselle Byrnes

2009 The New Oxford History of New Zealand. New York: OUP Australia and New Zealand.

Caldwell, Melissa L.

2004 Not by Bread Alone: Social Support in the New Russia. Berkeley and Los Angeles: University of California Press.

Cassanelli, Lee

2001Rethinking History and Identity in the Somali Diaspora.In Variations on the Theme of Somaliness. Muddle Lilius, ed. Pp. 272-280. Turku, Finland: Centre for Continuing Education, Åbo Akademi University.

Castells, Manuel.

1996The Rise of the Network Society: The Information Age: Economy, Society and Culture.

Malden, MA: Blackwell Publishers.

Chapman, Malcolm

1982 "Semantics" and the "Celt." In Semantic Anthropology. David Parkin, ed. Pp. 123-144.

London: Academic Press.

Cliggett, Lisa

2003 Gift Remitting and Alliance Building in Zambian Modernity: Old Answers to Modern

Problems. American Anthropologist 105(3). Wiley-Blackwell: 543-552.

Cohen, Anthony

1982 Belonging: The Experience of Culture. In Be- Longing: Identity and Social Organization in British Rural Cultures. Anthony Cohen, ed. Pp. 1-21. Manchester: Manchester University Press.

Crenshaw, Kimberle

1991 Mapping the Margins: Intersectionality, Identity Politics, and Violence against Women of Color. Stanford Law Review 43(6). JSTOR: 1241.

Dobson, Stephanie

2011 Asian Muslim Women Negotiating Identity in New Zealand. In Localizing Asia in Aotearoa. Paola Voci and Jacqueline Leckie, eds. Pp. 187-203. Wellington, N.Z.: Dunmore Publishing. 
2012 Contending with the Hyphen(s): Muslim Women Negotiating Identity, Gender and Conflict in New Zealand. Sites: A Journal of Social Anthropology and Cultural Studies 9(2). University of Otago Library: 92-113.

2013 Gender, Culture and Islam: Perspectives of Three New Zealand Muslim. Pakistan Journal of Women's Studies: Alam-E-Niswan 20(2): 1024-1256.

Dunstan, Stephen

2004 Refugee Voices: A Journey towards Resettlement Executive Summary. http://www.immigration.govt.nz/NR/rdonlyres/18C717C0-0720-4CFA-A81D-

672BBDE406CF/0/RefugeeVoicesExecutiveSummary.pdf, accessed February 17, 2016.

Elmi, Afyare Abdi., and Abdullahi Barise

2006 The Somali Conflict: Root causes, obstacles, and peace-building strategies. African Security Review 15(1). Taylor \& Francis Online: 32-54

Farah, Ahmed Y., and Ioan M. Lewis

1997 Making Peace in Somaliland. Cahiers D'études Africaines 37(146). PERSEE Program: 349377.

Faubion, James D.

1993 Modern Greek Lessons: A Primer in Historical Constructivism. New Jersey: Princeton University Press.

James Ferguson, Akhil Gupta 1997Culture, Power, Place: Explorations in Critical Anthropology. 3rd edition. Durham, NC: Duke University Press.

Fleras, Augie, and Paul Spoonley 1999 Recalling Aotearoa: Indigenous Politics and Ethnic Relations in New Zealand. Australia: OUP Australia and New Zealand.

Flores, Toni

1982 Field Poetry. Anthropology and Humanism 7(1). Wiley-Blackwell: 16-22.

Foucault, Michel, and Alan Sheridan

1977 Discipline and Punish: The Birth of the Prison. New York: Pantheon Books.

Fox, Mary-Jane

1999 Somalia divided: The African Cerberus (considerations on political culture). Civil Wars 2(1). Taylor \& Francis Online: 1-34

Fraser, Heather

2004 Doing Narrative Research: Analysing Personal Stories Line by Line. Qualitative Social Work 3(2). SAGE Publications: 179-201.

Freire, Paulo, and Myra Bergman Ramos Translated 1996 Pedagogy of the Oppressed. New York: Herder and Herder.

Gardner, Judith, and Judy El-Bushra

2004 Somalia: The Untold Story - the War through the Eyes of Somali Women. London: Pluto Press.

Geertz, Clifford

1973 The Interpretation of Cultures: Selected Essays. New York: Basic Books. 
Gibson, Lorena

2011 Hope, Agency, and the "side Effects" of Development in India and Papua New Guinea.

Gramsci, Antonio, Quintin Hoare, Geoffrey Nowell Smith, and Geoffrey Nowell-Smith 1971 Selections from the Prison Notebooks of Antonio Gramsci. New York: International Publishers.

Grbic, Douglas

2010 Social and Cultural Meanings of Tolerance: Immigration, Incorporation and Identity in Aotearoa, New Zealand. Journal of Ethnic and Migration Studies 36(1). Informa UK: 125-148.

Guerin, Bernard, Pauline Guerin, Roda Omar Diirye, and Susan Yates

2004 Somali Conceptions and Expectations Concerning Mental Health: Some Guidelines for Mental Health Professionals. New Zealand Journal of Psychology 33(2): 59-67.

Guerin, Pauline B., Fatuma Hussein Elmi, and Callie Corrigan

2007 Body Composition and Cardiorespiratory Fitness among Refugee Somali Women Living in New Zealand. Journal of Immigrant and Minority Health 9(3). Springer Science + Business Media: 191-196.

Gustafson, Per

2001 Roots and Routes: Exploring the Relationship between Place Attachment and Mobility. Environment and Behavior 33(5). SAGE Publications: 667-686.

Hadjiyanni, Tasoulla

2007 Bounded Choices: Somali Women Constructing Difference in Minnesota Housing. Journal of Interior Design 32(2). Wiley-Blackwell: 13-27.

Hage, Ghassan

1997 At Home in the Entrails of the West: Multiculturalism, Ethnic Food and Migrant HomeBuilding. In Home/World: Space, Community and Marginality in Sydney's West : Space, Community and Marginality in Sydney's West. Helen Grace, Ghassan Hage, Lesley Johnson, Julie Langsworth, and Michael Symonds, eds. Pp. 99-153. Australia: Pluto Press.

1998 White Nation: Fantasies of White Supremacy in a Multicultural Society. West Wickham, Kent, U.K: Pluto Press Australia Pty.

2003 Against Paranoid Nationalism: Searching for Hope in a Shrinking Society. London: The Merlin Press.

2009 Waiting. Victoria: Melbourne University Press.

Hajdukowski-Ahmed, Maroussia 2009 A Dialogical Approach to Identity. In Not Born a Refugee Woman : Contesting Identities, Rethinking Practices. Maroussia Hajdukowski-Ahmed, Nazilla Khanlou, and Helene Moussa, eds. Pp. 28-54. New York: Berghahn Books.

Hall, Stuart

1996 Questions of Cultural Identity. Thousand Oaks, CA: SAGE Publications.

Harper, Mary

2012 Getting Somalia Wrong? Faith, War and Hope in a Shattered State. London: Zed Books.

Hasan, Mushirul

1996 The Myth of Unity: Colonial and National Narratives. In Contesting the Nation: Religion, Community and the Politics of Democracy in India. David Ludden, ed. Pp. 185-208. Philadelphia: University of Pennsylvania Press. 
Hasan, Zoya, and Ritu Menon

2005 The Diversity of Muslim Women's Lives in India. Professor Centre for Political Studies

Zoya Hasan, ed. New Jersey: Rutgers University Press.

Herzfeld, Michael

1987 Anthropology through the Looking-Glass: Critical Ethnography in the Margins of Europe.

Cambridge: Cambridge University Press.

1992The Social Production of Indifference: Exploring the Symbolic Roots of Western Democracy. Chicago and London: The University of Chicago Press.

Hesse-Biber, Sharlene, and Patricia Leavy

2007 Feminst Stanpoint Epistemology: Building Knowledge an Empowerment through Women's Lived Experience. In Feminist Research Practice.

Hochreiter, Susanne

2014 Race, Class, Gender? Intersectionality Troubles. Journal of Research in Gender Studies 4(2): 401-408.

hooks, bell

1994 Outlaw Culture: Resisting Representations. New York: Routledge.

Hopkins, Gail

2010 A Changing Sense of Somaliness: Somali Women in London and Toronto. Gender, Place \&

Culture 17(4). Informa UK: 519-538.

Hua, Anh

2011 Homing Desire, Cultural Citizenship, and Diasporic Imaginings. Journal of International

Women's Studies 12(4): 45-56.

Ibrahim, Awad

2008 The New Flaneur: Subaltern Cultural Studies, African Youth in Canada and the Semiology of In-Betweenness. Cultural Studies 22(2). Informa UK: 234-253.

Jackson, Michael D.

2012 Between One and One Another. Berkeley: University of California Press.

Jelle, Hani Abdi, Pauline Guerin, and Suzette Dyer

2006 Somali Women's Experiences in Paid Employment in New Zealand. New Zealand Journal of Employment Relations 31(2): 61-69.

Jones, Emily

2013 You Can Never Be on One Side Alone": Some Young Somali-Kiwi Women's Narratives about Identity, Resettlement and Community Development in Wellington, Aotearoa New Zealand.

Joseph, May

1999 Nomadic Identities: The Performance of Citizenship. Minneapolis: University of Minnesota Press.

Kiely, Richard, Frank Bechhofer, and David McCrone

2005 Birth, Blood and Belonging: Identity Claims in Post-Devolution Scotland. Oxford: Blackwell Publishing Ltd.

Lakha, Salim

2009 Waiting to Return Home: Modes of Immigrant Waiting. InWaiting. Ghassan Hage, ed. Pp.

121-134. Australia: Academic Monographs. 
Langellier, Kristin M.

1999 Personal Narrative, Performance, Performativity: Two or Three Things I Know for Sure. Text and Performance Quarterly 19(2). Informa UK: 125-144.

2010Performing Somali Identity in the Diaspora. Cultural Studies 24(1). Informa UK: 66-94.

Leckie, Jacqueline

1995 Silent Immigrants? Gender, Immigration and Ethnicity in New Zealand. In Immigration and National Identity in New Zealand: One People - Two Peoples - Many Peoples? Stuart W. Greif, ed. Pp. 50-77. Palmerston North, New Zealand: The Dunmore press Ltd.

2002The Complexities of Women's Agency in Fiji. In Gender Politics in the Asia-Pacific Region: Agencies and Activisms. Brenda Yeoh and Peggy Teo, eds. Pp. 156-180. London: Routledge.

2007 Indian Settlers: The Story of a New Zealand South Asian Community. New Zealand: Otago University Press.

Lewis, Ioan M.

1994Blood and Bone: The Call of Kinship in Somali Society. United States: Red Sea Press,U.S.

1998 Doing Violence to Ethnography: A Response to Catherine Besteman's "Representing Violence and 'Othering' Somalia." Cultural Anthropology 13(1). Wiley-Blackwell: 100-108.

Lewis, Ioan M, and Michael J. Dwyer

2008 Understanding Somalia and Somaliland: Culture, History, Society. New York: Columbia University Press.

Madden, Raymond

2010 Being Ethnographic: A Guide to the Theory and Practice of Ethnography. London: SAGE Publications.

Marcus, George E.

1995 Ethnography In/of the World System: The Emergence of Multi-Sited Ethnography. Annual Review of Anthropology 24(1). Annual Reviews: 95-117.

Massey, Doreen

1995 Places and Their Pasts. History Workshop Journal 39(1). Oxford University Press (OUP): 182-192.

McDonald, Maryon

1993 The Construction of Difference: An Anthropological Approach to Stereotypes. In Inside European Identities. Sharon Macdonald, ed. Pp. 219-236. Oxford: Berg Publishers Limited.

McGeer, Victoria

2004 The Art of Good Hope. The Annals of the American Academy of Political and Social Science 592(1). SAGE Publications: 100-127.

McGown, Rima Berns

1999 Muslims in the Diaspora: The Somali Communities of London and Toronto. Toronto: University of Toronto Press.

McHoul, Alec, and Wendy Grace

1993A Foucault Primer: Discourse, Power, and the Subject. New York: New York University Press.

McLean, Moira

2004 Resettlement Issues for Refugee and Migrant Women: From the 39th Annual Conference of the New Zealand Federation of Business and Professional Women Inc., 2 - 4 May 2003, Waipuna 
Hotel \& Conference Centre, Mt Wellington. Auckland [N.Z.]: New Zealand Federation of Business and Professional Women.

McMichael, Celia, and Lenore Manderson

2004 Somali Women and Well-Being: Social Networks and Social Capital among Immigrant Women in Australia. Human Organization 63(1). Society for Applied Anthropology: 88-99.

Mohanty, Chandra Talpade

1988 Under Western Eyes: Feminist Scholarship and Colonial Discourses. Feminist Review(30). JSTOR: 61.

Ong, Aihwa

1999 Flexible Citizenship: The Cultural Logics of Transnationality. 4th edition. Durham: Duke University Press Books.

O’Reilly, Karen

2008 Key Concepts in Ethnography. Los Angeles: SAGE Publications.

Ortner, Sherry B.

2006 Anthropology and Social Theory: Culture, Power, and the Acting Subject. Durham: Duke University Press.

Paulicelli, Eugenia

2006 Dress, Gender, and Identity: Personal and National Identity-Formation. In Feminism and Multiculturalism : How Do They/we Work Together? Joyce W. Warren, ed. Pp. 45-56. Newcastle, UK: Cambridge Scholars Press.

Povinelli, Elizabeth A.

2002 The Cunning of Recognition: Indigenous Alterities and the Making of Australian

Multiculturalism (politics, History, and Culture Series). Durham: Duke University Press Books.

Pucherova, Dobrota

2013 Enlightenment, Modernity and Radical Cosmopolitanism in Autobiographies by Two Somali Women. Women: A Cultural Review 24(1). Informa UK: 1-25.

Ramazano, Caroline

2002 From Truth to Reality to Knowledge/power: Taking a Feminist Stand-Point. In Feminist Methodology. Janet Holland, ed.

Rapport, Nigel

1997 The Morality of Locality: On the Absolutism of Land Ownership in an English Village. In The Ethnography of Moralities. Signe Howell, ed. Pp. 74-97. London and New York: Routledge.

Rouse, Roger

1991 Mexican Migration and the Social Space of Postmodernism. Diaspora: A Journal of Transnational Studies 1(1). Johns Hopkins University Press: 8-23.

Saegert, Susan

1985 The Role of Housing in the Experience of Dwelling. InHome Environments. Irwin Altman and Carol M. Werner, eds. Pp. 287-309. New York: Springer.

Said, Edward W.

1978 Orientalism. New York: Pantheon Books.

Savage, Michael, Gaynor Bagnall, and Brian J. Longhurst

2005 Globalization and Belonging. Thousand Oaks, CA: SAGE Publications. 
Schrock, Richelle D.

2013 The Methodological Imperatives of Feminist Ethnography. Journal of Feminist Scholarship 5: 48-60.

Skeggs, Beverley

2001 Feminist Ethnography. In Handbook of Ethnography. Paul Atkinson, Amanda Coffey, Sara

Delamont, John Lofland, and Lyn Lofland, eds. Pp. 426-442. London: SAGE Publications.

Skinner, Jonathan

2012The Interview : An Ethnographic Approach. London ; New York : Berg.

Smith, Jo

2007 Post-Cultural Hospitality: Settler-Native-Migrant Encounters. Arena Journal 28.

2011 Aotearoa/New Zealand: An Unsettled State in a Sea of Islands. Settler Colonial Studies 1(1). Informa UK: 111-131.

Snow, David A., and Leon Anderson

1987 Identity Work among the Homeless: The Verbal Construction and Avowal of Personal Identities. American Journal of Sociology 92(6). University of Chicago Press: 1336.

Spitzer, Denise L.

2007 Immigrant and Refugee Women: Recreating Meaning in Transnational Context. Anthropology in Action 14(1). Berghahn Books.

Spry, Tami

2001 Performing Autoethnography: An Embodied Methodological Praxis. Qualitative Inquiry 7(6). SAGE Publications: 706-732.

Strathern, Marilyn

1982 The Village as an Idea: Constructs of Village-Ness in Elmdon, Essex. In Belonging: Identity and Social Organization in British Rural Culture. Anthony Cohen, ed. Pp. 247-277. Manchester: Manchester University Press.

1992After Nature: English Kinship in the Late Twentieth Century. Cambridge: Cambridge University Press.

2005 Kinship, Law and the Unexpected: Relatives Are Always a Surprise. Cambridge: Cambridge University Press.

Teaiwa, Katerina Martina

2004 Multi-Sited Methodologies: "Homework" in Australia, Fiji, and Kiribati. In Anthropologists in the Field: Cases in Participant Observation. Lynne Hume and Jane Mulcock, eds. New York: Columbia University Press.

Trnka, Susanna, and Catherine Trundle

2014 Competing Responsibilities: Moving beyond Neoliberal Responsibilisation. Anthropological Forum 24(2). Informa UK: 136-153.

Trundle, Catherine

2014 Americans in Tuscany: Charity, Compassion, and Belonging. Oxford: Berghahn Books.

Tupuola, Anne-Marie

2004 Pasifika Edgewalkers: Complicating the Achieved Identity Status in Youth Research. Journal of Intercultural Studies 25(1). Informa UK: 87-100. 
Turner, Victor

1987 Betwixt and between the Liminal Period in Rites de Passage. In Betwixt \& Between:

Patterns of Masculine and Feminine Initiation. Louise Mahdi, Steven Foster, and Meredith Little, eds. Pp. 3-22. Illinois: Open Court.

Wacquant, Loïc

2008 Pierre Bourdieu. In Key Sociological Thinkers. 2nd edition. R. Stones, ed. Basingstoke,

Hampshire: Palgrave Macmillan.

Waldron, Sidney R., and Naima A. Hasci

1995 Somali Refugees in the Horn of Africa: State of the Art Literature Review. Refugee Studies Programme Queen Elizabeth House University of Oxford: Nordic Africa Institute.

Werbner, Pnina

2013 Everyday Multiculturalism: Theorising the Difference between "Intersectionality" and

"Multiple Identities." Ethnicities 13(4). SAGE Publications: 401-419.

Yuval-Davis, Nira

2011 The Politics of Belonging: Intersectional Contestations. London: SAGE Publications. 